\title{
Earth-Science Reviews
}

\section{Predicting shoreline depositional process regimes using insights from palaeotidal modelling \\ --Manuscript Draft--}

\begin{tabular}{|c|c|}
\hline \multicolumn{2}{|l|}{ Manuscript Number: } \\
\hline Keywords: & $\begin{array}{l}\text { Numerical Modelling; Wave; Tide; Fluvial; Palaeotidal; Mixed process; Shoreline; } \\
\text { Deltaic; Shelf; Sedimentary Preservation }\end{array}$ \\
\hline Corresponding Author: & $\begin{array}{l}\text { Daniel Collins } \\
\text { Shell International Ltd } \\
\text { London, London UNITED KINGDOM }\end{array}$ \\
\hline First Author: & Daniel Collins \\
\hline \multirow[t]{8}{*}{ Order of Authors: } & Daniel Collins \\
\hline & Alexandros Avdis \\
\hline & Martin H. Wells \\
\hline & Howard D. Johnson \\
\hline & Gary J. Hampson \\
\hline & Jon Hill \\
\hline & Christopher D. Dean \\
\hline & Matthew D. Piggott \\
\hline Abstract: & $\begin{array}{l}\text { Tides are a fundamental element of predictive depositional models of ancient shoreline } \\
\text { process regimes. These models principally relate ancient tidal potential to shelf width } \\
\text { (c. 10-100 km) and shoreline geometry (c. 1-10 km) but rarely consider larger-scale } \\
\text { basin physiography (100-1000 km) or variability related to changing shoreline } \\
\text { geometry. A refined predictive decision tree for ancient shoreline process regimes is } \\
\text { developed based on a review of modern shoreline processes, supported by new } \\
\text { insight from numerical palaeotidal modeling studies. Modern depositional shorelines } \\
\text { are overwhelmingly wave dominated, suggesting a first-order control of wave fetch and } \\
\text { wave-generating wind conditions on shoreline processes. Several numerical } \\
\text { palaeotidal modeling studies highlight the following controls on tidal processes: (1) } \\
100-1000 \text { km-scale basin physiography on tidal inflow versus outflow; (2) 10-100 km- } \\
\text { scale shelf physiography on shelf tidal resonance potential; (3) tidal amplification } \\
\text { (funnelling and shoaling) versus frictional effects in shoreline embayments (1-10 km } \\
\text { scale); and (4) palaeogeographic uncertainty, which affects prediction of these latter } \\
\text { three controls. The predictive decision tree considers the effects of basin } \\
\text { physiography, shelf width and shoreline morphology on wave, tide and fluvial } \\
\text { processes separately. The two-tier classification of process regime in the decision tree } \\
\text { (limited to primary and secondary processes) reflects uncertainty and ambiguity in } \\
\text { applying three-tier process classification schemes to modern shorelines and, } \\
\text { especially, to ancient shoreline deposits. This review demonstrates the benefit of } \\
\text { numerical tidal modeling, calibrated by integrated comparison to the preserved } \\
\text { stratigraphic record, and offers a refined classification and prediction of shoreline } \\
\text { process regimes. Wider and consistent utilisation of these concepts, and numerical } \\
\text { simulations of other depositional processes, will further improve process-based } \\
\text { classifications and predictions of modern and ancient shoreline systems. }\end{array}$ \\
\hline \multirow[t]{2}{*}{ Suggested Reviewers: } & $\begin{array}{l}\text { Valentina Marzia Rossi } \\
\text { valentina.rossi@igg.cnr.it } \\
\text { Mixed-process shoreline-shelf systems }\end{array}$ \\
\hline & Shahin Dashtgard \\
\hline
\end{tabular}


Simon Fraser University - Surrey

sdashtga@sfu.ca

Mixed-process shoreline-shelf systems

Bruce Ainsworth

Chevron Corp

bruce.ainsworth@chevron.com

Mixed-process shoreline-shelf systems

Robert Dalrymple

dalrympl@queensu.ca

Mixed-process shoreline systems with focus on tidal systems

Chris Paola

cpaola@umn.edu

Numerical modelling of sedimentary systems

Opposed Reviewers: 
Daniel S. Collins

Shell International Ltd

Shell Centre, London

SE1 7NA

$14^{\text {th }}$ July 2020

dscollins.geo@gmail.com

\section{Dear Editor,}

We are pleased to submit our manuscript entitled 'Predicting shoreline depositional process regimes using insights from palaeotidal modelling' for your consideration as an original research article.

The submitted manuscript is a timely review of three intersecting facets of recent shorelineshelf sedimentological and stratigraphic research:

1. Classification and prediction of modern and ancient shorelines in terms of mixed process (fluvial, wave, tide) dynamics;

2. Calibration of numerical simulations of shoreline processes by process-based interpretations of the preserved facies and stratigraphic record; and

3. Understanding the sensitivity of tides to physiographic controls.

Through a review of three palaeotidal modelling case studies, the overall aim is to demonstrate the benefit of numerical simulations of ancient shoreline processes, calibrated by integrated comparison to the preserved stratigraphic record, in improving and refining classification and prediction of process regimes of modern and ancient shoreline systems. The three case studies investigated ancient tides in strongly contrasting geological settings and on various spatial and temporal scales: (1) the Oligocene-Miocene South China Sea (SCS); (2) the Early Cretaceous Lower Greensand Seaway, NW Europe; and (3) the Late Cretaceous Bohemian Cretaceous Basin, Central Europe. The comparison between palaeotidal model results and sedimentological and stratigraphic data in the rock record establishes the strengths, limitations and potential biases of the numerical simulation approach. Last, the implications of palaeotidal model simulations provide an updated framework for classification and prediction of shoreline depositional process regime to test against future modelling approaches for assessing ancient tidal, wave and additional shoreline sedimentary processes.

The paper is widely applicable to understanding modern shoreline processes, especially tides, and interpreting ancient mixed-process shoreline systems. This has applied significance on multiple fronts, for example: understanding modern shoreline dynamics, with implications for shoreline stability during climate and sea level change; and petroleum exploration and production, where predicting and characterising ancient shoreline-shelf depositional processes is vital to reconstructing depositional models, including reservoir, seal and source rock facies distribution.

The authors have no conflict of interests to declare. We look forward to hearing the outcome of your assessment in due course. 
Yours sincerely,

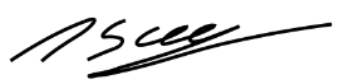

Daniel S. Collins

(corresponding author and on behalf of all co-authors)

\section{Information on submission:}

Number of words in main text and captions: 25,864

Number of figures: 31

Number of tables: 4

Number of Supplementary figures: 1 


\section{HIGHLIGHTS}

- Rivers, waves and tides impact sediment dynamics along shorelines

- Modern shoreline dynamics are overwhelmingly wave dominated

- Tides are controlled by basin, shelf and shoreline physiography

- Paleotidal models can be calibrated to preserved facies and stratigraphy

- Numerical models refine classifications and prediction of shoreline process regimes 


\section{ABSTRACT}

Tides are a fundamental element of predictive depositional models of ancient shoreline process regimes. These models principally relate ancient tidal potential to shelf width (c. 10$100 \mathrm{~km}$ ) and shoreline geometry (c. 1-10 km) but rarely consider larger-scale basin physiography $(100-1000 \mathrm{~km})$ or variability related to changing shoreline geometry. A refined predictive decision tree for ancient shoreline process regimes is developed based on a review of modern shoreline processes, supported by new insight from numerical palaeotidal modelling studies. Modern depositional shorelines are overwhelmingly wave dominated, suggesting a first-order control of wave fetch and wave-generating wind conditions on shoreline processes. Several numerical palaeotidal modelling studies highlight the following controls on tidal processes: (1) 100-1000 km-scale basin physiography on tidal inflow versus outflow; (2) 10-100 km-scale shelf physiography on shelf tidal resonance potential; (3) tidal amplification (funnelling and shoaling) versus frictional effects in shoreline embayments (1$10 \mathrm{~km}$ scale); and (4) palaeogeographic uncertainty, which affects prediction of these latter three controls. The predictive decision tree considers the effects of basin physiography, shelf width and shoreline morphology on wave, tide and fluvial processes separately. The two-tier classification of process regime in the decision tree (limited to primary and secondary processes) reflects uncertainty and ambiguity in applying three-tier process classification schemes to modern shorelines and, especially, to ancient shoreline deposits. This review demonstrates the benefit of numerical tidal modelling, calibrated by integrated comparison to the preserved stratigraphic record, and offers a refined classification and prediction of shoreline process regimes. Wider and consistent utilisation of these concepts, and numerical simulations of other depositional processes, will further improve process-based classifications and predictions of modern and ancient shoreline systems. 


\title{
1 Predicting shoreline depositional process regimes using insights
}

2 from palaeotidal modelling

\author{
3 Daniel S. Collins ${ }^{1,2}$, Alexandros Avdis², Martin H. Wells ${ }^{3}$, Andrew J. Mitchell ${ }^{2}$, Peter A. \\ 4 Allison$^{2}$, Howard D. Johnson², Gary J. Hampson², Jon Hill ${ }^{4}$, Christopher D. Dean ${ }^{5}$, and \\ 5 Matthew D. Piggott ${ }^{2}$ \\ $6 \quad{ }^{1}$ Shell International Ltd, London, SE1 7NA, UK \\ $7 \quad{ }^{2}$ Department of Earth Science and Engineering, Imperial College London, South Kensington \\ 8 Campus, London, SW7 2AZ, UK \\ $9{ }^{3}$ BP plc, Chertsey Road, Sunbury-on-Thames, Middlesex TW16 7LN, UK \\ $10{ }^{4}$ Environment Department, University of York, Heslington, York, YO10 5DD, UK \\ $11{ }^{5}$ School of Geography, Earth \& Environmental Sciences, University of Birmingham, \\ 12 Birmingham, B15 2TT, $U K$
}

\section{ABSTRACT}

15 Tides are a fundamental element of predictive depositional models of ancient shoreline process

16 regimes. These models principally relate ancient tidal potential to shelf width (c. $10-100 \mathrm{~km})$ and

17 shoreline geometry (c. 1-10 km) but rarely consider larger-scale basin physiography (100-1000

$18 \mathrm{~km}$ ) or variability related to changing shoreline geometry. A refined predictive decision tree for

19 ancient shoreline process regimes is developed based on a review of modern shoreline processes,

20 supported by new insight from numerical palaeotidal modelling studies. Modern depositional

21 shorelines are overwhelmingly wave dominated, suggesting a first-order control of wave fetch

22 and wave-generating wind conditions on shoreline processes. Several numerical palaeotidal 
23 modelling studies highlight the following controls on tidal processes: (1) 100-1000 km-scale

24 basin physiography on tidal inflow versus outflow; (2) 10-100 km-scale shelf physiography on

25 shelf tidal resonance potential; (3) tidal amplification (funnelling and shoaling) versus frictional 26 effects in shoreline embayments (1-10 km scale); and (4) palaeogeographic uncertainty, which

27 affects prediction of these latter three controls. The predictive decision tree considers the effects

28 of basin physiography, shelf width and shoreline morphology on wave, tide and fluvial processes

29 separately. The two-tier classification of process regime in the decision tree (limited to primary

30 and secondary processes) reflects uncertainty and ambiguity in applying three-tier process

31 classification schemes to modern shorelines and, especially, to ancient shoreline deposits. This

32 review demonstrates the benefit of numerical tidal modelling, calibrated by integrated

33 comparison to the preserved stratigraphic record, and offers a refined classification and

34 prediction of shoreline process regimes. Wider and consistent utilisation of these concepts, and

35 numerical simulations of other depositional processes, will further improve process-based

36 classifications and predictions of modern and ancient shoreline systems.

38 Keywords: Numerical Modelling; Wave; Tide; Fluvial; Palaeotidal; Mixed process; Shoreline;

39 Deltaic; Shelf; Sedimentary Preservation

\section{$41 \quad 1$ INTRODUCTION}

42 Shorelines are amongst the most geologically variable, environmentally diverse and climatically

43 sensitive sedimentary environments, with important social and economic implications (Giosan

44 and Bhattacharya, 2005; Syvitski and Saito, 2007). Physical, biological and chemical exchange

45 between the continents and oceans across this interface is fundamentally impacted by the 
46 interaction of hydrodynamic processes relating to fluvial, wave and tidal influence. Improved

47 understanding and recognition of process interactions along modern and ancient shorelines has

48 led to refined process-based classifications and predictive models of shoreline systems

49 (Ainsworth et al., 2008; $\underline{\text { Ainsworth et al., 2011; Vakarelov and Ainsworth, 2013; Nyberg and }}$

50 Howell, 2016). An important component has been wider application of theoretical relationships

51 between the strength of wave or tide processes and shoreline-shelf physiography, derived from

52 palaeogeographic reconstructions, in order to support facies and stratigraphic interpretations of

53 ancient depositional processes, most notably the impact of shoreline geometry and on tidal

54 resonance or amplification (Godin, 1993; Yoshida et al., 2007; van Cappelle et al., 2018;

55 Zuchuat et al., 2019). Simple theoretical relationships are a quick method of estimating

56 shoreline-shelf wave and tidal potential, but without the ability to assess or understand spatio-

57 temporal variability and the sensitivity to, and interaction of, potential physiographic controls.

58 Instead, hydrodynamic numerical modelling enables deeper discussion of these factors, ranging

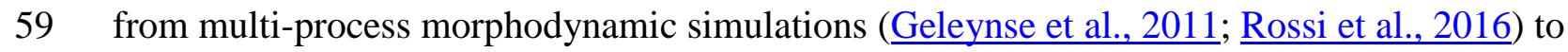

60 simulations of specific shorelines processes. In particular, numerical tidal simulations (e.g.

61 Slingerland, 1986; Ericksen and Slingerland, 1990; Martel et al., 1994; Wells et al., 2005a;

62 Mitchell et al., 2010; Collins et al., 2018a; Dean et al., 2019) have been extensively validated

63 against modern sedimentary environments and, through integration with sedimentological and

64 stratigraphic datasets, have provided unique information on the physiographic controls on tidal

65 processes and sedimentary preservation along ancient tide-influenced shorelines. However, the

66 implications of ancient tidal model simulations on the classification, prediction and interpretation

67 of shoreline-shelf depositional process regimes has not yet been fully explored.

68 
69 The aims of this review article are threefold. First, the results of three palaeotidal modelling

70 studies are integrated to identify the dominant physiographic controls on shoreline tidal

71 processes. The three case studies investigated ancient tides in strongly contrasting geological

72 settings and on various spatial and temporal scales: (1) the Oligocene-Miocene South China Sea

73 (SCS); (2) the Early Cretaceous Lower Greensand Seaway, NW Europe; and (3) the Late

74 Cretaceous Bohemian Cretaceous Basin, Central Europe. Second, the comparison between

75 model results and sedimentological and stratigraphic data in the rock record establishes the

76 strengths, limitations and potential biases of the palaeotidal modelling approach. Third, the

77 implications of palaeotidal model simulations for classification and prediction of shoreline

78 depositional process regime are assessed.

\section{$80 \quad 2$ BACKGROUND}

\section{$81 \quad 2.1 \quad$ Tidal theory and numerical modelling}

\section{$82 \quad$ 2.1.1 Equilibrium tidal theory}

83 The non-mathematical theory of Earth tides has been extensively reviewed (Defant, 1961;

84 MacMillan, 1966; Dalrymple, 1992; Allen, 1997; Open University Course Team, 1999; Willis,

85 2005; Kvale, 2006; Kvale, 2012; Longhitano et al., 2012). Astronomical tides are defined as 'any

86 periodic fluctuation in the water level that is generated by the gravitational attraction of the

87 Moon and Sun' (Dalrymple, 1992). The Moon, although smaller than the Sun, accounts for c.

$8870 \%$ of the tide-raising force due to its closer proximity. However, the tide-generating forces are

89 small. Significant tides, though typically $<1 \mathrm{~m}$ in tidal range (the difference in sea level between

90 high and low tide), only develop in the open oceans. Smaller enclosed water bodies (seas, lakes)

91 and water on continental shelves do not develop appreciable in situ tides (Dalrymple, 1992). 
93 Tides are most commonly understood in the context of equilibrium tidal theory, in which the

94 Earth is covered by water of uniform depth that responds instantaneously to changes in tractive

95 forces and the Moon rotates around the equator at a constant distance (e.g. MacMillan, 1966;

96 Dalrymple, 1992) The lunar tidal force, in combination with centrifugal forces associated with

97 the rotation of the earth-moon system about its common centre of mass, leads to the development

98 of two oceanic tidal bulges: one beneath the moon, one on the opposite side of the Earth. The

99 rotation of Earth every 24 hours, and the Moon around the Earth every 29 days (in the same

100 direction as the Earth rotates), means these bulges appear to move clockwise around the Earth.

101 This produces two high and two low (semi-diurnal) tides each day at a period of 12.42 hours, 102 with rising and falling tides termed 'flood tide' and 'ebb tide', respectively (Dalrymple, 1992).

103 Equilibrium model tides vary on many timescales due to changes in the magnitude of the tide104 generating forces produced by the Sun and Moon (Defant, 1961; MacMillan, 1966; Dalrymple, 105 1992; Kvale, 2006). For example, spring-neap tidal cycles (14.77 days) are caused by the relative 106 positioning of the Earth, Sun and Moon. Spring tides occur when the Earth, Moon and Sun are 107 aligned in a straight line at new or full Moon, resulting in greater than average tidal ranges. In 108 contrast, neap tides occur when the Sun and Moon are at right angles to the Earth at first- and 109 third-quarter phases of the Moon, resulting in smaller tidal ranges (Fig. 1A and B). The time 110 between successive new moons is called the 'synodic month', which has a modern period of 11129.53 days and encompasses two spring-neap cycles. For semi-diurnal tides, each spring-neap 112 cycle (every 14.77 days) contains up to 28 tidal cycles (Dalrymple, 1992; Kvale, 2006).

113 Furthermore, due to the tilt of the Earth's axis, the declination of the Moon varies by $28.5^{\circ}$ north 114 and south of the equator monthly (Fig. 1C). Daily, the declination of the Moon can lead to one 
115 semi-diurnal tide being higher (dominant) than the other (subordinate), which is termed 'diurnal 116 inequality' (Fig. 1D). Monthly, there is a 'tropical' spring-neap cyclicity with increased diurnal

117 inequality when the Moon is at its maximum declination (Fig. 1D) (e.g. Kvale, 2012).

119 While equilibrium tidal theory explains the astronomical forcing causing tides, real-world tides 120 are complicated by several factors. First, a mean ocean depth of c. $22 \mathrm{~km}$ is needed to account 121 for rotation of a tidal bulge around the circumference of the Earth in 24 hours, whereas the mean 122 measured ocean depth is c. $4 \mathrm{~km}$ (Wells et al., 2005a). Second, ocean basins are interrupted by 123 landmasses and the ocean water depth varies globally, which means two bulges either side of the 124 Earth cannot exist. Instead, oceanic tides rotate as waves around fixed (amphidromic) points with 125 negligible tidal amplitude (half the tidal range) (Fig. 2). Third, inertia and friction mean that the 126 ocean does not respond instantaneously to the tidal forcing. Last, equilibrium tidal theory does 127 not explain the occurrence of the following: (1) diurnal (one high tide and one low tide in a tidal 128 day) tides in low latitude positions, which are only predicted at high latitudes; (2) mid-latitude 129 semi-diurnal tides with minimal diurnal inequality; and (3) spring-neap cycles synchronized with 130 the 27.32 day (tropical month) lunar orbital cycle of the Moon (tropical month), rather than the 131 more common 29.53 day cycle of lunar phases (synodic month or 'lunar month'). 
A Spring-neap cycles

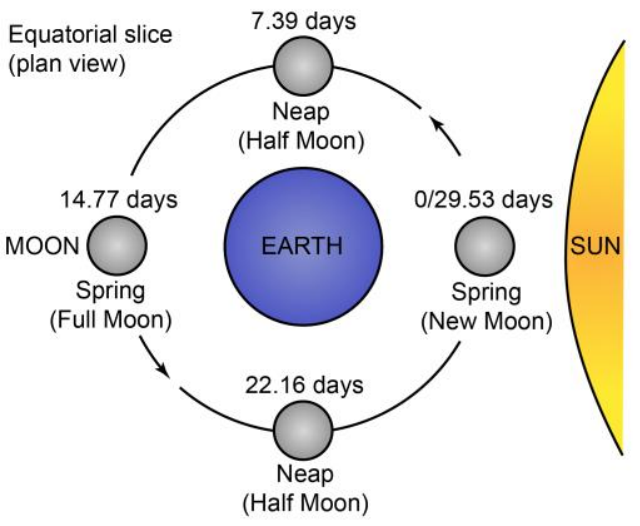

C Diurnial inequality

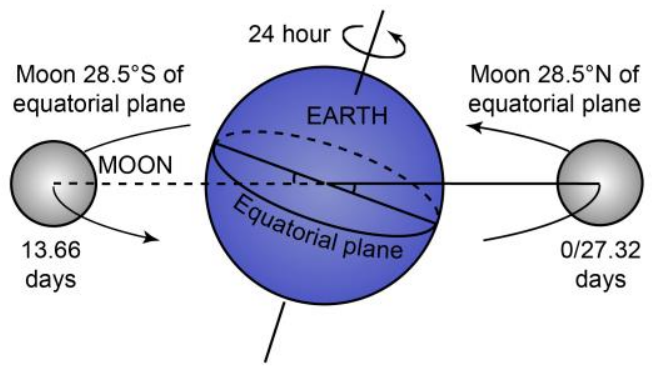

B

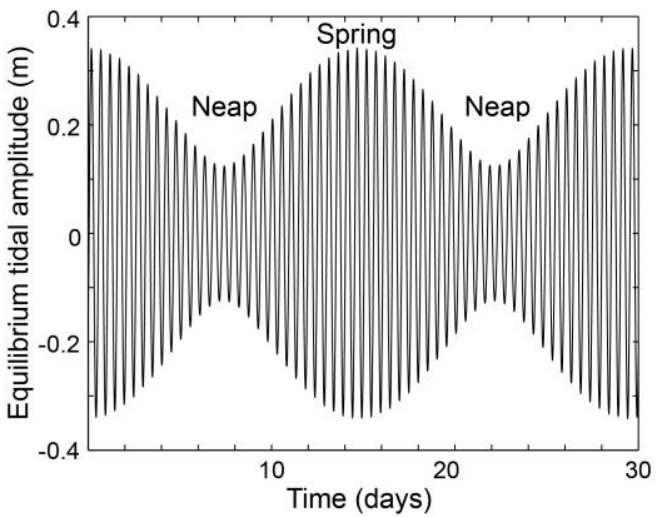

D

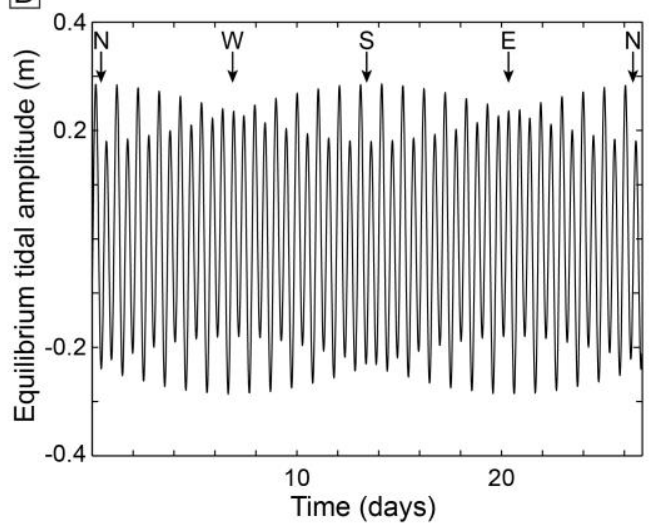

134 Fig. 1. (A) Astronomical explanation of synodic spring-neap tidal cycles. Synodic spring tides 135 occur when the Sun and Moon are above the same line of Earth's longitude (conjunction) or are $136180^{\circ}$ of longitude apart (opposition). Synodic neap tides occur when the Sun and Moon are 137 separated by $90^{\circ}$ of Earth's longitude. (B) Graph of equilibrium tidal amplitude over a 30-day 138 period displaying synodic spring-neap tidal cycles caused by the interaction of $\mathbf{M}_{2}$ and $\mathrm{S}_{2}$ tidal 139 constituents. (C) Monthly variation in the Moon's declination between $28.5^{\circ}$ north and south of 140 the Earth's equatorial plane caused by the tilt of the Earth's axis, which is accounted for by the $141 \mathrm{~K}_{1}$ and $\mathrm{O}_{1}$ tidal constituents (Table 1). (D) Graph of equilibrium tidal amplitude over a 27-day 142 period caused by the interaction of the $\mathrm{M}_{2}$ and $\mathrm{K}_{1}$ tidal constituents. Daily, one tide is larger than 143 the other (diurnal inequality). Monthly, there is a 'tropical' spring-neap cyclicity of more 144 pronounced diurnal inequality when the Moon is at its maximum declination north or south of 145 the equator. N-Moon north of the Equator; W-Moon west of the equator; S-Moon south of 146 the equator; E-Moon east of the equator. After Wells (2008). 


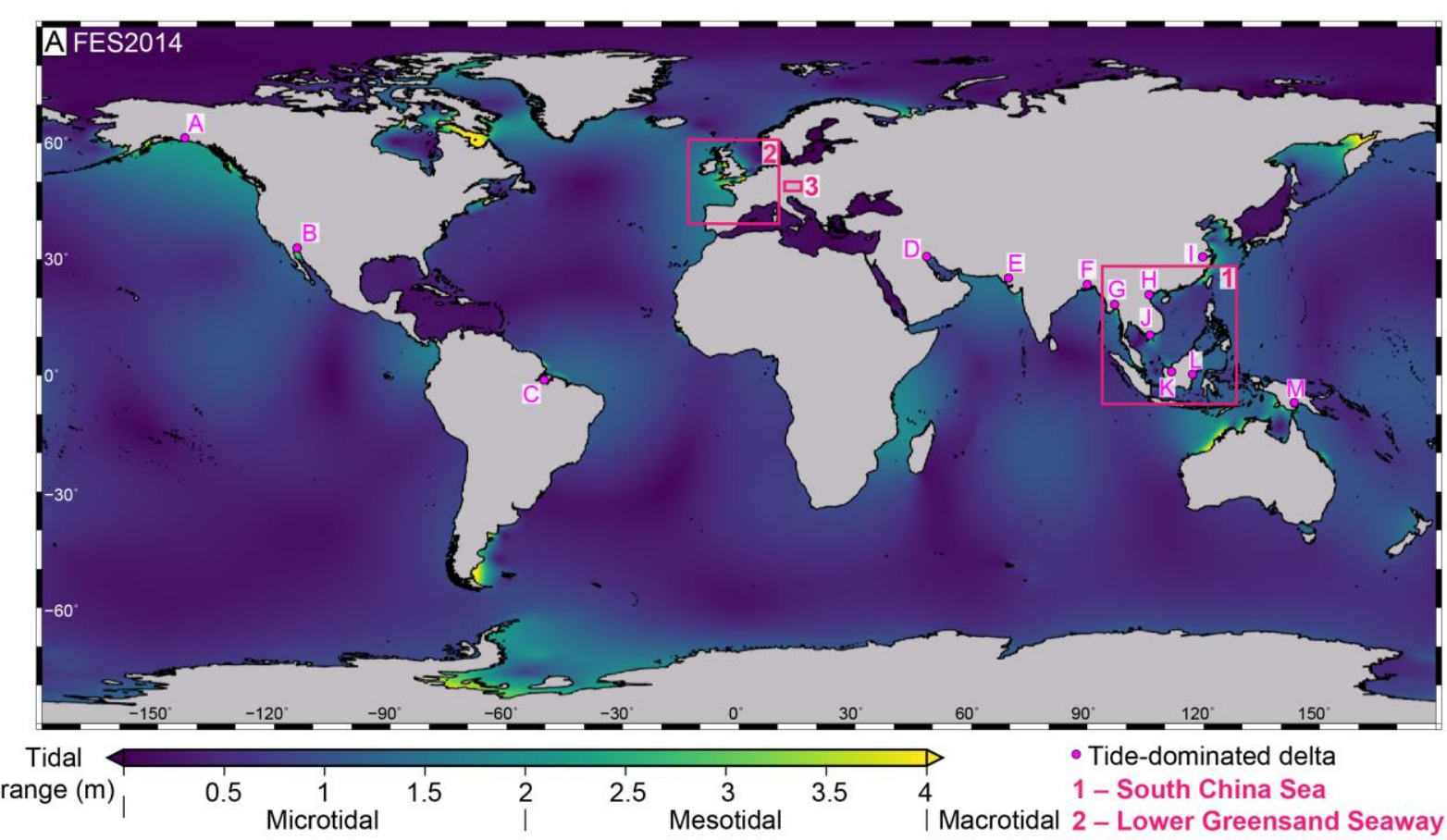

\section{B $M_{2}$ tide FES2014}

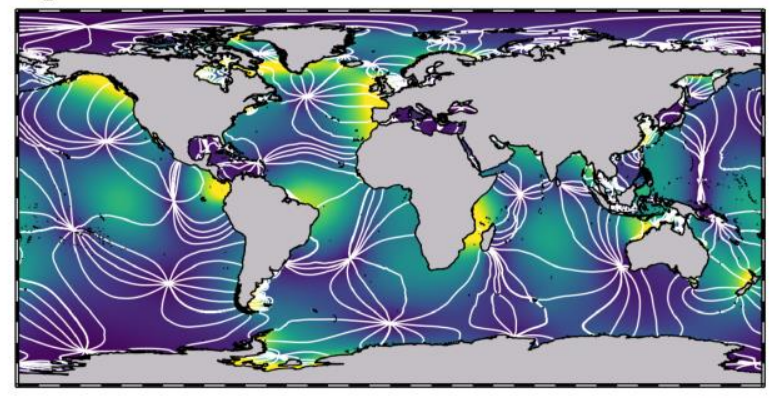

C K tide FES2014

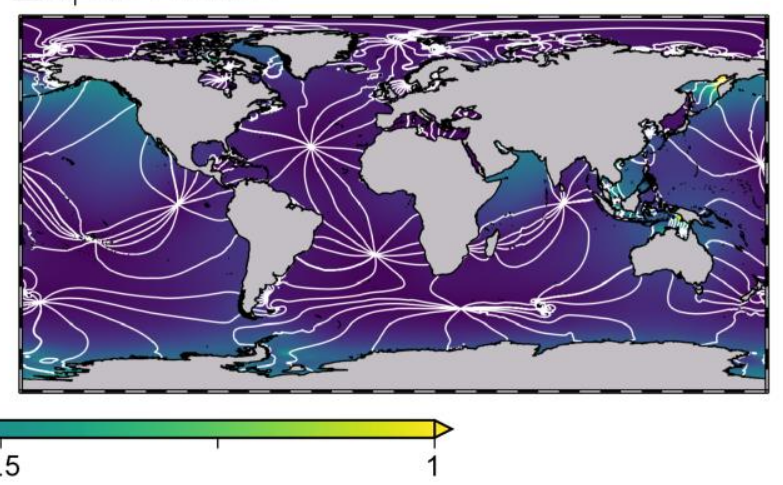

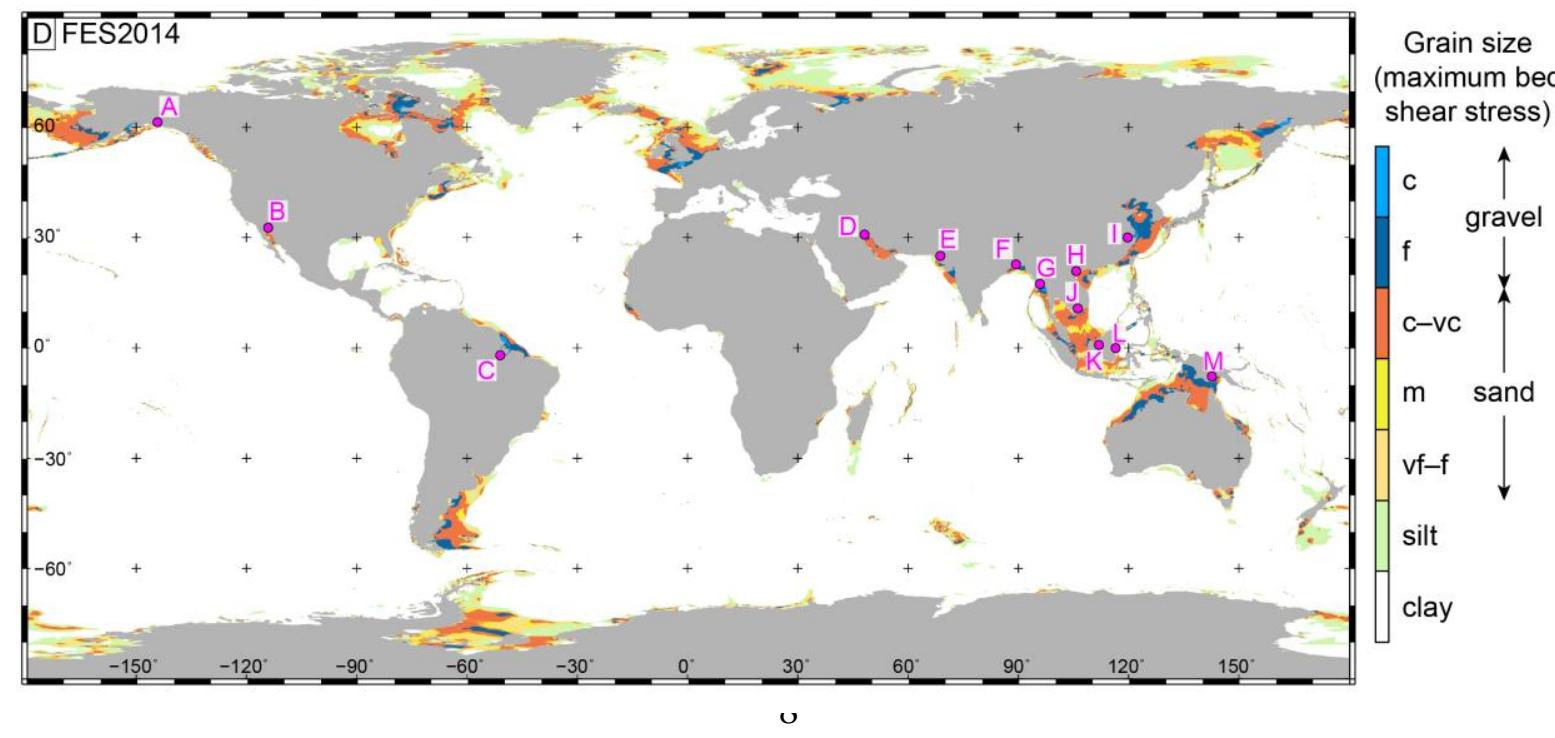


Fig. 2. (A) Present day global tidal range based on the FES 2014 tidal model (Carrère et al., 2015), showing the locations (pink dots) of tide-dominated deltas (Goodbred and Saito, 2012):

150 A) Copper; B) Colorado; C) Amazon; D) Shatt-al-Arab; E) Indus; F) Ganges-Brahmaputra; G) Irrawaddy; H) Red River; I) Yangtze; J) Mekong; K) Rajang; L) Mahakam; and M) Fly. Pink boxes show approximate locations of the palaeotidal modelling case studies. (B, C) Global map of $\mathrm{M}_{2}$ (B) and $\mathrm{K}_{1}$ tidal amplitude (C) from FES 2014. Contours join lines of equal phase in $30^{\circ}$ intervals and white arrows give the sense of rotation of the major ocean amphidromic systems. (D) Maximum tidal bed shear stress, plotted as the equivalent grain size that could be entrained if available, for FES2014, including the difference in sediment grain size class. Grain size abbreviations: $\mathrm{vf}=$ very fine; $\mathrm{f}=$ fine; $\mathrm{m}=$ medium; $\mathrm{c}=$ coarse $; \mathrm{vc}=$ very coarse.

\subsubsection{Dynamic tidal theory}

Given the limitations of equilibrium tidal theory, real-world tides are more accurately explained by dynamic tidal theory. In this model, the tidal forcing due to the movement and angular speed of the Moon and Sun are modelled as the combined effects of a series of imaginary satellites (Foreman and Henry, 1979; Pugh, 1987; Kvale, 2006; Kvale, 2012). Each modelled satellite generates its own tidal wave of a given tidal amplitude, period and phase angle (response time) moving around an amphidromic point (Pugh, 1987; Kvale, 2006; Kvale, 2012). Each tide is referred to as a tidal constituent, each of which are represented by alphanumeric terms and can be derived from the harmonic decomposition of tidal station water level measurements. From over 100 possible tidal constituents, 11 account for c. $82 \%$ of the variability observed in measured tides (Table 1) (e.g. Defant, 1961; Kantha and Clayson, 2000). The main tidal cycles (i.e. synodic, tropical and anomalistic) are related to harmonic convergence and divergence of major tidal constituents, most notably: (1) diurnal inequality exists because the $\mathrm{O}_{1}$ and $\mathrm{M}_{2}$ tidal constituents are in phase only once a day; (2) synodic neap-spring cycles are generated when the 
$173 \quad \mathrm{M}_{2}$ and $\mathrm{S}_{2}$ constituents are in phase (every 14.77 days); and (3) tropical neap-spring cycles

174 reflect the convergence of the $\mathrm{K}_{1}$ and $\mathrm{O}_{1}$ constituents (every 13.66 days) (Kvale, 2006; Kvale,

175 2012). Amphidromic systems are primarily the result of the combined interaction of tidal

176 constituents, basin geometry and the Coriolis force. Table 2 provides a summary of key tide-

177 related terms.

\begin{tabular}{|c|c|c|c|c|}
\hline \multicolumn{2}{|c|}{ Name } & Description & $\begin{array}{l}\text { Period } \\
\text { (hr or day) }\end{array}$ & $\begin{array}{l}\text { Equilibrium } \\
\text { amplitude (m) }\end{array}$ \\
\hline \multicolumn{5}{|c|}{ Semidiurnal } \\
\hline$M_{2}^{*+\S}$ & Principal Lunar & Rotation of Earth with respect to the Moon & $12.42 \mathrm{hr}$ & 0.242334 \\
\hline $\mathrm{S}_{2}{ }^{*+\S}$ & Principal Solar & Rotation of Earth with respect to the Sun & $12.00 \mathrm{hr}$ & 0.112841 \\
\hline $\mathrm{N}_{2}^{*}$ & Lunar elliptic & Eccentricity of Lunar orbit & $12.66 \mathrm{hr}$ & 0.046398 \\
\hline & $\begin{array}{l}\text { Luni-solar } \\
\text { declinational }\end{array}$ & $\begin{array}{l}\text { Modulation of } \mathrm{M}_{2} \text { and } \mathrm{S}_{2} \text { due to Lunar } \\
\text { and Solar declination changes }\end{array}$ & $11.97 \mathrm{hr}$ & 0.030704 \\
\hline \multicolumn{5}{|c|}{ Diurnal } \\
\hline $\mathrm{K}_{1}^{*}+\S$ & $\begin{array}{l}\text { Luni-Solar } \\
\text { declinational }\end{array}$ & Change in Lunar and Solar declination & $23.94 \mathrm{hr}$ & 0.141565 \\
\hline $\mathrm{O}_{1}^{*+\S}$ & Principal Lunar & Change in Lunar declination & $25.82 \mathrm{hr}$ & 0.100514 \\
\hline & Principal Solar & Change in Solar declination & $24.07 \mathrm{hr}$ & 0.046843 \\
\hline$Q_{1}^{*}$ & Lunar elliptic & $\begin{array}{l}\text { Modulation of } \mathrm{O}_{1} \text { due to the elliptical orbit } \\
\text { of the Moon }\end{array}$ & $26.87 \mathrm{hr}$ & 0.019256 \\
\hline \multicolumn{5}{|c|}{ Long-period } \\
\hline$M_{f}^{*}$ & Lunar fortnightly & Non-sinusoidal Lunar declination changes & $13.66 \mathrm{~d}$ & 0.041742 \\
\hline$M_{m}^{*}$ & Lunar monthly & $\begin{array}{l}\text { Irregularities in the rate of change of } \\
\text { distance and speed of the Moon in orbit }\end{array}$ & $27.55 d$ & 0.022026 \\
\hline $\mathrm{S}_{\mathrm{sa}}{ }^{*}$ & $\begin{array}{l}\text { Solar semi- } \\
\text { annual }\end{array}$ & $\begin{array}{l}\text { Non-uniform changes in the Sun's } \\
\text { declination and distance }\end{array}$ & $182.6 \mathrm{~d}$ & 0.019446 \\
\hline
\end{tabular}

"tidal constituent used in Collins et al. (2017) and Collins et al. (2018) (Oligocene-Miocene South China Sea)

†tidal constituent used in Wells et al. (2010b) (Early Cretaceous Lower Greensand Seaway)

$\S$ tidal constituent used in Mitchell et al. (2010) (Late Cretaceous Bohemian Cretaceous Basin)

180 Table 1. Origin, period (in solar hours, hr or days, d) and equilibrium amplitude of 11 important 181 tidal constituents (after Defant, 1961; Kantha and Clayson, 2000; Wells, 2008). 
Table 2. Explanations of several tide-related terms used in this paper ( $\underline{\text { modified from Wells et }}$ 185 al., 2010b).

\subsubsection{Shoaling, funneling and resonance effects on tides}

191 Shoaling effects involve a transformation of the tidal wave in order to conserve the energy flux.

192 This occurs by a reduction in the wave speed and wavelength and an associated increase in the 193 wave amplitude and the current velocity (Allen, 1997). Assuming a flat bed and ignoring 
194 reflected energy and bottom drag, the relative change in amplitude is proportional to the

195 quadratic root of the relative change in water depth:

$$
\frac{h_{1}}{h_{2}}=\left(\frac{A_{2}}{A_{1}}\right)^{4}
$$

where, $h_{1}$ and $h_{2}$ are the deep and shallow water depths and $A_{1}$ and $A_{2}$ are the corresponding amplitudes, respectively (Allen, 1997). The relative current velocity $\mathrm{U}\left(\mathrm{ms}^{-1}\right)$ increases by

$$
\frac{h_{1}}{h_{2}}=\left(\frac{U_{1}}{U_{2}}\right)^{\frac{3}{4}}
$$

200 where subscripts 1 and 2 denote the initial deep shallow water depths, respectively (Allen, 1997).

202 Funnelling of a tidal wave occurs when the flow is physically constricted by a physiographic

203 feature like a strait or embayment. For a landward-tapering and landward-shallowing

204 embayment, assuming that energy is conserved and ignoring bottom friction, the combined effect

205 of funnelling and shoaling (convergence effects) are estimated by

$\frac{A_{e}}{A_{o}}=\left(\frac{w_{o}}{w_{e}}\right)^{1 / 2}\left(\frac{h_{o}}{h_{e}}\right)^{1 / 4}$

where $\mathrm{A}=$ tidal range $(\mathrm{m}), \mathrm{w}=$ water body width $(\mathrm{m}), \mathrm{h}=$ water body depth $(\mathrm{m})$, subscript ' $\mathrm{o}$ '

denotes the open deeper water body and subscript 'e' the constricted shallower water body

(Slingerland, 1986; Allen, 1997). The comparison between theoretical convergence effects ( $A_{e} /$

$A_{o}$ ) on tides in ancient physiographic embayments calculated using this equation, and tidal

211 amplitude and convergence effects predicted by palaeotidal modelling, can illustrate the possible

212 effects of bottom friction and attenuation by physiographic features (e.g. shoals, islands,

213 headlands) (Wells et al., 2007a; Collins et al., 2018a). 
4234 where $1=$ embayment length $(\mathrm{m}), \mathrm{g}=$ gravitational acceleration $\left(\mathrm{ms}^{-2}\right)$, and $\mathrm{h}=$ embayment depth

(m) (e.g. Allen, 1997). In an 'enclosed' water body, the simplest period of resonance (T) is a half wavelength

$$
T=\frac{2 l}{\sqrt{g h}}
$$

where $\mathrm{l}=$ basin width $(\mathrm{m}), \mathrm{g}=$ gravitational acceleration $\left(\mathrm{ms}^{-2}\right)$ and $\mathrm{h}=$ water depth $(\mathrm{m})$ (e.g.

Allen, 1997). In these situations, resonance occurs when the tidal wave reflected off one

boundary of the embayment entrance reaches the opposite boundary (for a partly enclosed water

241 body) at the same time as another tidal wave begins to propagate, such that the waves

constructively interfere.

244 Tidal resonance in embayments is illustrated by using the tidal model Fluidity (Section 3.1) and 245 simple physiographic box models that were centred on the equator, ranged between 0 to $3000 \mathrm{~km}$ 246 wide and 0 to $300 \mathrm{~m}$ deep (192 experiments in total), and had a constant bottom drag coefficient 247 of 0.0025 and mesh resolution of c. $15 \mathrm{~km}$ (Fig. 4) (Wells, 2008). The model was forced with the $248 \mathrm{M}_{2}, \mathrm{~S}_{2}, \mathrm{~K}_{1}$, and $\mathrm{O}_{1}$ tidal constituents such that the total boundary tide amplitude was $1 \mathrm{~m}$, the 249 total amplitudes of semidiurnal (i.e. $\mathrm{M}_{2}+\mathrm{S}_{2}$ ) and diurnal (i.e. $\mathrm{K}_{1}+\mathrm{O}_{1}$ ) constituents were equal, and 250 the ratios of the $\mathrm{M}_{2}$ to $\mathrm{S}_{2}$ constituents and $\mathrm{K}_{1}$ to $\mathrm{O}_{1}$ constituents were equal to the ratio of their 251 equilibrium amplitudes (Table 1). The modelled tidal range at the head of the embayment was 252 plotted on a graph of basin width versus depth, which illustrates that even the shallowest basins 253 must be several hundred kilometres wide to attain resonance (Fig. 4).

254 The relative importance of diurnal $\left(\mathrm{K}_{1}\right.$ and $\left.\mathrm{O}_{1}\right)$ to semidiurnal $\left(\mathrm{M}_{2}\right.$ and $\left.\mathrm{S}_{2}\right)$ tides is quantified 255 using the ratio $F$, where 
1

2

3

4

9

10

11

12

13

14

15

16

17

18

19

20

21

22

23

24

25

26

27

28

29

30

31

$F=\left(\frac{K_{1}+O_{1}}{M_{2}+S_{2}}\right)$

257 If $F<0.25$, the tide is semi-diurnal, $0.25<F<3$, the tide is mixed, and $F>3$, the tide is diurnal

(Open University Course Team, 1999).
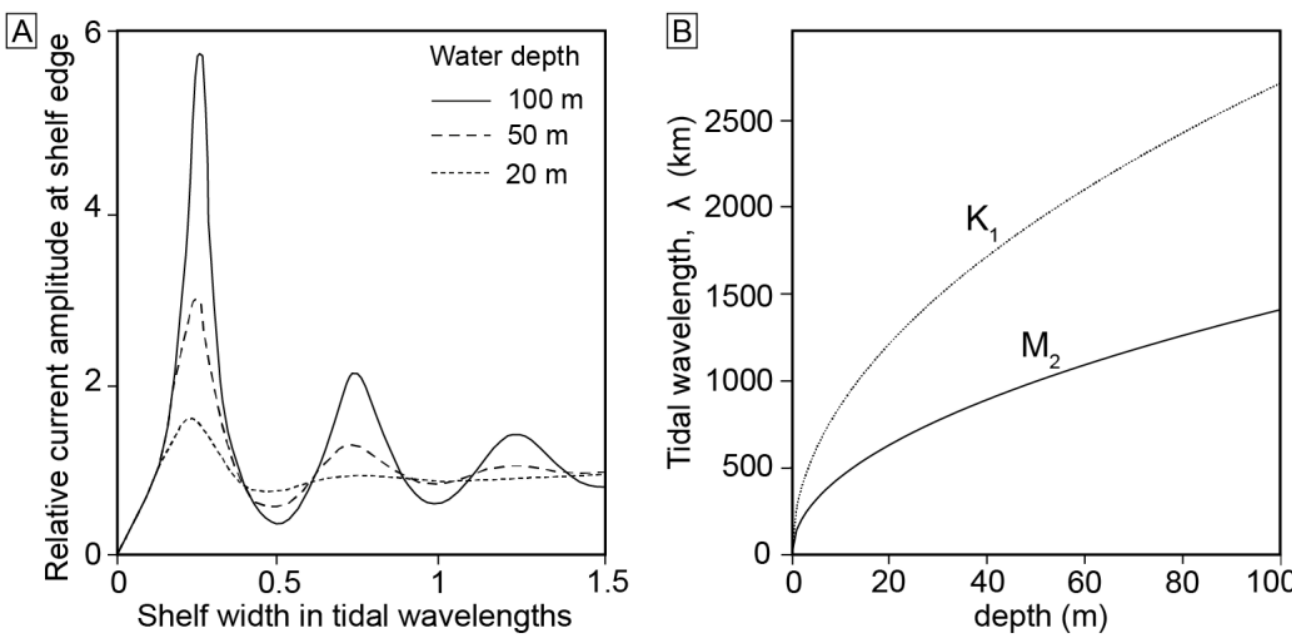

261 Fig. 3. Influence of shelf width on tidal resonance. (A) Plot of tidal resonance widths of straight 262 shelves in terms of tidal wavelengths for water depths of 100, 50 and $25 \mathrm{~m}$. Relative current amplitude is the amplitude divided by the current amplitude of a progressive wave (after 264 Howarth, 1982). (B) Relationship between tidal wavelengths and water depth for the $\mathrm{M}_{2}$ and $\mathrm{K}_{1}$ 265 tidal constituents (after Kowalik and Luick, 2013). 


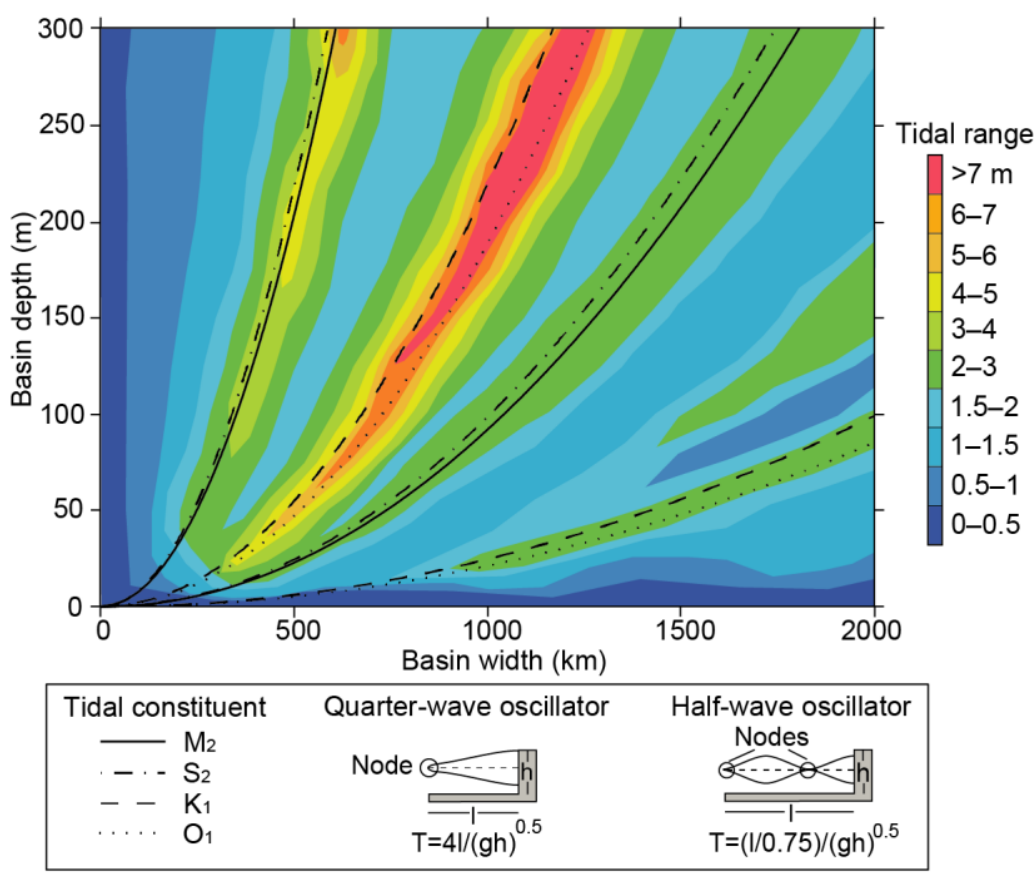

Fig. 4. Tidal resonance effect in embayments. Graph shows increase in modeled tidal range for 269 the semidiurnal $\left(\mathrm{M}_{2}, \mathrm{~S}_{2}\right)$ and diurnal $\left(\mathrm{K}_{1}, \mathrm{O}_{1}\right)$ tidal constituents at the head of embayments of 270 various dimensions for simple box models using the Fluidity tidal model (from Wells, 2008; 271 Collins et al., 2018a).

\subsubsection{Numerical palaeotidal modelling}

274 Palaeotidal numerical modelling can provide quantitative information on ancient shoreline tidal 275 processes and can test their sensitivity to palaeogeographic and palaeobathymetric uncertainty 276 (e.g. Martel et al., 1994; Wells et al., 2005a; Collins et al., 2018a). Computational methods for 277 ancient tidal modelling, including tidal forcing boundary conditions and mesh generation, have 278 advanced since early approaches that used structured meshes and open boundary tidal forcing by 279 the $\mathbf{M}_{2}$ (principal lunar semi-diurnal) tide only, and output tidal amplitude or range (Slater, 1985; 280 Slingerland, 1986; Ericksen and Slingerland, 1990; Martel et al., 1994). More recent simulations

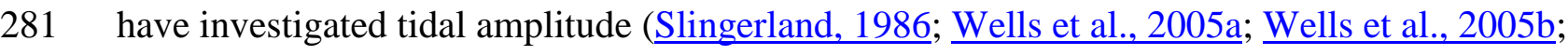


2

3

4282 Wells et al., 2007a; Wells et al., 2010a; $\underline{\text { Wells et al., 2010b) and bed shear stress (Mitchell et al., }}$

6

7

8 


\section{Key findings}

\section{method}

$\begin{array}{ll}\text { Late Devonian } & \text { Catskill } \\ \text { c. } 370 \mathrm{Ma} & \text { epicontinental } \\ \text { (Slingerland, } & \text { sea of North } \\ \text { 1986) } & \text { America }\end{array}$

Structured grid,

finite difference

scheme; Navier

Stokes equations;

Coriolis parameter

(f -plane).

$\begin{array}{llll}\text { Mid } & \text { Western } & \text { Structured grid, } & \text { Open boundary and } \\ \text { Cretaceous c. } & \text { Interior } & \text { finite difference } & \text { astronomical tidal forcing; } \\ \text { 100 Ma } & \text { Seaway of } & \text { scheme; Laplace } & \text { M2 tide only; Uniform } \\ \text { (Slater, 1985) } & \text { North America } & \text { Tidal Equations; } & \text { depths; Linear bottom } \\ & & \text { No Coriolis } & \text { friction with respect to } \\ & & \text { parameter. } & \text { velocity. }\end{array}$

Mi

Cretaceous c Interior

$100 \mathrm{Ma}$

(Ericksen and

Slingerland,

1990)

$\begin{array}{ll}\text { Miocene c. 22 } & \text { Alpine } \\ \text { Ma (Martel et } & \text { foreland basin } \\ \text { al., 1994) } & \text { of France and } \\ & \text { Switzerland }\end{array}$

Structured grid,

Open boundary tidal forcing, no astronomical tidal forcing; M2 tide only; finite difference scheme; Navier Stokes equations; Coriolis Parameter (f -plane).
Open boundary tidal

forcing, no astronomical tidal forcing; M2 tide only; Variable bathymetry; Chezy approximation for bottom friction.
Open boundary tidal forcing, no astronomical tidal forcing; M2 tide only; Variable bathymetry; Chezy approximation for bottom friction.
Microtidal-low mesotidal, loca mesotidal-macrotidal areas due resonance, funnelling and shoaling effects. Tidal ranges increased by: 1) increasing the boundary tidal range; 2) increasing the open boundary width; and 3) increasing the dep of the seaway.

Microtidal; Astronomical tidal forcing dominates; Open boundary tide negligible from $t$ Arctic Ocean and possibly significant from the Gulf of Mexico; Tidal range sensitive to water depth (resonance at $200 \mathrm{n}$ water depth).

Microtidal, locally mesotidalmacrotidal near Gulf of Mexico open boundary; Tidal range increases as seaway depth and Gulf of Mexico connection increases; Open boundary tides argued to be dominant contribu to tides, not astronomically forc tides (cf. Slater, 1985).

Higher tidal current speeds predicted with wider and deepe open-ocean connections and $2 \mathrm{n}$ open boundary tide applied. Variable bathymetry; Chezy approximation for bottom friction.

\begin{tabular}{|c|c|c|c|c|}
\hline $\begin{array}{l}\text { Late } \\
\text { Carboniferous } \\
\text { c. } 300 \mathrm{Ma} \\
\text { (Wells et al., } \\
\text { 2005a,b) }\end{array}$ & $\begin{array}{l}\text { Late } \\
\text { Carboniferous } \\
\text { sea of NW } \\
\text { Europe }\end{array}$ & $\begin{array}{l}\text { Unstructured, } \\
\text { tetrahedral mesh, } \\
\text { finite element } \\
\text { scheme; Navier } \\
\text { Stokes equations; } \\
\text { No Coriolis } \\
\text { parameter. }\end{array}$ & $\begin{array}{l}\text { Astronomical tidal forcing } \\
\text { only; M2 tide only; Variable } \\
\text { bathymetry; No treatment of } \\
\text { bottom friction. }\end{array}$ & $\begin{array}{l}\text { Extremely microtidal seaway } \\
\text { (typically }<10 \mathrm{~cm} \text { tidal range) } \\
\text { across NW region across variou } \\
\text { sensitivity tests; Putative tidal } \\
\text { deposits interpreted to be } \\
\text { confined to localised estuaries. }\end{array}$ \\
\hline $\begin{array}{l}\text { Late } \\
\text { Carboniferous } \\
\text { c. } 300 \mathrm{Ma} \\
\text { (Wells et al., } \\
\text { 2008) }\end{array}$ & $\begin{array}{l}\text { Late } \\
\text { Carboniferous } \\
\text { sea of NW } \\
\text { Europe }\end{array}$ & $\begin{array}{l}\text { Unstructured, } \\
\text { tetrahedral mesh, } \\
\text { finite element } \\
\text { scheme; Navier } \\
\text { Stokes equations; }\end{array}$ & $\begin{array}{l}\text { Astronomical tidal forcing } \\
\text { only; } \mathrm{M} 2, \mathrm{~S} 2, \mathrm{~N} 2, \mathrm{~K} 2, \mathrm{Q} 1, \\
\mathrm{O} 1, \mathrm{P} 1, \mathrm{~K} 1, \mathrm{M}_{\mathrm{f}}, \mathrm{M}_{\mathrm{m}} \text { and } \mathrm{S}_{\mathrm{sa}} \\
\text { tidal constituents; Variable } \\
\text { bathymetry; Bottom drag } \\
\text { applied as surface-integral }\end{array}$ & $\begin{array}{l}\text { Microtidal ranges predicted } \\
\text { across the northwest European } \\
\text { region (similar to Wells et al., } \\
2005 \mathrm{a}, \mathrm{b} \text { ); Extra tidal constituer } \\
\text { increase the predicted tidal rang } \\
\text { to } 20-80 \mathrm{~cm} \text {. }\end{array}$ \\
\hline
\end{tabular}


Coriolis parameter based on quadratic friction included.

Unstructured, tetrahedral mesh, finite element scheme; Navier Stokes equations; Coriolis parameter included. law.

\begin{tabular}{|c|c|c|c|}
\hline $\begin{array}{l}\text { Early } \\
\text { Cretaceous, } \\
\text { late Aptian, c. } \\
116 \mathrm{Ma} \text { (Wells } \\
\text { et al., 2010a) }\end{array}$ & Global & $\begin{array}{l}\text { Unstructured, } \\
\text { tetrahedral mesh, } \\
\text { finite element } \\
\text { scheme; Navier } \\
\text { Stokes equations; } \\
\text { Coriolis parameter } \\
\text { included. }\end{array}$ & $\begin{array}{l}\text { Astronomical tidal forcing } \\
\text { only; M2, S2, O1 and K1 } \\
\text { tidal constituents modelled } \\
\text { independently; Variable } \\
\text { bathymetry; Bottom drag } \\
\text { applied as surface-integral } \\
\text { based on quadratic friction } \\
\text { law. }\end{array}$ \\
\hline
\end{tabular}

\begin{tabular}{|c|c|c|}
\hline $\begin{array}{l}\text { Early } \\
\text { Cretaceous, } \\
\text { late Aptian - } \\
\text { early Albian, c. } \\
112-107 \mathrm{Ma} \\
\text { (Wells et al., } \\
\text { 2010b) }\end{array}$ & $\begin{array}{l}\text { Lower } \\
\text { Greensand } \\
\text { Seaway of NW } \\
\text { Europe }\end{array}$ & $\begin{array}{l}\text { Unstructured, } \\
\text { tetrahedral mesh, } \\
\text { finite element } \\
\text { scheme; Navier } \\
\text { Stokes equations; } \\
\text { Coriolis parameter } \\
\text { included. }\end{array}$ \\
\hline
\end{tabular}

\begin{tabular}{|c|c|c|}
\hline $\begin{array}{l}\text { Middle } \\
\text { Cretaceous, } \\
\text { Early-Middle } \\
\text { Turonian, c. } 93 \\
\text { Ma } \\
\text { (Mitchell et al., } \\
\text { 2010) }\end{array}$ & $\begin{array}{l}\text { Bohemian } \\
\text { Cretaceous } \\
\text { Basin of } \\
\text { Central Europe }\end{array}$ & $\begin{array}{l}\text { Unstructured, } \\
\text { tetrahedral mesh, } \\
\text { finite element } \\
\text { scheme; Navier } \\
\text { Stokes equations; } \\
\text { Coriolis parameter } \\
\text { included. }\end{array}$ \\
\hline
\end{tabular}

\begin{tabular}{|c|c|c|}
\hline $\begin{array}{l}\text { Early Jurassic, } \\
\text { c. } 200 \mathrm{Ma} \\
\text { (Mitchell et al., } \\
\text { 2011) }\end{array}$ & $\begin{array}{l}\text { Laurasian } \\
\text { Seaway of NW } \\
\text { Europe }\end{array}$ & $\begin{array}{l}\text { Unstructured, } \\
\text { tetrahedral mesh, } \\
\text { finite element } \\
\text { scheme; Navier } \\
\text { Stokes equations; } \\
\text { Coriolis parameter } \\
\text { included. }\end{array}$ \\
\hline
\end{tabular}

\begin{tabular}{lll}
\hline Oligocene- & South China & Unstructured, \\
Miocene, c.. & Sea, SE Asia & tetrahedral mesh, \\
26-5 Ma & & finite element \\
(Collins et al., & & scheme; Navier \\
2017, 2018) & & Stokes equations; \\
& & Coriolis parameter \\
& included.
\end{tabular}

\begin{tabular}{ll}
\hline Late & Western \\
Cretaceous & Interior \\
\hline
\end{tabular}
Unstructured, Astronomical tidal forcing tetrahedral mesh, $\mathrm{M} 2, \mathrm{~S} 2, \mathrm{~N} 2, \mathrm{~K} 2, \mathrm{Q} 1, \mathrm{O} 1$,
Open boundary conditions (from Wells et al., 2010a) and astronomical tidal forcing; M2, S2, O1 and K1 tidal constituents modelled independently; Variable bathymetry; Bottom drag applied as surface-integral based on quadratic friction law.

Open boundary conditions and astronomical tidal forcing; varying combinations of M2, S2, O1 and $\mathrm{K} 1$ tidal constituents; Variable bathymetry; Bottom drag applied as surface-integral based on quadratic friction law.

\section{Astronomical tidal forcing;}

M2, S2, O1 and K1 tidal constituents; Variable bathymetry; Bottom drag applied as surface-integral based on quadratic friction law.
Model results compared to published geologic records; Hig mesotidal to macrotidal on the Arabian Platform, around India along the Pacific coast between North and South America, northeast of Australia, and arou Southeast Asia; Low microtidal ranges in the proto-South Atlan Ocean and Weddell Sea. Overall microtidal increasing to microtidal-macrotidal with increased width and depth of open-ocean connections and mo localised funnelling, shoaling a Coriolis effects.

Microtidal-mesotidal across the Bohemian Cretaceous Basin and range of sensitivity tests; Elevated tidal ranges and velocity in local embayments and straits due to funnelling anc shoaling effects.

Seaway largely microtidal; Flo constriction associated with shallow platforms and straits produced elevated bed shear stresses that were decoupled fro tidal range.

Astronomical tidal forcing;

M2, S2, N2, K2, Q1, O1, $\mathrm{P} 1, \mathrm{~K} 1, \mathrm{M}_{\mathrm{f}}, \mathrm{M}_{\mathrm{m}}$ and $\mathrm{S}_{\mathrm{sa}}$ tidal constituents; Variable bathymetry; Bottom drag applied as surface-integral based on quadratic friction law.
Spring tides along South China Sea coastline were largely mesotidal-macrotidal and capable of transporting sand throughout the Late Oligocene to Middle Miocene. Astronomical tidal forcing; Regionally microtidal and 
middle Seaway of finite element $\mathrm{P} 1, \mathrm{~K} 1, \mathrm{M}_{\mathrm{f}}, \mathrm{M}_{\mathrm{m}}$ and $\mathrm{S}_{\mathrm{sa}}$ tidal

Campanian, c. North America

75-77.5 Ma

(Dean et al., 2019) scheme; Navier

Stokes equations;

Coriolis parameter

included. constituents; Variable bathymetry; Bottom drag applied as surface-integral based on quadratic friction law. mesotidal (2-4 m) along most $\mathrm{o}$ the eastern margin of the seawa increased tidal bed shear stress when seaway center and entran to Gulf of Mexico are deeper.
290

291

292 (excluding the Quaternary).

\section{$294 \quad 2.2 \quad$ Process-based sedimentological analysis}

295 The study and interpretation of ancient physical processes from sedimentary rocks requires a 296 rigorous, multi-scale approach that has developed over the last 60-70 years (see reviews by

297 Walker and Plint, 1992; Reading, 1996). The approach is underpinned by rigorous facies 298 analysis, which relies on detailed, qualitative descriptions of distinctive combinations of 299 sedimentary and biological structures (e.g. Reading, 1978; Reading, 1996) \}(De Raaf et al., 1965; 300 Walker, 1979; Anderton, 1985). However, small-scale (c. 1-100s cm) facies are typically based 301 on subtle differences that are non-unique in terms of depositional processes and environment 302 (Walker and James, 1992). Process and environment interpretation more readily occurs at the 303 facies association (typically several metres to 10s metre) and facies succession (10s-100s m)

304 levels but even at these scales process and environment interpretation may remain ambiguous 305 (Walker and James, 1992; Dalrymple, 2010; Colombera and Mountney, 2020b). Understanding 306 the relationship between process, sedimentation and resultant sedimentary structures and 307 stratigraphy ideally requires close comparison to the modern, where these aspects may be 308 observed and measured directly in different environments (Middleton, 1965; Allen, 1968; $\underline{\text { Allen, }}$ 309 1982b; Collinson and Mountney, 2019). 
In shoreline systems, the process-based sedimentological approach centres upon determining the relative influence of river, wave and tide processes, with the inherent understanding that these are characterised by different groups of physical process types, principally unidirectional and bidirectional traction currents and gravitational, oscillatory and suspension flow processes. The application of a three-tier process classification depends on: (1) the availability and quality of the rock data; and (2) the process implications of sedimentological and biological features. However, both these considerations are subject to potential biases. For example, higher-quality exposure may be sandstone dominated due to preferential weathering of finer-grained or thinner-bedded facies, the identification and interpretation of which often requires exceptional outcrop or core data quality. Furthermore, sediment texture, particularly grain size distribution, has a significant control on the type of sedimentary structures and facies formed, and can vary significantly between different sedimentary systems (Jopling and Walker, 1968; Allen, 1982b; Harms et al., 1982; Kvale et al., 1989; Orton and Reading, 1993; Yoshida et al., 2007).

326 that a bed or stratal unit was formed by wave, tide or fluvial processes ('process percentage') and 327 quantifying the relative proportion of each bed or stratal unit (Rossi et al., 2017; Peng et al., 328 2018). The 'process percentage' is determined based on the proportion of preserved sedimentary 329 structures, and also the proportion of wave-, tide- or fluvial-dominated interpretations of each 330 sedimentary structure in an extensive literature database (Rossi et al., 2017; Peng et al., 2018). 331 However, end-member process interpretations of various sedimentary structures are commonly 332 ambiguous, and it is difficult to assign percentage values to those formed by combined processes. 
Whilst this statistical method provides a theoretical framework for more accurate estimation of process variability, in reality interpretations may be subjective and biased, partly reflecting uncertainties in original literature studies and revisions in process interpretations of different sedimentary structures. Indeed, original literature interpretations may have skewed, and even self-reinforced, the process interpretation of some key sedimentary structures and facies (Colombera et al., 2012; Rossi et al., 2017). For example, it is now recognized that heterolithic facies are not limited to tidal settings, as was originally emphasized (e.g. Reineck and Wunderlich, 1968), but can form in a wider range of depositional environments (e.g. Ainsworth et al., 2012). This effect is captured in the growing uncertainty regarding the process

342 classification of heterolithic deposits in terms of the balance of fluvial versus tidal processes, 343 especially: (1) those displaying unidirectional-dominated, current ripple cross-lamination (e.g. 344 Dalrymple et al., 2015; Gugliotta et al., 2016b; Kurcinka et al., 2018; Collins et al., 2020; $\underline{\text { Van }}$ 345 Yperen et al., 2020), including within inclined heterolithic strata ( 346 et al., 2015; Jablonski and Dalrymple, 2016); and (2) discriminating between tidal influence 347 (secondary process) versus tidal modulation (tertiary processes) in cross-stratification (Martinius and Gowland, 2011; Gugliotta et al., 2016a) (Martinius et al., 2015). Similarly, hummocky and 349 swaley cross-stratification with mudstone drapes have been interpreted to record mixed storm 350 and tidal processes (Vakarelov et al., 2012; Wei et al., 2016), but the variability in flow and 351 sedimentation required for mud draping may occur inherently occur during storm flows (e.g. 352 Collins et al., 2017b). A further example is the process origin of hummocky and swaley cross353 stratification and related structures (e.g. combined-flow ripples and planar lamination), including 354 the balance of oscillatory to unidirectional flow and the influence of hyperpycnal flow (Dott and 355 Bourgeois, 1982; Arnott and Southard, 1990; Myrow and Southard, 1996; Myrow et al., 2002; 
Dumas and Arnott, 2006; Lamb et al., 2008; Tinterri, 2011; Basilici et al., 2012; Perillo et al., 2014). Consequently, assigning the relative contribution of wave, tidal or fluvial processes to a given sedimentary structure remains uncertain.

\subsection{Classification and prediction of shoreline depositional process regime}

\subsubsection{Process classifications}

Shoreline systems encompass a wide range of depositional settings, including deltas, strandplains, estuaries, barrier islands and a host of sub-environments (e.g. lagoons, tidal flats, distributary channels, mouth bars, etc.). Seminal models for clastic shoreline systems initially focused on modern deltas, particularly the relationship between delta front morphology and the relative influence of wave, tidal and fluvial process (Coleman and Wright, 1975; Galloway, 1975). This ternary classification scheme was widely adopted and modified to include a wider range of depositional settings by Boyd et al. (1992), notably the bivariate wave versus tide classification of clastic coasts (Hayes, 1975; Hayes, 1979) and variability in grain size (Orton and Reading, 1993). Furthermore, Boyd et al. (1992) and Dalrymple et al. (1990) interpreted the predictive evolutionary relationships between long-term equilibrium depositional environments and the rates of sediment supply versus relative sea level change (shoreline transgression vs. regression). The most recent manifestation of the ternary classification scheme has been a more detailed descriptive process model of the spectrum of shoreline systems, including aspects of their spatial and temporal variability (Ainsworth et al., 2011).

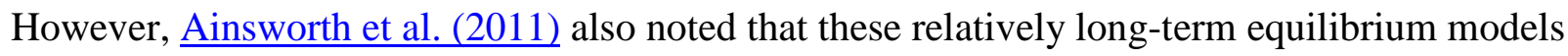
are unable to predict more precise process variations in space at a given time ('environmental 
disequilibrium'; (Boyd et al., 1992). In addition, they cannot convolve the effects of dynamic temporal changes (at varying timescales) in depositional processes caused by (1) changes in shoreline physiography (morphology and bathymetry), (2) fluctuations in accommodation space creation versus sediment supply rates, and (3) variations in regional basin physiography.

Within individual shoreline systems, complex arrangements of discrete depositional elements attributed to different combinations of wave, tide and fluvial processes have been recognized in analyses of: (1) modern delta geomorphology and sedimentological data, including the Danube (e.g. Bhattacharya and Giosan, 2003), Ganges-Brahmaputra (e.g. Willis, 2005), Mahakam (e.g. Allen and Chambers, 1998), Mekong (e.g. Nguyen et al., 2000; Ta et al., 2002b), Mitchell (e.g. Nanson et al., 2013) and Changjiang (Yangtze) (e.g. Hori et al., 2002) deltas; and (2) approximately contemporaneous ancient stratigraphic units, including the Permian Kookfontein and Waterford formations in the Karoo Basin (Gomis-Cartesio et al., 2016), Cretaceous Ferron Sandstone, Western Interior Seaway (e.g. Gardner et al., 2004; Bhattacharya and MacEachern, 2009; Li et al., 2011; Li et al., 2015), Cretaceous Sego Sandstone, Western Interior Seaway (Willis and Gabel, 2001; Legler et al., 2014; van Cappelle et al., 2016), Cretaceous Horseshoe 395 Canyon Formation, Western Interior Seaway (Willis and Gabel, 2001; Legler et al., 2014; 396 Ainsworth et al., 2015; Ainsworth et al., 2016; van Cappelle et al., 2016) and Miocene Belait 397 Formation, NW Borneo (Lambiase et al., 2003; Collins et al., 2017b; Collins et al., 2018b). 398 Consequently, these and many other depositional systems indicate frequent mixed-process 399 regimes, with variable wave, tide and fluvial interactions in both space (e.g. along and/or 400 perpendicular to depositional strike) and time (on various timescales e.g. daily, seasonal, annual or longer). These mixed-energy systems cannot be fully resolved in the early process 
classification models (Coleman and Wright, 1975; Galloway, 1975; Boyd et al., 1992).

Therefore, Ainsworth et al. (2011) developed a new semi-quantitative, process-based classification scheme based on the relative importance of primary, secondary and tertiary processes (generating 'dominated', 'influenced' or 'affected' descriptors, respectively). This higher-resolution process-based approach enables a more rigorous comparison of modern and ancient shoreline deposits (Fig. 5A). However, a quantitative process analysis of modern shorelines by Nyberg and Howell (2016) suggests the thresholds separating primary, secondary and tertiary processes are ambiguous, resulting in these authors favouring a two-tier classification (Fig. 5B). Furthermore, the additional ambiguity in the process interpretation of 411 several common sedimentary structures means that most studies of ancient, mixed-process 412 shoreline deposits have adopted a two-tier process classification (e.g. Bhattacharya and Giosan, 413 2003; Lambiase et al., 2003; Coates and MacEachern, 2007; Gani and Bhattacharya, 2007;

414 Hansen et al., 2007; Buatois et al., 2012; Vakarelov et al., 2012; Amir Hassan et al., 2013; Legler 415 et al., 2013; Chen et al., 2014; Legler et al., 2014; Ainsworth et al., 2015; Gugliotta et al., 2015; 416 Li et al., 2015; Ainsworth et al., 2016; Amir Hassan et al., 2016; Gomis-Cartesio et al., 2016; 417 Gugliotta et al., 2016a; Rossi and Steel, 2016; Vaucher et al., 2016; Collins et al., 2017b; Collins 418 et al., 2018b). 

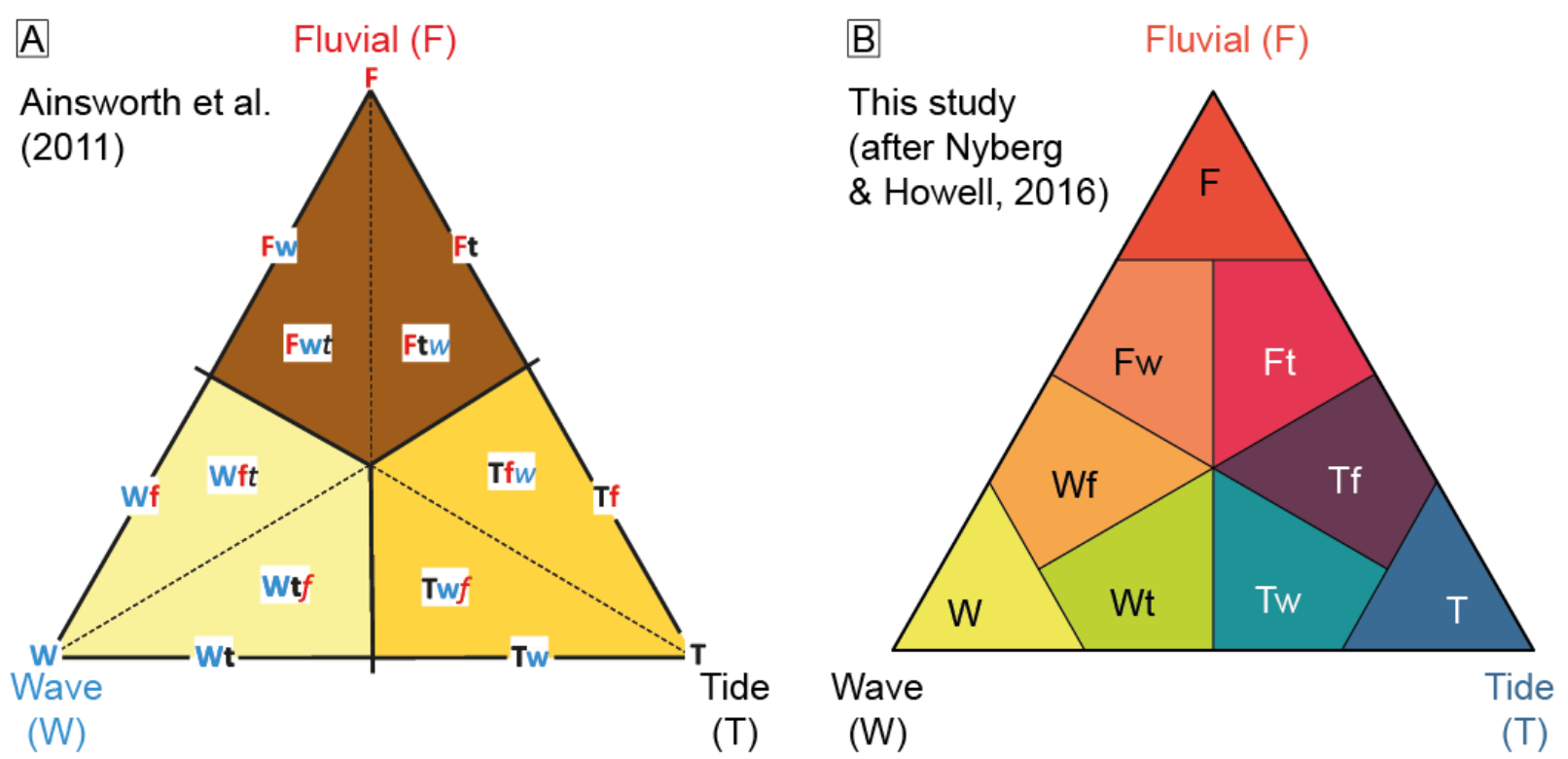

(T)

421 Fig. 5. Two contrasting ternary process classifications for shoreline depositional systems. (A)

422 The three-tier classification of Ainsworth et al. (2011) utilizes primary, secondary, and tertiary 423 processes, which are referenced as 'dominated' (capitalized and bold), 'influenced' (lower case 424 and bold) and 'affected' (lower case italics and not bold), respectively. For example, wave 425 dominated, tide influenced and fluvial affected is written $\mathbf{W t f}$. (B) The two-tier classification of 426 Nyberg and Howell (2016) recognizes the primary and secondary processes, and is favored in 427 this study (see text for discussion).

$429 \quad$ 2.3.2 Process classification of present-day global shorelines

$430 \quad$ Nyberg and Howell (2016) developed the first, systematic, semi-automated classification of 431 global shoreline process regime (Fig. 6) by combining several datasets and methodologies: (1) 432 proxies for wave, tide and fluvial processes, including wave height, tidal amplitude and river 433 discharge; (2) depositional versus erosional shorelines, determined by combining global 434 lithology maps and digital elevation models; and (3) algorithms for determining the 'tidal 435 coefficient' for modifying tidal amplitude using shoreline rugosity or 'roughness index'. This 436 integrated approach predicts shoreline classification with an $85 \%$ success rate compared to 
manual interpretation based principally on shoreline morphology (e.g. Ainsworth et al., 2011), and is consistent with earlier comparisons of shoreline morphology with quantitative metrics of wave, tide and river power along large, but non-global, stretches of siliciclastic coastlines (e.g. Harris et al., 2002). By subdividing the global shoreline into $5 \mathrm{~km}$ segments, this methodology classifies $28 \%$ of global shorelines as depositional, of which $62 \%$ are wave-dominated, $35 \%$ 442 tide-dominated and 3\% fluvial-dominated (Fig. 6A) (Nyberg and Howell, 2016). On a global 443 scale, over $90 \%$ of shorelines on narrow shelves $(\leq 25 \mathrm{~km})$ are wave-dominated and $<5 \%$ tide444 dominated, whereas over $30 \%$ of shorelines on wide shelves (>75 km) are tide-dominated (Fig. 445 6B). Along depositional shorelines, tide dominance increases from $<20 \%$ on narrow shelves to $446>50 \%$ on wide shelves (Fig. 6C). Fluvial systems along shorelines are more wave modified on 447 narrow shelves and more tide modified on wide shelves (Fig. 6B and C).

449 Tide-dominated deltas are widely distributed (Figs 2A and 6A), including: (1) at low and high 450 latitudes; (2) along open-ocean shorelines and in partly enclosed oceans and seas; and (3) along 451 straight and highly embayed shorelines. Their locations encompass a range of tectonic settings, 452 including strike-slip transtensional rift (e.g. Colorado delta), forearc (e.g. Cooper delta), foreland 453 (e.g. Mahakam and Fly deltas) and passive margin settings (Ganges Brahmaputra delta) (Nyberg 454 and Howell, 2016). Whilst tide-dominated deltas preferentially occur along macrotidal shorelines 455 (Fig. 2A), they also occur along mesotidal shorelines (e.g. Mekong and Mahakam deltas). 456 However, tide-dominated deltas exclusively occur along shorelines with elevated tidal bed shear 457 stresses, where tidal currents at their maximum strength are capable of transporting at least 458 coarse sand (Fig. 2D). 
Although the Nyberg and Howell (2015) classification provides a consistent, reproducible approach for identifying process distribution along global shorelines, it has significant

462 limitations. There are inherent biases between shoreline morphology and process dominance: i.e. more rugose and funnel-shaped shorelines are inherently biased towards tide dominance and smoother shorelines towards wave-dominance. None of the tidal coefficients consider theoretical 465 and quantifiable relationships between shoreline physiography and the tidal prism. Lastly, wave 466 height and tidal range are inadequate proxies for differentiating wave- and tide-dominance in 467 mixed-energy systems (e.g. Anthony and Orford, 2002; Mulhern et al., 2017) because these 468 parameters are not directly related to sediment entrainment (unlike bed shear stress). 
A

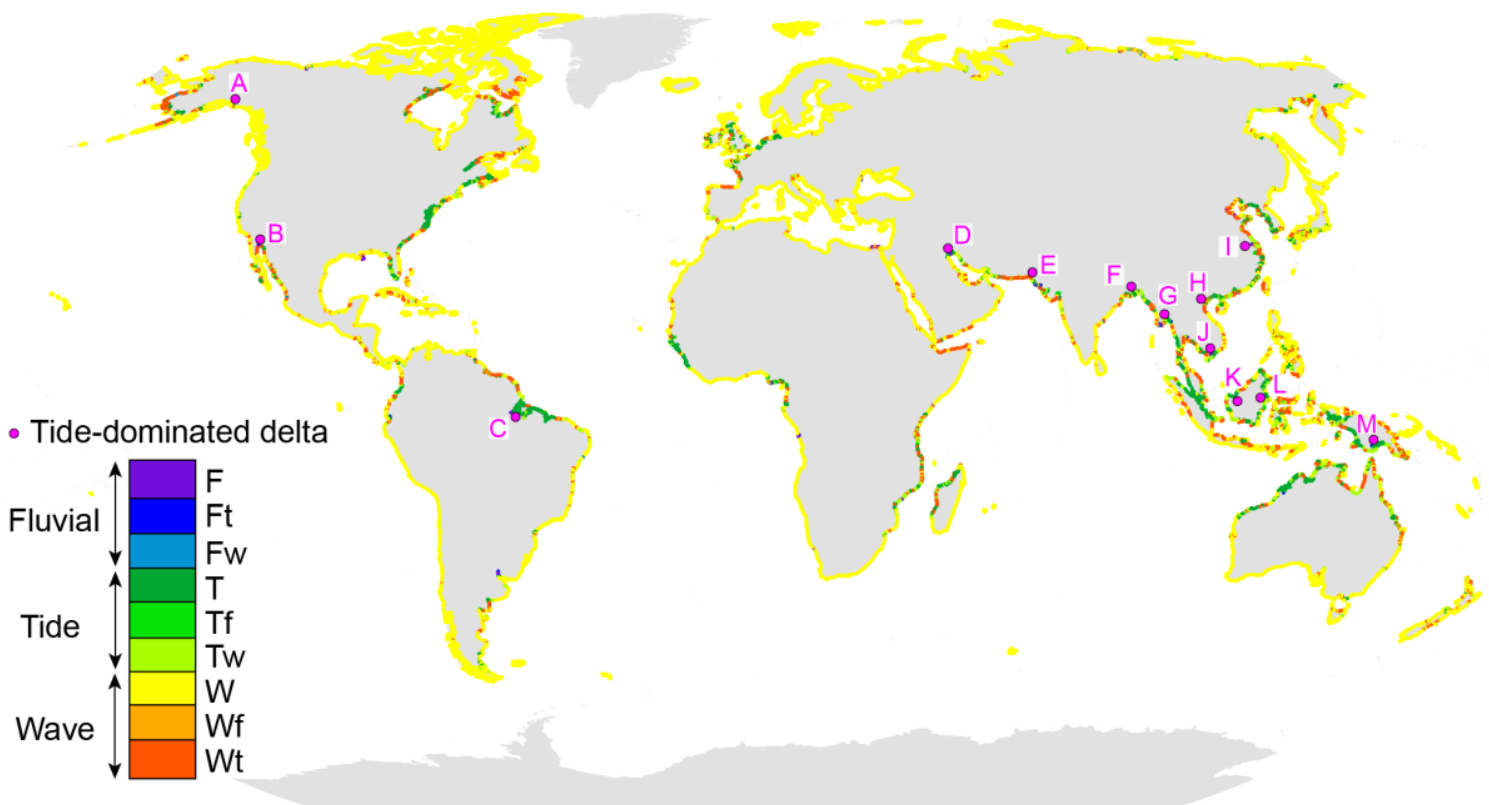

B

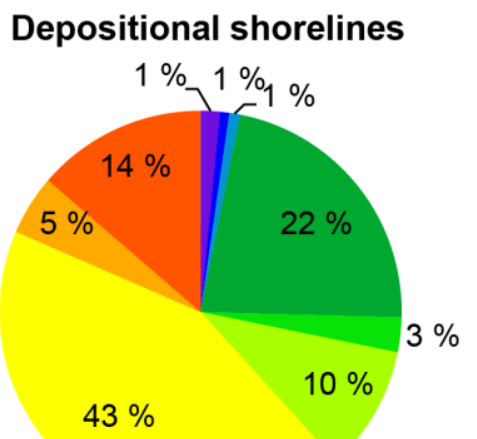

C

Shelf width 


\subsubsection{Prediction of ancient shoreline process regime}

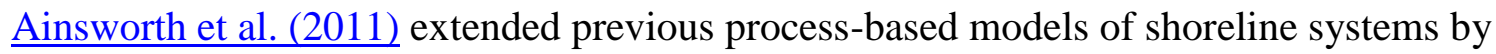
introducing other critical aspects to the palaeoenvironmental diagnosis, most notably: (1) basin physiography (100-1000 km scale), (2) shelf width (10-100 km scale), (3) fluvial versus wave effectiveness, (4) accommodation versus sediment supply (A/S ratio), and (5) shoreline morphology (1-10 km scale). These were incorporated into a predictive decision tree (Fig. 7A) and matrices (Fig. 7B and C) for shoreline depositional process regime.

Basin physiography and shelf width are combined to determine the 'tidal resonance potential of the basin', which is the first query on the decision tree (Fig. 7A) and distinguishes two predictive matrices (Fig. 7B and C). Tidal resonance occurs when the natural period of oscillation on the shelf, or within a shoreline embayment, is coincident with the tidal period (Slingerland, 1986;

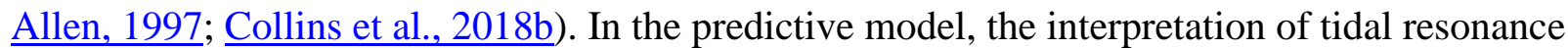
potential is calibrated empirically to shelf width (cf. Howarth, 1982). Since analysis of presentday shorelines suggests that they are more likely to be tide-dominated adjacent to shelves greater than $75 \mathrm{~km}$ in width (Heap et al., 2004; Ainsworth et al., 2011), a shelf width of $75 \mathrm{~km}$ is an approximate empirical cut-off between modern and ancient shorelines with lower $(<75 \mathrm{~km}$ shelf width) and higher tidal potential (>75 km shelf width), respectively.

501 The effect of basin physiography is complicated by (1) the influence of tidal inflow versus 502 outflow to partly enclosed water bodies, and (2) the funnelling, shoaling and resonance effects on continental shelves and within shoreline embayments, which occur on a range of scales $(c .1-$ 
1000s km width and 1-100s m depth) (Mitchell et al., 2010; Wells et al., 2010b; Collins et al., $\underline{2018 b}$ ). However, despite this complexity, basin physiography does not constitute a separate query in the predictive model (Fig. 7) and is treated as a modifying factor to shelf tidal resonance potential (Ainsworth et al., 2011). Open oceans are sufficiently large to allow generation of relatively high in-situ tides (Dalrymple, 1992). Therefore, basins that have restricted access to the open oceans generally have a lower potential for producing amplified tidal currents by resonance effects, whereas basins with less restricted access to open oceans have a higher tidal resonance potential. An exception is that certain restrictive basin physiographies, typically on a smaller-scale (1-10s km), may cause significant amplification of tides by funnelling, shoaling and/or resonance effects (Piper et al., 1990; Martel et al., 1994) (Mitchell et al., 2010; $\underline{\text { Ainsworth }}$ et al., 2011; Mitchell et al., 2011) (Androsov et al., 2002; Leckie and Rumpel, 2003).

Consequently, the generalized treatment of basin physiography in the existing predictive model (Ainsworth et al., 2011) combines two very different effects on tides relating to: (1) basin geography (100-1000 km width scale) and bathymetry (100-1000 m depth scale), which has a first order control on the balance of tidal inflow versus outflow; and (2) second-order funnelling and resonance effects relating to basin physiography (10-100s km width scale and 1-100s m depth scale) (Wells et al., 2005a; Wells et al., 2007a; Mitchell et al., 2010; Wells et al., 2010b; Collins et al., 2018a). Distinguishing between these two controls of basin physiography is achieved most rigorously through numerical tidal modelling (Slingerland, 1986; Martel et al., 1994; Wells et al., 2007a; Collins et al., 2018a).

Fluvial versus wave effectiveness is related to ancient shoreline palaeogeography. Hence, shorelines facing large open water bodies are likely to be strongly influenced by wind-driven 
waves, with a large fetch resulting in a relatively high wave effectiveness. In contrast, shorelines that are more sheltered from direct oceanic waves and/or face smaller water bodies experience lower wave effectiveness. Fluvial effectiveness is controlled by a range of continental processes, including climate, weathering, river hydrology, drainage basin area, slope of the alluvial plain, and hinterland relief and gradient. Predictions of higher fluvial effectiveness must be supported by palaeogeographic, palaeodrainage and palaeohydrological reconstructions, especially where these indicate proximity to large fluvial drainage areas. Consequently, wave and fluvial effectiveness are determined by very different factors. Hence, determining the nature of wave and fluvial interactions, including predictions of their relative effectiveness, must rely on facies analysis of preserved stratigraphy.

538 The rate of accommodation space creation versus sediment supply ( $\mathrm{A} / \mathrm{S}$ ratio) is a useful 539 theoretical concept (Muto and Steel, 1997) but difficult to apply practically, even for extensive 540 datasets (Ainsworth et al., 2008; Ainsworth et al., 2011), and for predictions based on 541 parasequence characteristics (Colombera and Mountney, 2020a). The A/S ratio does not directly affect shoreline depositional processes but may modify their relative interaction through changes 543 in physiography. For embayed shorelines, which favour tidal amplification, the degree of wave 544 protection will be: (1) reduced under low $\mathrm{A} / \mathrm{S}$ conditions because higher progradation rates cause 545 shorelines to straighten more quickly; and (2) increased under high A/S conditions, when 546 accommodation exceeds sediment supply, because the embayed shoreline geometry will more likely persist (Fig. 7) (Ainsworth et al., 2011). 
Shoreline morphology (c. 1-10 km scale) can have a significant impact on the relative balance of tide, wave and fluvial processes (Fig. 2) (Boyd et al., 1992; Dalrymple et al., 1992; Ainsworth et al., 2008; Ainsworth et al., 2011). Highly-embayed, more rugose, shoreline morphologies may promote: (1) amplification of the tidal wave by funnelling and/or resonance effects (Slingerland, 1986; Allen, 1997); and (2) protection from direct wave approach from the open ocean or sea. Therefore, Ainsworth et al. (2011) use shoreline rugosity as a direct proxy for tidal influence: increasing rugosity corresponds to increased potential for tidal influence (Fig. 7). Their model predicts that all interpreted highly embayed shorelines, and half of interpreted moderately embayed shorelines, are tide-dominated, whereas only a quarter of interpreted straight to lobate shorelines are tide-dominated (Fig. 7A). However, this simplified differentiation is inconsistent with observations of Holocene to present-day embayed shorelines, most notably estuaries (e.g. Dalrymple, 1992; Roy et al., 2001; Boyd et al., 2006; Dalrymple, 2006), which may be wavedominated (e.g. Roy et al., 1980; Honig and Boyd, 1992; Cooper, 2001; Anthony et al., 2002), tide-dominated (e.g. Hori et al., 2001; Dalrymple et al., 2012), river-dominated (e.g. Cooper, 1993; Sondi et al., 1995), and mixed process (d'Anglejan and Brisebois, 1978; Jouanneau and Latouche, 1981; Clifton, 1983; Allen and Posamentier, 1993; Roy et al., 2001). Furthermore, 565 amplifying of tides due to funnelling and resonance effects in embayments may be counteracted 566 by frictional effects (e.g. Dalrymple et al., 1992; Allen, 1997; Mitchell et al., 2010; Collins et al., 567 2018a). Consequently, the variability in predicted processes for ancient embayed shorelines may 568 be higher than that proposed by Ainsworth et al. (2011) (Fig. 7).

570 For prediction of ancient shoreline processes, it is important that the data used to interpret the 571 impact of the different controls on shoreline processes have: (1) reliable chronostratigraphic 
2

3

4

5

7

8

9574 varies significantly. For example, the temporal resolution of interpreted system tracts relating to

5753 rd-order (c. 0.5-3.0 Myr) or $4^{\text {th }}$-order (few 10s ka to c. $0.5 \mathrm{Myr}$ ) sea-level cycles (Haq, 2014;

13

14

15 
4. Shoreline geometry

1. Tidal resonance potential of basin

2. Fluvial vs. wave effectiveness

3. A/S ratio

Shorelineshelf process dominance

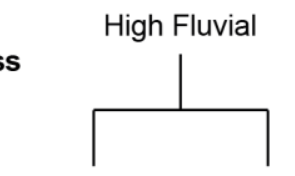

B Low tidal resonance potential (shelf width $<75 \mathrm{~km}$ )

\begin{tabular}{|c|c|c|c|c|c|}
\hline \multirow{5}{*}{ 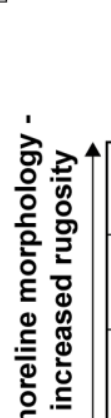 } & & \multicolumn{2}{|c|}{$\begin{array}{c}\text { Fluvial } \\
\text { effectiveness }\end{array}>\begin{array}{c}\text { Wave } \\
\text { effectiveness }\end{array}$} & \multicolumn{2}{|c|}{$\begin{array}{c}\text { Wave } \\
\text { effectiveness }\end{array}>\begin{array}{c}\text { Fluvial } \\
\text { effectiveness }\end{array}$} \\
\hline & & Low A/S & High A/S & Low A/S & High A/S \\
\hline & $\begin{array}{l}\text { Highly } \\
\text { embayed }\end{array}$ & $\mathrm{Tf} \longleftrightarrow \mathrm{Tf}$ & Tf & $T w f \leadsto T w \rightarrow T$ & \begin{tabular}{|l|} 
\\
\end{tabular} \\
\hline & $\begin{array}{l}\text { Moderately } \\
\text { embayed }\end{array}$ & $\mathrm{Ft} \leftrightarrow \mathrm{Ftw} \rightarrow \mathrm{Fwt}$ & $\mathrm{Ft} \leftrightarrow \mathrm{Ftw} \rightarrow \mathrm{Fwt}$ & $\mathrm{Wft} \leadsto-\mathrm{Wtf} \rightarrow \mathrm{Wt}$ & $\mathrm{T} \longleftrightarrow \mathrm{Tw}$ \\
\hline & $\begin{array}{l}\text { Straight to } \\
\text { lobate }\end{array}$ & & & $\mathrm{Wf} \longleftrightarrow \mathrm{W}$ & $\mathrm{Wf} \leftrightarrow \mathrm{W}$ \\
\hline
\end{tabular}

C High tidal resonance potential (shelf width $>75 \mathrm{~km}$ )

\begin{tabular}{|c|c|c|c|c|c|}
\hline & & $\begin{array}{c}\text { Fluvial } \\
\text { effectiveness }\end{array}$ & $\begin{array}{c}\text { Wave } \\
\text { effectiveness }\end{array}$ & $\begin{array}{c}\text { Wave } \\
\text { effectiveness }\end{array}$ & $\begin{array}{c}\text { Fluvial } \\
\text { effectiveness }\end{array}$ \\
\hline ' & & Low A/S & High A/S & Low A/S & High A/S \\
\hline 층 궁 & $\begin{array}{l}\text { Highly } \\
\text { embayed }\end{array}$ & \begin{tabular}{|l|}
$\mathrm{Tf}$ \\
\end{tabular} & Tf & $T w f \nrightarrow T w \rightarrow T$ & \begin{tabular}{|l|}
$T$ \\
\end{tabular} \\
\hline 은 른 & $\begin{array}{l}\text { Moderately } \\
\text { embayed }\end{array}$ & Tf & Tf & $T w f \leftrightarrow T w \rightarrow T$ & $\mathrm{~T} \leftrightarrow \mathrm{Tw}$ \\
\hline 들 & $\begin{array}{l}\text { Straight to } \\
\text { lobate }\end{array}$ & $\mathrm{Tf} \longleftrightarrow \mathrm{Tfw}$ & $\begin{array}{c}\mathrm{F} F \mathrm{Ft} F \mathrm{Fw} \\
\mathrm{Ftw} \text { Fwt }\end{array}$ & $T w f \leftrightarrow T w \rightarrow T$ & $\begin{array}{c}\text { Wf } W t \quad W \\
\text { Wft } \overline{W t f}\end{array}$ \\
\hline
\end{tabular}

583 Fig. 7. Predictive model for shoreline process regime (modified from Ainsworth et al. (2011).

584 (A) Decision tree with four main queries predicting shoreline process regime. (B) Predictive 
matrix for settings with a low tidal potential. (C) Predictive matrix for settings with a high tidal potential. Abbreviations and color coding are shown in the inset (opposite B).

\section{METHODS}

\subsection{Numerical tidal modelling}

\section{$590 \quad 3.1 .1$ Mesh generation}

591 Fluidity (http://fluidityproject.github.io/), formerly the Imperial College Ocean Model (ICOM), 592 is a hydrodynamic, finite element ocean model that solves the Navier-Stokes equations and uses 593 unstructured, multi-scale, three-dimensional, tetrahedral meshes that (1) smoothly and accurately 594 conform to coastline and bathymetry, (2) have focused resolution in areas of complex 595 bathymetry (e.g. straits and embayments), along coastlines and/or in areas of interest, and (3) maximize computational accuracy and efficiency (Pain et al., 2005; Wells et al., 2005a; Gorman et al., 2007; Gorman et al., 2008; Piggott et al., 2008; Geuzaine and Remacle, 2009; Avdis et al., 2018). Meshes used in Fluidity palaeotidal simulations may be global or regional and have been constructed using Terreno (Gorman et al., 2007; Gorman et al., 2008) or qmsh (Avdis et al., 600 2018). By working directly on an arbitrary geodetic in Cartesian space, Fluidity eliminates the 601 'pole problem' by which lines of constant longitude converge at the poles producing very small 602 elements (Madec and Imbard, 1996; Comblen et al., 2009; Wells et al., 2010a). A minimum 603 depth of $10 \mathrm{~m}$ along the shoreline prevents the free surface from intersecting the bottom surface 604 as it propagates but the increased water depth impacts shallow water current velocities and 605 possibly tidal amplification effects (e.g. Wells et al., 2010a).

\subsubsection{Hydrodynamic modelling of astronomical and forced boundary tides}


Fluidity can simulate both astronomical and co-oscillating boundary tides (Table 2). The astronomical tide results directly from the tide-generating force on the water in an open ocean or seaway due to the gravitational and rotational effects of the Moon and Sun. Astronomical tidal potential is calculated at each mesh node for each time step using the multi-constituent equilibrium theory of tides:

$$
\begin{aligned}
\eta_{\mathrm{eq}}(\lambda, \theta, t) & =\sin ^{2} \theta \sum_{i} K_{i} \cos \left(\sigma_{i} t+\chi_{i}+2 \lambda\right) \\
& +\sin 2 \theta \sum_{j} K_{j} \cos \left(\sigma_{j} t+\chi_{j}+\lambda\right) \\
& +\left(3 \sin ^{2} \theta-2\right) \sum_{k} K_{k} \cos \left(\sigma_{k} t+\chi_{k}\right)
\end{aligned}
$$

614 where $\eta_{\mathrm{eq}}=$ equilibrium tidal potential $(\mathrm{m}), \lambda=$ east longitude (radians), $\theta=$ colatitude $(\pi / 2-$ 615 latitude, radians), $\chi=$ astronomical argument (radians), $\sigma=$ frequency of tidal constituent $\left(\mathrm{s}^{-1}\right), t$ $616=$ universal standard time (s) and $K=$ equilibrium amplitude of tidal constituent (m). Subscripts $i$, $617 j$ and $k$ represents the semidiurnal, diurnal and long-period tidal constituents, respectively, which 618 allows constituents to be modelled individually or in combination (Schwiderski, 1980; Kantha 619 and Clayson, 2000; Wells et al., 2007a; Mitchell et al., 2010). The overall forcing is applied as 620 the product of the equilibrium tidal potential gradient and the gravitational acceleration $(\mathrm{g})$ 621 (Mellor, 1996; Kantha and Clayson, 2000).

623 The co-oscillating or boundary tide results from propagation of the astronomical tidal wave into 624 a connected water body. This is especially important for simulations of tides in partly-enclosed seas and shallow seaways (straits), which typically have limited potential for internally generated 626 astronomical tides because of their smaller water masses (Tsimplis et al., 1995; Wells et al., 627 2005a). Co-oscillating tides along designated open boundaries are forced as either one fixed 
cosine wave of constant amplitude and phase applied across the entire boundary length or interpolated as many cosine waves of different amplitudes and phases at a series of points along the boundary. Ideally, the amplitude and phase values for each tidal constituent would be derived from a larger-scale model of the adjacent water body.

633 The bottom drag is applied as a surface integral boundary condition based on a quadratic friction 634 law of the form $-\mathrm{C}_{\mathrm{D}} \overline{\mathrm{u}}|\overline{\mathrm{u}}|$ where $\mathrm{C}=$ drag coefficient and depth averaged current velocity $|\bar{u}|=$ $635 \sqrt{u^{2}+v^{2}+w^{2}}$, where $u, v$ and $w$ represent the velocities in the $\mathrm{x}, \mathrm{y}$, and $\mathrm{z}$ dimensions, 636 respectively $\left(\mathrm{ms}^{-1}\right)$ (Wells et al., 2007a; Mitchell et al., 2010). The drag coefficient is set as 637 0.0025, a generic value used in most ocean models (Pietrzak et al., 2002), but the drag 638 coefficient may vary between $10^{-2}-10^{-3}$ as a function of bathymetry and sediment grain size, 639 shape and sorting (Safak, 2016).

641 A spin-up period of at least 120 hours (five days) simulation time is sufficient to remove spin-up 642 effects and reach steady state (Wells et al., 2007a; Wells et al., 2007b), after which all fields are set to zero.

645 The equations of motion describing the movement of the tidal bulge include the Coriolis 646 acceleration (f), which is simplified to $\mathrm{f}=2 \Omega \sin \varphi(\underline{\text { Cushman-Roisin, 1994; }}$ 647 Beckers, 2011), where $\Omega$ is the rotation rate of the Earth $\left(7.27 \times 10-5 \mathrm{rad} \mathrm{s}^{-1}\right)$ and $\varphi$ is the latitude. 648 Model outputs are the amplitude of tidal components, tidal range, average and maximum tidal 649 current velocity, the magnitude and direction of average and maximum tidal bed shear stress, and 650 the tidal phase. Tidal range is calculated as the difference between the maximum and minimum 
free surface heights over the post spin-up simulation period, which approximately equals the maximum spring tidal range. The amplitude and phase of the four major tidal constituents $\left(\mathrm{M}_{2}\right.$, $\mathrm{S}_{2}, \mathrm{~K}_{1}$ and $\mathrm{O}_{1}$ ) are determined using tidal harmonic analysis of the modelled time series of free surface heights (Foreman, 1979). Tidal bed shear stress $(\tau)$ is the frictional force exerted by tides on the sediment surface and is calculated using $\tau=\underline{\underline{C_{D}}} \underline{\bar{u}|\bar{u}|}$ where $\rho=$ the density of water $\left(1023 \mathrm{~kg} \mathrm{~m}^{-3}\right)$ (Pingree and Griffiths, 1979; Wells et al., 2007a; Mitchell et al., 2010). Bed shear stress magnitudes can be converted to the equivalent grain size that could be entrained by the tidal flow based on the modelled and calculated critical bed shear stress values for sediment transport (Miller et al., 1977; Soulsby et al., 1993; Julien and Raslan, 1998).

stress(Mitchell et al., 2010; Mitchell et al., 2011; Collins et al., 2017a; Collins et al., 2018a). This

\subsubsection{Validation of tidal model results}

Tidal modelling using Fluidity has been extensively validated against real-world modern tidal amplitude (Wells et al., 2005a; Wells et al., 2005b; Wells et al., 2007a; Wells, 2008; Wells et al., 2010a; Wells et al., 2010b; Collins et al., 2017a; Collins et al., 2018a) and tidal bed shear includes global (Wells et al., 2010a; Collins et al., 2018a) and regional comparisons in the 667 Mediterranean Sea (Wells et al., 2005a), North Sea (Wells et al., 2007a; Mitchell et al., 2010), 668 Baltic Sea (Wells, 2008) and South China Sea (Collins et al., 2017a; Collins et al., 2018a).

670 On a global-scale, comparison of the modeled amplitude of the $\mathrm{M}_{2}, \mathrm{~S}_{2}, \mathrm{~K}_{1}$ and $\mathrm{O}_{1}$ tidal 671 constituents using Fluidity, which utilises the GEBCO (General Bathymetric Chart of the 672 Oceans) 2014 bathymetric data and an unstructured mesh with maximum resolution of $10 \mathrm{~km}$, to 673 tidal guage data and the FES 2014 tidal model, clearly illustrates that Fluidity accurately predicts 
tidal range without the need for data assimilation (Fig. 8). Tidal constituent amplitudes at 423 stations were calculated using tidal harmonic analysis of sea surface elevation data (Caldwell et al., 2015) (Fig. 8A-F) and the calculated mean root-mean-squared (RMS) error includes absolute values of both tidal amplitude and phase (Cummins and Thupaki, 2018). Fluidity very slightly underpredicts tidal amplitude compared to tidal gauge data, with the relative error varying between $-0.01 \%\left(\mathrm{~S}_{2}\right.$ tide) to $-0.23 \%\left(\mathrm{O}_{1}\right.$ tide $)$ and the root-mean-squared (RMS) amplitude varying between $0.10 \mathrm{~m}\left(\mathrm{~K}_{1}\right.$ and $\mathrm{O}_{1}$ tide) to $0.37 \mathrm{~m}\left(\mathrm{M}_{2}\right.$ tide) (Fig. 8B-F). However, these errors are comparable to those between the FES 2014 tidal model and tidal gauge data for 162 stations (Fig. 8B, G-J), despite the FES2014 model using tidal data from satellite altimetry and gauges, highly-accurate global and regional bathymetries, an unstructured mesh with up to c. $7 \mathrm{~km}$ $\left(1 / 16^{\circ}\right)$ resolution, and corrections for internal and load tides (Carrère et al., 2015). Local-scale differences between the Fluidity model and the FES 2014 model and tidal gauge data are likely caused by (1) mesh resolution limitations that simplify bathymetry (e.g. between islands) and affect modelled tidal flow and frictional effects, (2) the lack of correction for internal drag and load tides, and (3) frictional drag parameterisation (Egbert et al., 2004; Wells et al., 2010a). 689 Overall, tidal modelling using Fluidity accurately predicts present-day global tidal amplitude 690 without the need for data assimilation and to a degree of accuracy that is sedimentologically 691 useful, most notably predicting the following: (1) tidal amplitude and range to a decimetre-scale 692 accuracy; (2) microtidal ( $<2 \mathrm{~m})$, mesotidal (2-4 m) and macrotidal ( $>4 \mathrm{~m})$ regimes, which is 693 within the limit of ancient tidal range estimates e.g. (Wells et al., 2005a); (3) the position of amphidromic systems; (4) predominance of semidiurnal versus diurnal tides; and (5) areas of tidal amplification due to shoaling, funnelling and/or resonance effects. 
On a global scale, the maximum bed shear stress and potential sediment grain size transport modeled by Fluidity (Fig. 2B) have been compared to those modeled using FES 2014 (Fig. 9), which were calculated based on the modeled tidal current velocity vectors (Equation 1)

700 (Supplementary Fig. 1). Overall, the patterns of potential sediment mobility are similar for the 701 two models, with elevated bed shear stress (and equivalent grain size) in areas of shallower 702 bathymetry and/or physiographic constriction (Fig. 9A and B). However, the potential sediment 703 grain size mobility in shelf areas modeled using Fluidity tends to be one or two grain size classes 704 above or below that modeled by FES 2014 (Fig. 10A and B). Overprediction most likely reflects 705 insufficient frictional damping of modeled tidal energy due to locally coarser mesh and 706 bathymetry resolution and lack of internal drag in the Fluidity model. Underprediction is 707 especially common in relatively large, shallow areas that are partially restricted from the open 708 ocean due to complex physiography. For example, results from the high-latitude seas of North 709 America probably reflect reduced penetration of the ocean tidal wave through the constricted 710 physiography due to coarse mesh and bathymetry resolution. Despite these differences, modeled 711 bed shear stress using Fluidity and FES2014 are closely matched in many areas, notably the Gulf 712 of Saint Lawrence, Meditarranean Sea, North Sea and South China Sea. These results illustrate 713 that Fluidity is capable of reproducing the first-order variability in modeled tidal bed shear stress 714 related to physiography in modern domains and is capable of modelling the same in ancient 715 domains, provided that palaeobathymetric and palaeogeographic uncertainties are adequately 716 defined. 

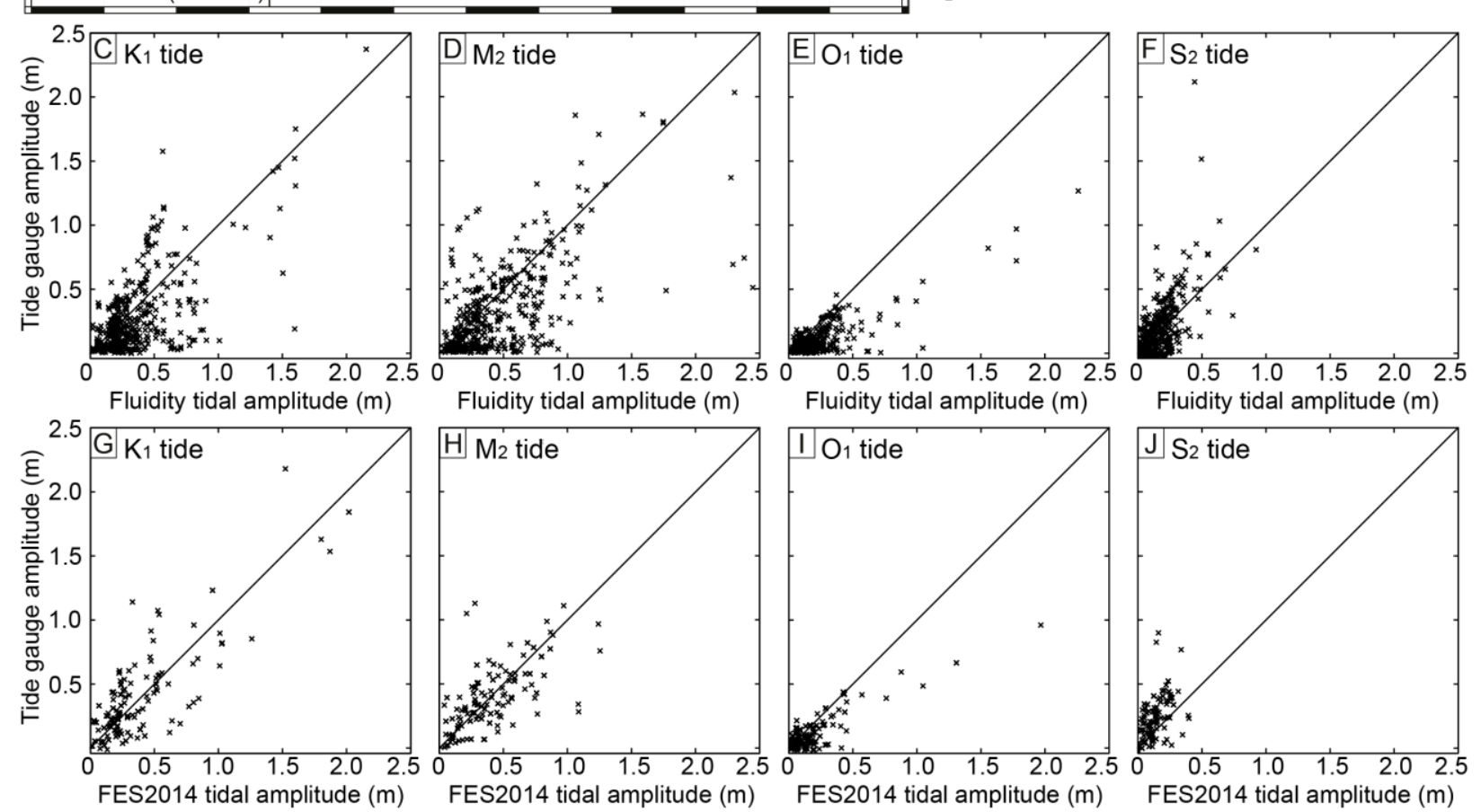

Fig. 8. Validation of modeled tidal amplitude using Fluidity and FES2014 (Carrère et al., 2015). (A) Number (n) and position of a global set of tidal stations used for the comparisons to FES2014 (white circles, $n=162$ ) and Fluidity (red circles, $n=423$ ) model data. (B) Summary of root-mean-squared (RMS) and relative percentage errors between the model and tidal gauge data of tidal constituent amplitude. Tidal gauge amplitude data was derived by tidal harmonic analysis of sea surface elevation data. $(\mathrm{C}-\mathrm{J})$ Plots of tidal gauge versus modeled tidal amplitude for the $\mathrm{K}_{1}(\mathrm{C}, \mathrm{G}), \mathrm{M}_{2}(\mathrm{D}, \mathrm{H}), \mathrm{O}_{1}(\mathrm{E}, \mathrm{I})$ and $\mathrm{S}_{2}(\mathrm{~F}, \mathrm{~J})$ tidal constituents using Fluidity $(\mathrm{C}-\mathrm{F})$ and FES2014 $(\mathrm{G}-\mathrm{J})$. 


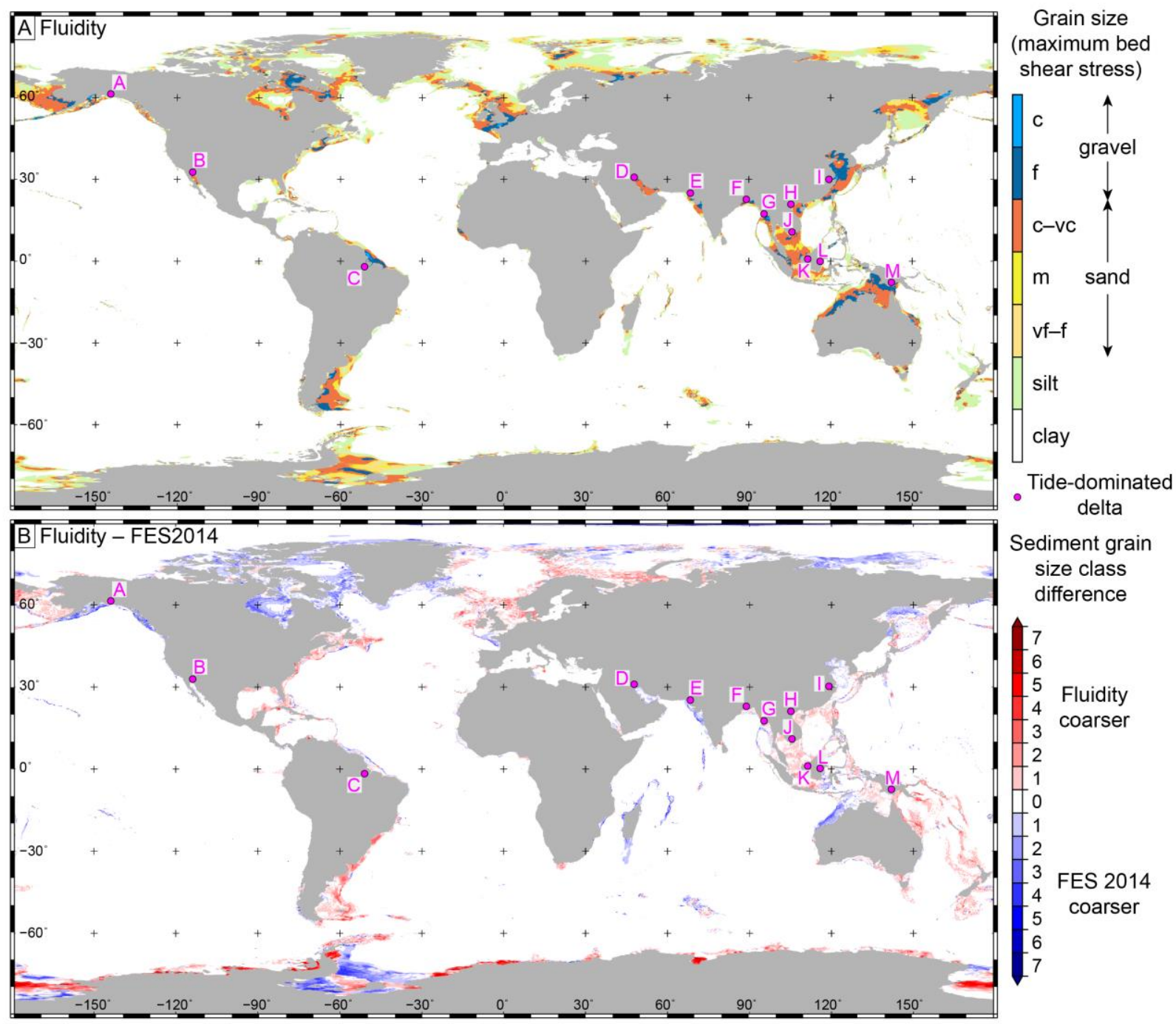

Fig. 9. (A) Maximum tidal bed shear stress modeled using Fluidity, plotted as the equivalent grain size that could be entrained if available. (B) Difference in sediment grain size class between maximum tidal bed shear stress for Fluidity (A) and FES2014 (Fig. 2D) (Carrère et al., 732 2015). Grain size abbreviations: vf = very fine; $\mathrm{f}=$ fine; $\mathrm{m}=$ medium; $\mathrm{c}=$ coarse; $\mathrm{vc}=$ very 733 coarse. Pink dots show location of tide-dominated deltas (Goodbred and Saito, 2012): A) 734 Copper; B) Colorado; C) Amazon; D) Shatt-al-Arab; E) Indus; F) Ganges-Brahmaputra; G) 735 Irrawaddy; H) Red River; I) Yangtze; J) Mekong; K) Rajang; L) Mahakam; and M) Fly.

\section{$737 \quad 3.2$ Comparison of tidal model results with the rock record}


For each case study, tidal model results have been compared to available 'rock-record' data, notably palaeogeographic, stratigraphic, sedimentological and micropaleontological information and interpretations. The majority of referenced datasets invariably include both (1) welldocumented sedimentological and/or micropaleontological data, and (2) interpretations of depositional processes and environments that are supported by the available data. Comparison of tidal model results with rock-record data from the equivalent stratigraphic interval relies on several steps at different scales but is fundamentally underpinned by detailed facies analysis.

\subsubsection{Tidal facies analysis}

Validation of tidal model results using sedimentological data relies on recognising sedimentary characteristics at the bedform-scale (c. mm-10s m-scale) that are indicative of tidal processes. These have been widely documented from several different shallow-water depositional environments, most notably deltas, estuaries, barrier inlets, embayments, straits and open shelves (e.g. De Raaf and Boersma, 1971; Ginsburg, 1975; De Raaf and Boersma, 1977; Reineck and Singh, 1980; Terwindt, 1981; De Boer et al., 1988; Nio and Yang, 1991; Smith et al., 1991;

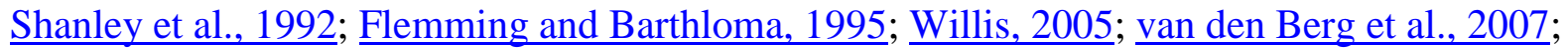

754 MacEachern and Bann, 2008; Martinius and van den Berg, 2011; Davis, 2012; Shanmugam, 755 2013). The most significant features are those related to tidal flow reversals, flood-ebb tide 756 versus slack water dynamics, tide-related periodicity and/or physico-chemical stress, particularly 757 the following: (1) bidirectional cross-bedding and cross-lamination (cm-dm-scale), including the 758 relatively rare variant of 'herringbone' patterns (e.g. Van Straaten, 1953; Reineck, 1963;

759 Boersma, 1969; Klein, 1970a; Klein, 1970b; Klein, 1971; Hayes, 1980; Boersma and Terwindt, 1981; Yoshida et al., 2004); (2) larger-scale (10s m-scale) bidirectionality, such as between 
separate but closely spaced sand bodies with oppositely-dipping cross-bedding, which have been interpreted to reflect mutually evasive ebb- and flood-tidal channels and bars (Robinson, 1966;

Johnson, 1975; Johnson and Levell, 1995; Sixsmith et al., 2008; Legler et al., 2013; Levell et al., 2020); (3) sigmoidal 'shovel-shaped' cross-bed sets, with extended mud-rich toesets, sometimes with oppositely-dipping current ripples (e.g. Boersma and Terwindt, 1981; Mutti et al., 1984;

Mutti et al., 1985; Kreisa and Moila, 1986; Dalrymple and Rhodes, 1995; van den Berg et al., 2007; Tinterri, 2011); (4) multiple reactivation surfaces with an apparent cyclicity or predictable and repeated pattern (e.g. Boersma, 1969; McCabe and Jones, 1977; Reineck and Singh, 1980; Boersma and Terwindt, 1981; Allen, 1982a; Allen and Homewood, 1984); (5) 'paired drapes' or 'double drapes' comprising sandy foresets and associated mudstone and/or carbonaceous 771 (typically finely comminuted 'coffee ground' type) drapes (mm-cm-scale), which are interpreted 772 to form by semi-diurnal to diurnal tidal inequality (e.g. Reineck and Singh, 1980; Visser, 1980; 773 Smith, 1988; De Boer et al., 1989; Nio and Yang, 1991); (6) 'tidal bundles' in the form of lateral and vertical thickness variations of sandy foresets and associated mudstone/carbonaceous drapes (dm-m-scale), which have been related to spring-neap semi-lunar cycles (e.g.Visser, 1980; Allen, 1981b; Boersma and Terwindt, 1981; Allen and Homewood, 1984; Kreisa and Moila, 1986; Nio and Yang, 1991) (cf. Martinius and Gowland, 2011); (7) heterolithic bedding (cm-m778 scale) with apparent, or preferably measured and statistically analysed, cyclicity in the thickness 779 of sandstone-mudstone layers, which are referred to as 'couplets' if other evidence of tidal 780 deposition (e.g. bidirectional current ripples etc.) are observed (Reineck and Wunderlich, 1968; 781 Terwindt, 1971; Terwindt and Breusers, 1972; Reineck and Singh, 1980; Kvale et al., 1989;

782 Archer et al., 1991; Archer, 1995; Greb and Archer, 1995; Kvale, 2006; Kvale, 2012); (8) 783 inclined heterolithic strata (dm-10s m-scale) (Thomas et al., 1987; Smith, 1988; Dalrymple et 
al., 2003; Choi et al., 2004; Dalrymple and Choi, 2007); (cf. Sisulak and Dashtgard, 2012;

Jablonski and Dalrymple, 2016); and (9) ichnofabrics which, in general, show reduced but variable and sporadic bioturbation intensities and predominance of facies-crossing ichnofauna (MacEachern et al., 2005; McIlroy, 2006; McIlroy, 2007; MacEachern and Bann, 2008;

Longhitano et al., 2010; Gingras and MacEachern, 2012; Gingras et al., 2012).

790 Definitive recognition of tide-influenced sedimentation relies on observing combinations of the 791 features described above because, in isolation, some of these features can form by other processes (e.g. wave, storm and/or fluvial) operating by themselves or, especially, in combination with tides (Frey and Howard, 1986; Thomas et al., 1987; Shanley et al., 1992;

Hovikoski et al., 2008; MacEachern and Bann, 2008; Ichaso and Dalrymple, 2009; Martinius and Gowland, 2011; Tinterri, 2011; Sisulak and Dashtgard, 2012; Vakarelov et al., 2012; Johnson and Dashtgard, 2014; Dalrymple et al., 2015; Gugliotta et al., 2016a; Gugliotta et al., 2016b; Jablonski and Dalrymple, 2016; Kurcinka et al., 2018). Mixed-process settings, especially those where fluvial and tidal currents coexist, can exacerbate differences in the strength and sediment transport capacity of ebb- and flood-tidal currents. Strongly skewed palaeocurrent patterns, with one dominant offshore-directed mode, and a weaker oppositely-directed secondary mode, may occur when fluvial and ebb-tidal processes are combined, such as in deltaic and estuarine settings (Legler et al., 2013; van Cappelle et al., 2016; Collins et al., 2020; Levell et al., 2020). For example, in the modern microtidal Po Delta, preserved tidal signals in open-water prodelta facies are correlatable to cyclical variation in water-surface steepness and consequent changes in river discharge velocity and sediment transport capacity in distributary channels (Maselli et al., 2020). In modern open-marine shelf settings, storm-induced currents can also contribute to tidal current 


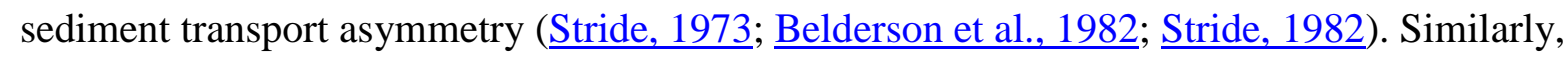
storm-enhanced tidal transport systems have been inferred to explain unidirectional palaeocurrent patterns in ancient shallow-marine deposits (Banks, 1973; Johnson, 1975; Anderton, 1976; Levell, 1980). Autogenic tidal processes responsible mutually evasive ebb and 811 flood tidal channels can also create skewed palaeocurrent patterns in the stratigraphic record, 812 particularly where: (1) channel preservation is unequal, (2) ebb and flood tidal channels are so 813 effectively shielded from each other that evidence of the secondary reversing tide is absent, 814 and/or (3) incomplete outcrop or subsurface dataset (Sixsmith et al., 2008; Legler et al., 2014).

816 Confident identification of tidal influence and its relative importance with respect to other 817 processes (e.g. wave, storm and/or fluvial) requires reconstruction of shoreline palaeo818 geomorphology at the scale of the depositional system (c. 1-100s km), based on detailed facies 819 analysis in the context of high-resolution stratigraphic and regional palaeogeographic 820 relationships. Such confidence in interpretation requires data of high quality and density, such as 821 provided by extensive outcrop data (e.g. Willis and Gabel, 2001; Legler et al., 2013; Legler et

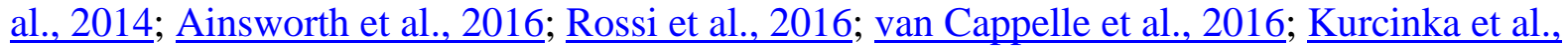
823 2018; Van Yperen et al., 2020) or subsurface datasets containing 3D seismic data, densely 824 spaced wells and/or extensive cores (e.g. Hubbard et al., 2011; Willis and Fitris, 2012; Holgate et 825 al., 2013). In practice, such datasets and confident interpretations are rare. It is therefore 826 appropriate to focus comparison of 'rock-record' data with tidal model predictions at bedform scale $(c . \mathrm{mm}-10 \mathrm{~s} \mathrm{~m})$, at which interpretations of bed shear stress as a proxy for tidal current 828 velocity (section 3.2.3) can be readily made. Other tidal model outputs, including tidal range 
(section 3.2.2) and tidal phase, are typically less straightforward to interpret from available 'rock-record' data (e.g. Wells et al., 2005a; (Mitchell et al., 2010)).

\section{$832 \quad$ 3.2.2 Palaeotidal range analysis}

833 Analysis of palaeotidal range from the rock record requires observations and interpretation at a 834 range of scales: depositional system morphology (c. 1-100s km), depositional environments (c. $8350.1-1 \mathrm{~km})$ and depositional elements and facies ( $<1$ to $10 \mathrm{~s} \mathrm{~m})$ may all preserve an imprint of 836 tidal sedimentary processes, but do not offer more detailed constraints on tidal range beyond inferring microtidal, mesotidal and macrotidal regimes (Table 4) (Wells et al., 2005a). Alternative methods used to estimate palaeotidal range are: (1) interpretations of water depth from stratigraphic position within interpreted fining-upward channel-fill units (Nio et al., 1983) (Yang and Nio, 1985); (2) stratigraphic thickness estimates of interpreted intertidal deposits in tidal flat units (Klein, 1970a; Klein, 1971), although these units are very similar to interpreted channel-fill units within the fluvial-to-marine transition zone (e.g. Olson, 1972; Dalrymple and Choi, 2007; Amir Hassan et al., 2013; Gugliotta et al., 2016a; Collins et al., 2018b; Collins et al., 2020); and (3) average calculations of characteristic mudstone drape spacings based on groups of sandstone-mudstone couplets from interpreted spring and neap conditions, and various assumptions regarding dune height and speed, dry bulk sediment density, and current velocity for sediment entrainment (Allen, 1981b) . Depositional systems subject to higher tidal ranges are more likely to be tide-dominated, but this relationship is inconsistent, especially for mixedprocess systems (e.g. Davis and Hayes, 1984). Furthermore, higher tidal ranges may not always correspond to stronger tidal currents (Mitchell et al., 2011). 

elongate shore-normal mouth bars, sinuous tidal creeks, tidal flats, saltmarsh and/or mangroves, and smaller-scale tidal indicators (e.g. Ganges-Brahmaputra, Irrawaddy, Fly deltas)

Fluvial-dominated deltas display digitate ('birds-foot') to lobate morphologies and rapid progradation due to higher relative stream power compared to wave/tide reworking (e.g. Mississippi delta).

Wave-dominated deltas display cuspate geometries with intermediate progradation rates due to wave action ('littoral energy fence') (e.g. Baram)

\begin{tabular}{|c|c|c|}
\hline Open shelf tidal sand-sheets & $10 \mathrm{~s}-100 \mathrm{~s} \mathrm{~km}$ & $\begin{array}{l}\text { Tabular sandbodies with planar tops and bases formed by open-shelf } \\
\text { tidal currents. Super-imposed sedimentary structures including scour } \\
\text { hollows, longitudinal furrows, obstacle marks, sand ribbons, sand } \\
\text { waves, rippled sand sheets and longitudinal sand patches. }\end{array}$ \\
\hline
\end{tabular}


Linear bedforms with long axes orientated up to 20 obliquely to tidal

Mesotidal

currents. Distinguished from Aeolian dunes by the presence of 2 main current directions at 180 , shelly debris, mud drapes, reactivation surfaces, low angle (3-6) cross-stratification and marine trace fossils

\section{Estuarine/incised valley-fill} tidal sandbodies

$\mathrm{W}<30 \mathrm{~km} ; \mathrm{T}$ ca 1

$\mathrm{m}$

\begin{tabular}{|c|c|c|c|}
\hline Sand ribbons & $\begin{array}{l}\mathrm{L}<15 \mathrm{~km} ; \mathrm{W}< \\
200 \mathrm{~m} ; \mathrm{T} \text { ca } 1 \mathrm{~m}\end{array}$ & $\begin{array}{l}\text { Ribbons or strips of sand elongated parallel to tidal currents consisting } \\
\text { of sandwaves trains (e.g. western English Channel). }\end{array}$ & Mesotidal to Macrotidal \\
\hline Saltmarsh & $\begin{array}{l}\text { L } 10 \mathrm{~km} ; \mathrm{W}<5 \\
\mathrm{~km} ; \mathrm{T}<10 \mathrm{~m}\end{array}$ & $\begin{array}{l}\text { Gently sloping coastal wetland which extends landwards to the high- } \\
\text { tide mark. Evaporating pools of saline water form localized 'salt-pans' } \\
\text { and fauna and flora adapted to highly fluctuating salinities dominate. }\end{array}$ & Mesotidal to macrotidal \\
\hline Mangroves & $\begin{array}{l}\mathrm{L}<200 \mathrm{~km} ; \mathrm{W}<60 \\
\mathrm{~km} ; \mathrm{T}<10 \mathrm{~m}\end{array}$ & $\begin{array}{l}\text { Densely vegetated forests occupying the lower intertidal zone (ca mean } \\
\text { sea level to low-tide mark) of tide-dominated, typically mud-rich deltaic } \\
\text { shorelines. Flora sub-zonations related to topography and often diverse } \\
\text { fauna adapted to salinity variations (e.g. Mekong, Ganges-Brahmaputra } \\
\text { deltas). }\end{array}$ & Mesotidal to macrotidal \\
\hline Tidal creeks & $\begin{array}{l}\mathrm{W}<100 \mathrm{~m} ; \mathrm{T} 10 \\
\mathrm{~m}\end{array}$ & $\begin{array}{l}\text { Shore-normal creeks which do not pass into a fluvial system landwards, } \\
\text { often mud-rich. }\end{array}$ & Microtidal to macrotidal \\
\hline
\end{tabular}

Outer estuary characterized by elongate sand ridges and tidal channels

Microtidal to macrotidal with super-imposed, smaller-scale tidal indicators. Middle and inner estuary characterized by heterolithic strata with isolated sandbodies (e.g. Thames estuary, southern North Sea) 
Table 4. Larger-scale tidal indicators, ranging from depositional environments to systems, and their generalized implication for tidal- 


\subsubsection{Ancient bed shear stress analysis}

Analysis of ancient bed shear stress is possible based on preserved grain size distribution and sedimentary structures (Fig. 10). Tidal currents that exceed the critical bed shear stress threshold for sediment entrainment will impact sedimentary processes (Mitchell et al., 2011; Collins et al., 2018a). However, the type of sedimentary structures formed by currents of varying flow velocity is also strongly dependent on the available grain size and water depth during deposition (Fig. 10), which can only be estimated in the context of facies successions, permitted by the availability of appropriate rock record data. Less reliable predictions of available grain size range may be possible based on catchment area geology, interpreted palaeo-drainage systems and other indirect data sources (e.g. seismic geometries of clinoforms, seismic amplitudes, well logs and other borehole data). For a given water depth, if tidal bed shear stress was insufficient to rework the minimum grain size available, tides will not have influenced sediment transport. In contrast, the size, type and texture of sedimentary structures may vary depending on tidal current strength and the frequency with which the critical bed shear stress for entrainment of the available grain size range was exceeded.

872 Comparison of tidal model results to micropaleontological information strongly depends on the 873 availability of suitable data. The most important potential indicator of tidal processes are 874 palynomorph acmes of coastal biomes whose distribution, abundance and productivity within a 875 depositional system is strongly related to tidal processes, most notably those associated with deposition in mangrove, seagrass and salt marsh settings (e.g. Grindrod, 1988; Wolanski et al., 1992; Woodroffe et al., 2016). 
A Current bedform stability (c. $20 \mathrm{~cm}$ water depth)

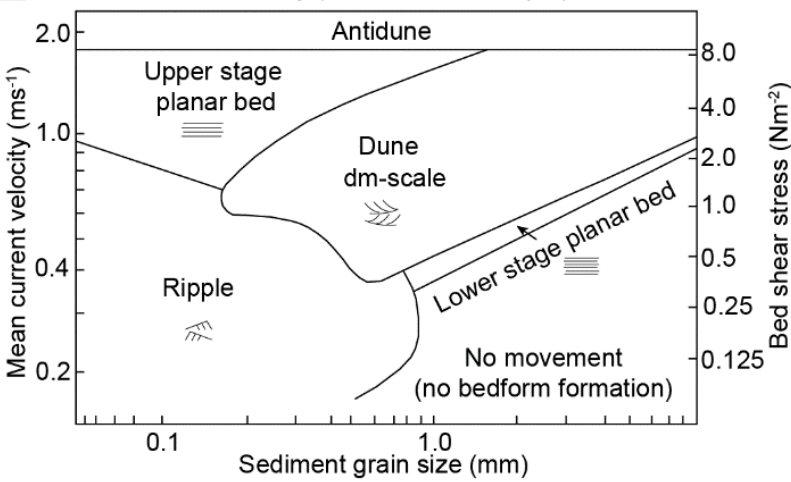

B Current bedform stability (c. $20 \mathrm{~m}$ water depth)

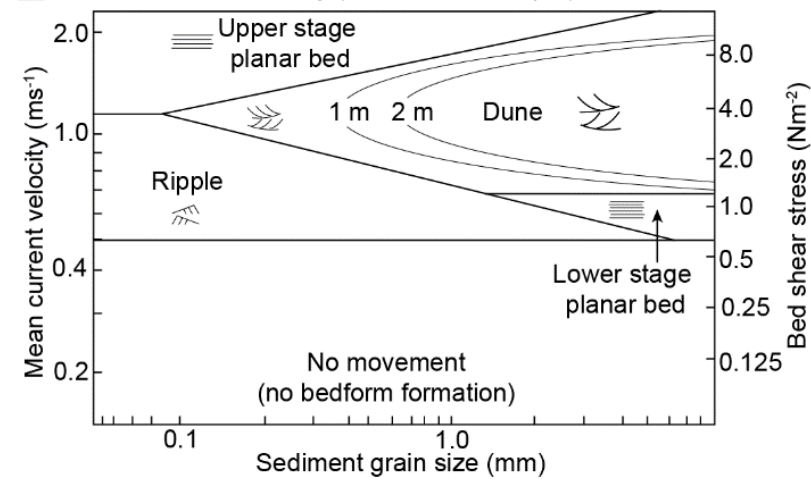

880 Fig. 10. (A) Bedform stability diagram, including bed shear stress, for unidirectional flow at 881 approximately $20 \mathrm{~cm}$ water depth (flume tank) (Harms et al., 1982; Mitchell et al., 2010). (B) 882 Bedform stability diagram, including bed shear stress, for unidirectional flow at approximately 2 883 m water depth (Rubin and McCulloch, 1980).

\section{RESULTS}

\subsection{Oligocene-Miocene South China Sea, Southeast Asia}

\subsubsection{Overview}

The Oligocene-Miocene SCS provides a compelling case study for investigating the impact of regional-scale (100-1000s km) physiographic changes on shoreline tidal processes and stratigraphic preservation for several reasons. Firstly, the region underwent significant, geologically-rapid, tectonically-driven (plate-related) palaeogeographic changes during a c. 25 Myr time period in the Oligo-Miocene, which would have impacted large-scale oceanic flow

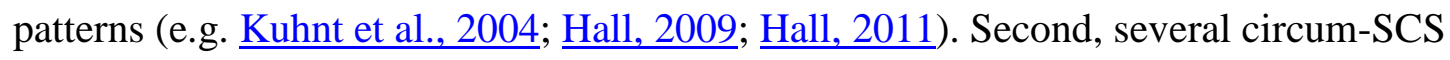

897 of the SCS, which resulted in the formation of several shoreline embayments that were 
influenced by local-scale (10-100s km) tidal processes (Collins et al., 2017a; Collins et al., 2018a).

\subsubsection{Geological Setting}

During the Oligo-Miocene, the SCS and wider Southeast Asia region experienced extensive tectonic reorganization of several microplates and sub-plates in response to major movements of the Indo-Australian, Eurasian, Pacific and Philippine Sea plates (Fig. 11) (Lee and Lawver, 1995; Hall, 1996; Hall, 2002). Extensional rifting preceding oceanic spreading in the SCS occurred from the latest Cretaceous (e.g. Hinz and Schlüter, 1985; Ru and Pigott, 1986). Active spreading of the SCS initiated in the Early Oligocene at c. 32 Ma (Briais et al., 1993;

Barckhausen et al., 2014) or 31 Ma (Barckhausen and Roeser, 2004) due to the combination of (1) slab-pull effect due to subduction of the proto-SCS beneath north-west Borneo, which caused rifting along southern China (Fig. 3) (Holloway, 1982; Taylor and Hayes, 1983; Huchon et al., 1994; Hall, 1996), and (2) extrusion of Indochina along the sinistral Ailao Shan-Red River Fault Zone, and other faults, during collision of the India-Australia plate with Eurasia (e.g. Tapponnier et al., 1982; Tapponnier et al., 1986; Peltzer and Tapponnier, 1988; Replumaz and Tapponnier, 2003). Spreading ceased at around 20.5 Ma (Barckhausen and Roeser, 2004) or $15 \mathrm{Ma}$ (Briais et

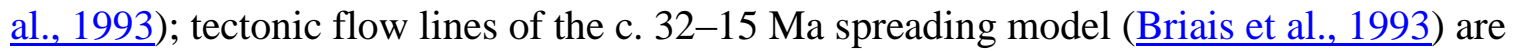
consistent with the trend of ocean floor fracture zones, unlike the c. 31-20.5 Ma model (Barckhausen and Roeser, 2004), but the c. 32-20.5 Ma spreading model (Barckhausen et al. $\underline{(2014)}$ has not yet been tested (Mazur et al., 2012). Cessation of spreading was approximately 919 simultaneous with final closure of the proto-SCS and subsequent collision between Borneo and extended continental crust from the rifted South China margin (Taylor and Hayes, 1983; $\underline{\text { Hall, }}$ 
2002; Hutchison, 2010), as evidenced by the 17-15 Ma Deep Regional Unconformity (in Sabah) and its broadly equivalent Base Middle Miocene Unconformity (in Sarawak) throughout the Neogene basins of NW Borneo (Levell, 1987; Hazebroek and Tan, 1993; Hutchison, 1996; Hutchison et al., 2000). Post-collision uplift resulted in formation of a foredeep trough along NW Borneo by the Late Miocene (Fig. 11) (Hinz et al., 1989; Hall, 2002; Ingram et al., 2004; Franke et al., 2008; Hutchison, 2010).

During the Oligocene-Miocene, clockwise rotation and northward translation of the Philippine Sea Plate, and the Izu-Bonin-Mariana (IBM) arc along its eastern margin, was associated with (1) complex assembly of the present-day Philippine islands by the Middle-Late Miocene, (2) narrowing of the oceanic connections into the SCS (Luzon Strait) and to the Pacific Ocean (north of the IBM arc), and (3) back-arc rifting in the IBM arc (Taylor, 1992; Hall et al., 1995; $\underline{\text { Hall, }}$ 2002; Gaina and Müller, 2007), which is modelled as emergent in some palaeogeographic interpretations due to physiographic uncertainty (Fig. 11) (Collins et al., 2017a; Collins et al., 2018a). Emergence of the Sunda Shelf created a 'blind gulf'-type basin morphology throughout the Oligocene-Miocene (Fig. 11) (van Hattum et al., 2006; Hall, 2013; Shoup et al., 2013). In contrast, the Sunda Shelf is presently submerged, which facilitates ocean outflow from the SCS, with connections via the Malacca Straits, among others, into the Indian Ocean (e.g. Gordon et al., 2012; Hu et al., 2015). The western SCS margin experienced spatially- and temporallyvariable extension and compression, combined with frequent variations in eustatic sea level and sediment supply. This resulted in the rapid subsidence and infill of several shelf basins, including 942 the Gulf of Thailand and, further south, the Malay, Penyu and West Natuna basins (Doust and

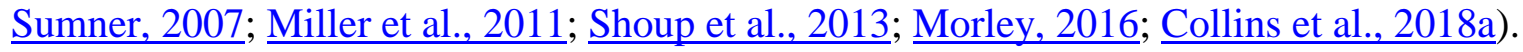



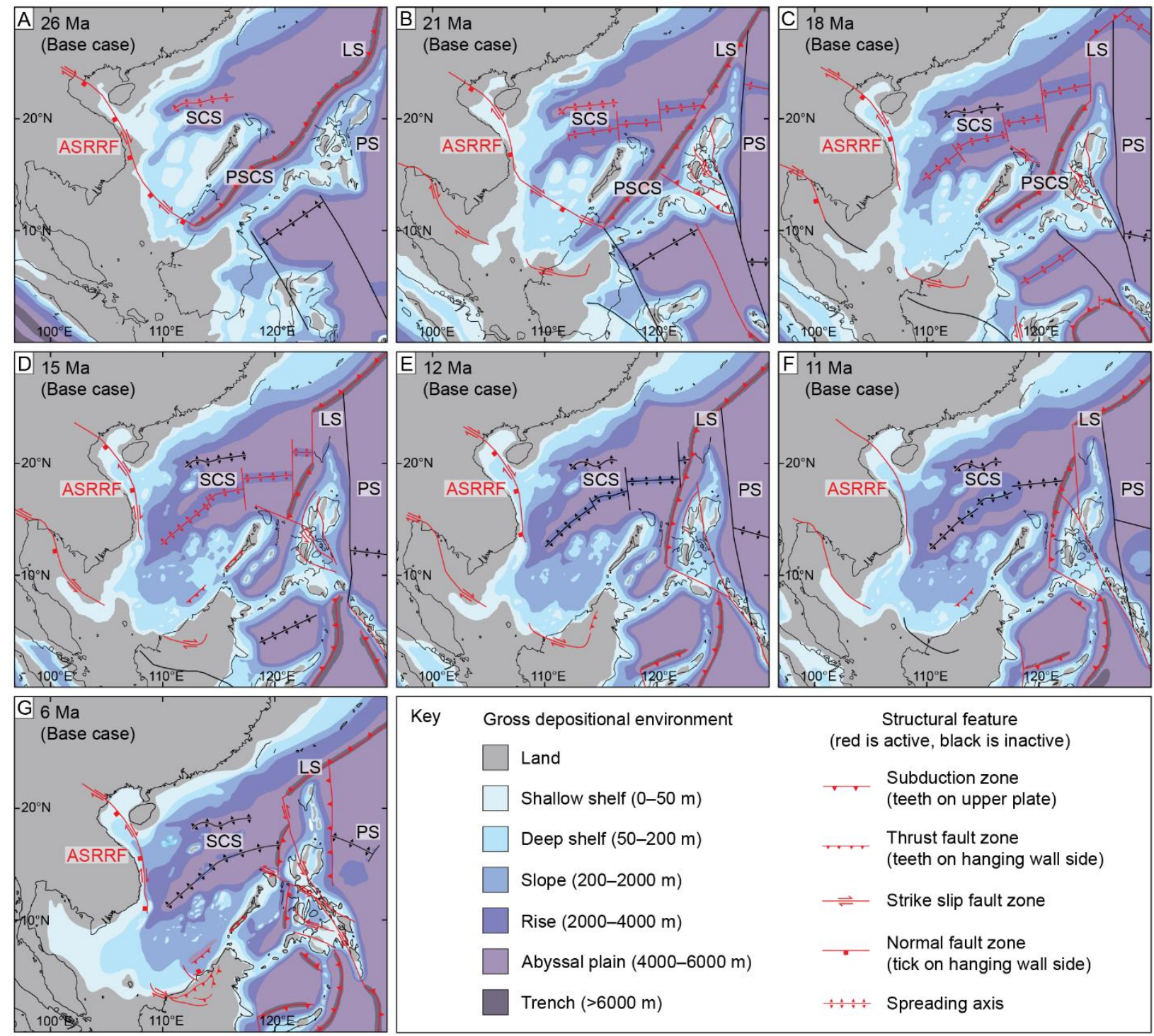

Key Gross depositional environment

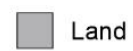

$\square$ Shallow shelf $(0-50 \mathrm{~m})$

$\square$ Deep shelf $(50-200 \mathrm{~m})$

Slope (200-2000 m)

Rise (2000-4000 m)

Abyssal plain (4000-6000 m)

Trench (>6000 m)

Structural feature

(red is active, black is inactive)

.. Subduction zone

(teeth on upper plate)

.... Thrust fault zone

(teeth on hanging wall side)

$\rightleftharpoons$ Strike slip fault zone

_. Normal fault zone

(tick on hanging wall side)

$\ldots+$ Spreading axis

946 Fig. 11. Gross depositional environmental reconstructions for the Late Oligocene-Late Miocene 947 in Southeast Asia based on sea-level highstand for eight time-slices: (A) 26 Ma (Chattian); (B) $21 \mathrm{Ma}$ (Aquitanian); (C) $18 \mathrm{Ma}$ (Burdigalian); (D) $15 \mathrm{Ma}$ (Langhian); (E) $12 \mathrm{Ma}$ (Serravallian); (F) $11 \mathrm{Ma}$ (Tortonian); (G) $6 \mathrm{Ma}$ (Messinian). Alternative gross depositional environmental 950 reconstructions include a submerged Palawan: (H) $26 \mathrm{Ma}$ (Chattian); (I) $21 \mathrm{Ma}$ (Aquitanian); (J) $95118 \mathrm{Ma}$ (Burdigalian). After Collins et al. (2018a). 952 


\subsubsection{Model Setup and Outputs}

Global simulations using Fluidity represent full astronomical tidal forcing with a spin-up period of period of 120 hours and no open boundary tidal forcing or data assimilation. Global computational meshes produced using qmsh ( $\underline{\text { Avdis et al., 2018) }}$ were three-dimensional and multi-scale, with the highest mesh resolution of $c a 10 \mathrm{~km}$ in areas of complex bathymetry. Model outputs included herein are maximum spring tidal range and the magnitude and direction of maximum tidal bed shear stress, plotted as the equivalent grain size capable of being transported (see Section 3.1.3). 'Base case' model simulations use the preferred palaeogeographic interpretations at sea level highstand for three timeslices in the Early, Middle and Late Miocene (Fig. 12). Sensitivity tests of the base-case models include (1) tidal models for $50 \mathrm{~m}$ sea level lowstand palaeogeographic interpretations for Late Oligocene-Late Miocene timeslices, and (2) a Late Miocene (6 Ma; Messinian) tidal model for a palaeogeographic reconstruction with a submerged $(10 \mathrm{~m})$ IBM arc. A wider range of model outputs, timeslices and sensitivity analyses have also been evaluated (Collins et al., 2017a; Collins et al., 2018a).

\subsubsection{Model Results}

969 On a regional-scale, the base-case palaeotidal model suggests an overall decrease in prevailing 970 maximum tidal range and bed shear stress through the Miocene in the SCS (Fig. 12). Tidal range 971 in the central part of the SCS decreased from macrotidal (>4 m) in the Early Miocene (Fig. 12A) 972 to mesotidal (>2 to $4 \mathrm{~m}$ ) in the Middle-Late Miocene (Figs 12C, E). This was contemporaneous with a decrease in the incoming boundary tide from the Pacific Ocean, from high microtidalmesotidal in the Early Miocene to microtidal in the Middle-Late Miocene. Along shorelines in the central SCS, maximum strength tidal currents in base-case simulations could generally 
transport up to coarse sand to gravel in the Early Miocene (Fig. 12B), fine to coarse sand in the Middle Miocene (Fig. 12D), and fine sand to silt in the Late Miocene (Fig. 12F). These regionalscale changes in modelled tidal processes were coincident with (1) narrowing of the Luzon Strait from c. $1500 \mathrm{~km}$ to $350 \mathrm{~km}$ and the Pacific Ocean connection between the IBM arc and Eurasia from c. $1600 \mathrm{~km}$ to $370 \mathrm{~km}$ through the Miocene (Fig. 11), and (2) obstruction of a major outflow from the SCS at its southwestern end due to the emergent Sunda Shelf.

Sensitivity analyses also emphasize the potential impact of regional-scale physiographic changes on shoreline tides. Tidal models for sea-level lowstand during the Miocene suggest that shutdown of throughflow into the Sea of Japan increased tidal inflow into the SCS. This causes an increase in modelled maximum tidal range and bed shear stress along SCS shorelines (Fig. 13A-B) compared to equivalent highstand models (Fig. 12E-F). A Late Miocene tidal model with a submerged IBM arc (to only $10 \mathrm{~m}$ water depth) causes a substantial increase in maximum tidal range and bed shear stress in all areas of the SCS (Fig. 13C-D) compared to the base-case model (Fig. 12 E-F).

992 On a local-scale, temporal variation in the magnitude of modelled tidal processes generally 993 reflects the fundamental control of regional-scale tectonophysiographic changes. However, 994 whereas on a regional-scale tidal range decreased through the Miocene, tidal range in the Gulf of 995 Thailand (western SCS) generally increased from microtidal to low mesotidal (cf. Figs. 12C, E): widening and deepening of the submerged region permitted greater tidal inflow and larger tidal 997 prism, potentially enhanced by resonance effects (Collins et al., 2018a). Furthermore, the disconnection between calculated and modelled funnelling potential in the Miocene Gulf of 
4999 Thailand illustrates the strong modifying effect of embayment physiography relative to incoming

71000 tidal potential: the narrow and shallow entrance in the Early-Middle Miocene initially prevented 8 91001 tidal inflow into the restricted embayment despite the higher-magnitude regional tides. 

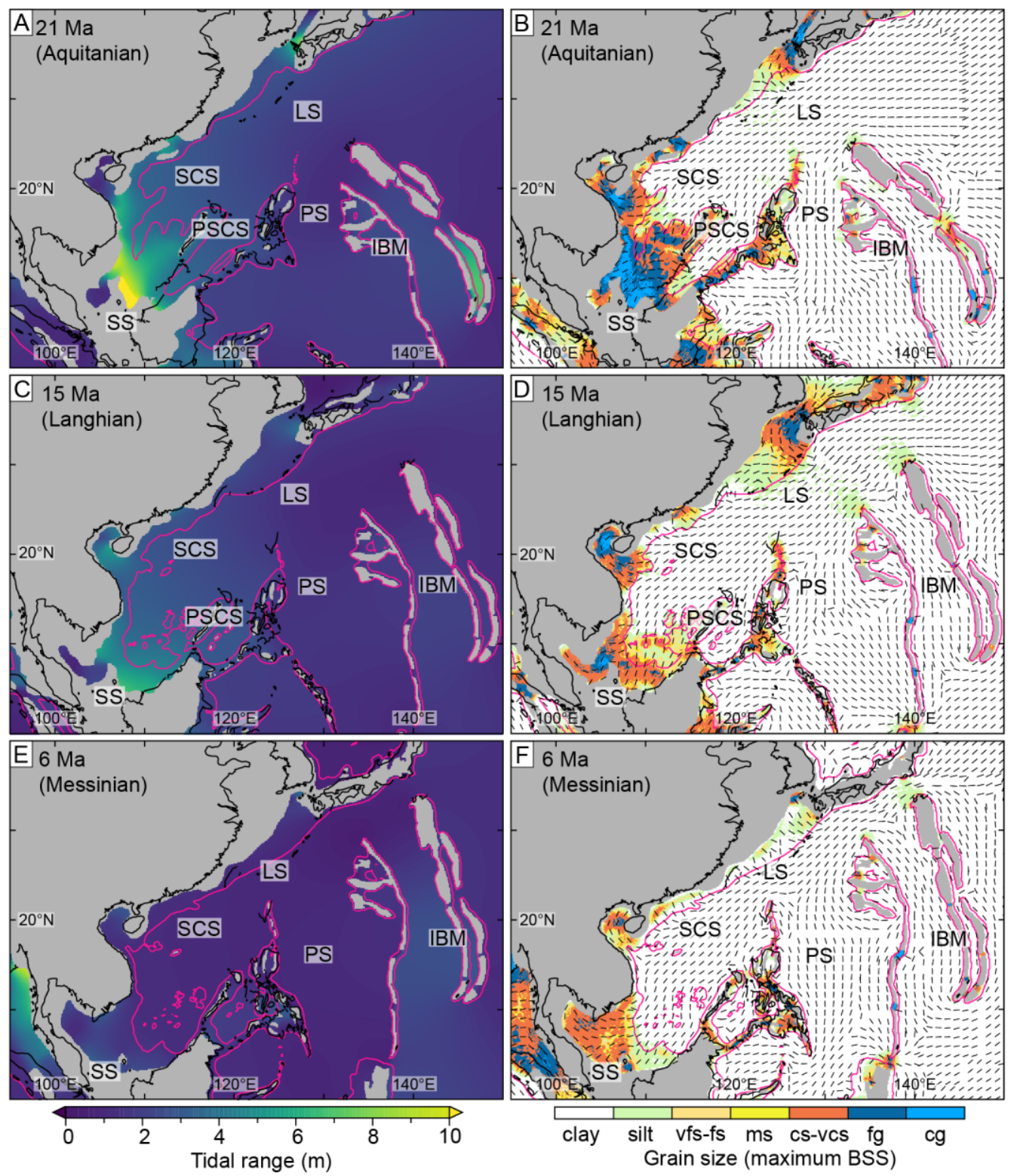

Fig. 12. Palaeotidal model results in the Oligo-Miocene South China Sea for tidal range (A, C,

561014 indicate the interpreted $200 \mathrm{~m}$ palaeobathymetric contour and approximate palaeo-shelf edge.

581015 See Collins et al. (2018a) for all model results and sensitivity analyses. Map abbreviations: IBM 
${ }_{5}^{4} 1016$ - Izu-Bonin-Mariana Arc; LS - Luzon strait; PS - Philippine Sea; SCS - South China Sea; SS -

61017 Sunda Shelf. Grain size abbreviations: vfs = very fine sand; fs = fine sand; $\mathrm{ms}=$ medium sand; cs $81018=$ coarse sand; $\mathrm{vcs}=$ very coarse sand; $\mathrm{fg}=$ fine gravel; $\mathrm{cg}=$ coarse gravel .$$
9
$$
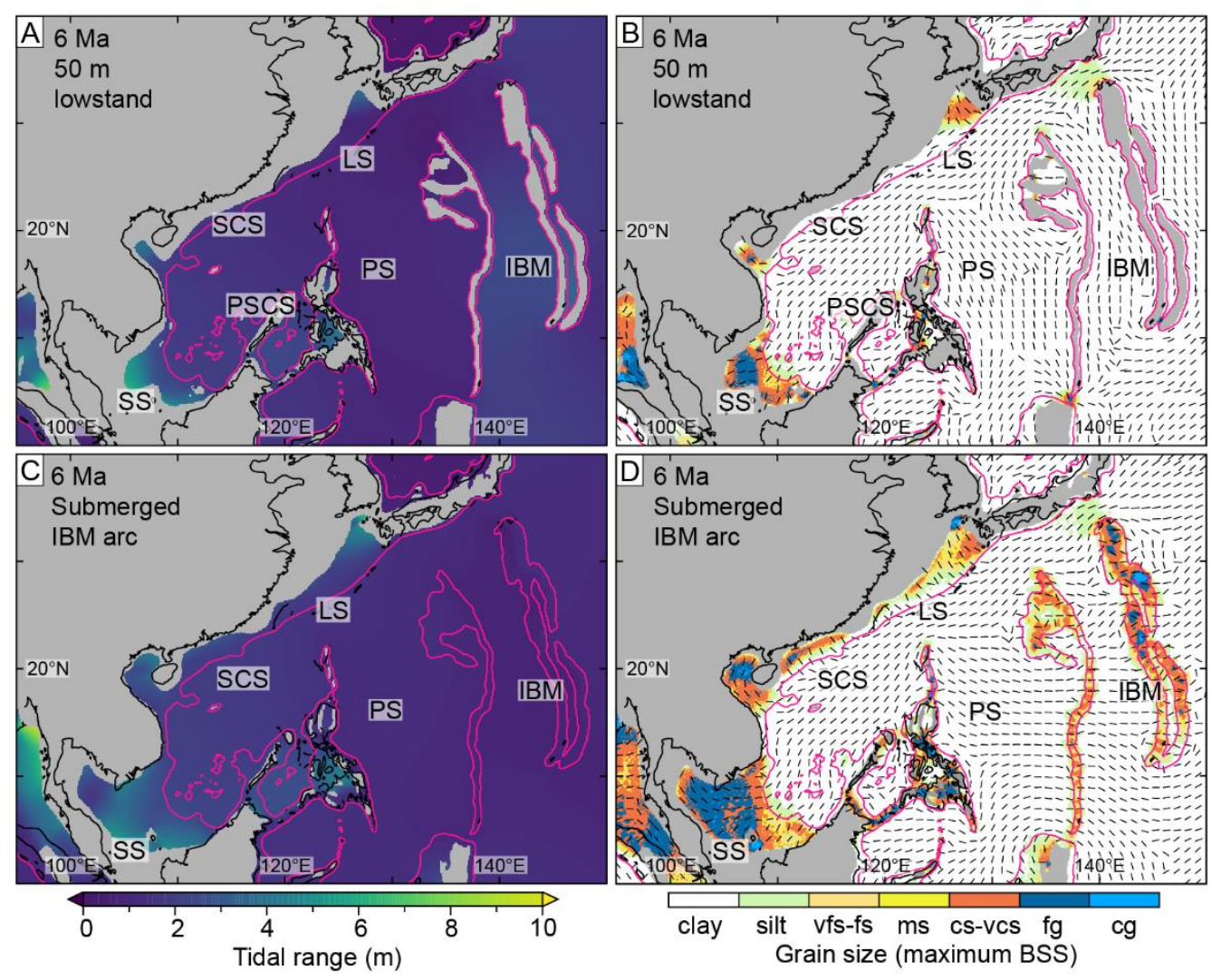

Fig. 13. Sensitivity analyses of the base-case for the Late Miocene (6 Ma) base case

palaeogeographic reconstruction (cf. Fig. 12E, F) showing modeled tidal range (A, C) and maximum tidal bed shear stress, plotted as the maximum sediment caliber entrained (B, D), for a $50 \mathrm{~m}$ sea-level lowstand reconstruction (A, B) and submerged Izu-Bonin-Mariana (IBM) arc (C, D). Refer to Fig. 12 for abbreviations.

\subsubsection{Comparison with the rock record}

Maximum tidal range and bed shear stress model results have been compared with Miocene

sedimentological and micropaleontological data for several circum-SCS basins (Collins et al., 2017a; Collins et al., 2018a). 
Model results are broadly corroborated by sedimentological and micropaleontological data (Fig. 14) and are consistent with previous Miocene paleoenvironmental stratigraphic interpretations (e.g. Doust and Sumner, 2007), including the distribution of interpreted mangrove-related facies in the western SCS (Morley et al., 2011; Shoup et al., 2013). Modelled highs in regional-scale tidal range and bed shear stress compare favourably with Late Oligocene to Middle Miocene sedimentological and mangrove palynomorph data in several basins (Fig. 14), including the following open shoreline systems: (1) mangrove palynomorph acmes in the approximately Late Oligocene, late Early Miocene and Middle Miocene Bach Ho and Con Son Formations in the Cuu Long Basin (basin 2-Fig. 14) (Morley et al., 2011; Chung et al., 2015); (2) the Late Oligocene-Early Miocene Dua Formation in the Nam Con Son Basin, southern Vietnam (basin 3-Fig. 14), which contains paralic coals and mudstones with abundant mangrove pollen (Morley et al., 2011) and tide-influenced fine- to medium-grained sandstones (Tin and Ty, 1995); (3) very fine- to fine-grained tidal cross-bedded sandstones and heterolithic facies, and interstratified carbonaceous mudstone and coals, with abundant mangrove material and pollen, in the Early Miocene Nyalau Formation, Sarawak Basin (Wan Hasiah, 2003; Amir Hassan et al., 2013; Togunwa et al., 2015; Amir Hassan et al., 2016; Murtaza et al., 2018); and (4) mixed fluvial- and tide-influenced, very fine- to fine-grained cross-bedded sandstones and heterolithic facies, and mangrove-bearing carbonaceous mudstones in mixed-process deltaic units in the early Middle Miocene Lambir Formation, Baram-Balabac Basin (basin 8-Fig. 14) (Collins et al., 2020). Evidence of tidal influence is also preserved from the Late Oligocene-Early Miocene embayed Gulf of Thailand, most notably: (1) medium-grained tidal sandstones and abundant mangrove pollen in carbonaceous mudstones and coals in the Early Miocene Pattani Basin (basin 
4-Fig. 14) (Jardine, 1997; Lockhart et al., 1997; Charusiri and Pum-Im, 2009; Ridd et al., 2011);

and (2) paralic mudstones and coals with abundant mangrove and freshwater flora pollen in the Late Oligocene-Early Miocene Malay Basin (basin 5-Fig. 6) (Todd et al., 1997; Morley et al., 2011; Shoup et al., 2013). However, sedimentary evidence for preservation of wave-dominated processes (e.g. swaley and hummock cross-stratification) and environments in regions of modelled tidal range and bed shear stress include: (1) interpreted barred, wave- and stormdominated, shoreface-shelf system in the Early Miocene, southern Malay Basin (Ramli, 1986); and (2) wave- and storm-dominated environments in locations relatively distal and/or lateral to tidally-influenced coastal-delta environments in the Early Miocene Nyalau Formation (Amir

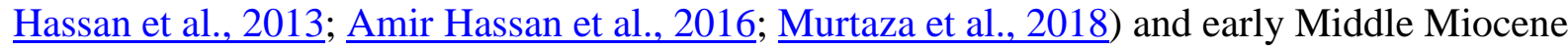
Miri Formation (Abieda et al., 2005; Siddiqui et al., 2016; Collins et al., 2020) in the Sarawak and Baram-Balabac basins, NW Borneo, respectively.

Tidal signals are less widespread in Middle-Late Miocene strata (Fig. 14) but preferentially occurred in the embayed shoreline settings, including: (1) medium-grained sandstones with mangrove-bearing mudstones and coals in the Middle-Late Miocene Pattani Basin, Gulf of Thailand (Jardine, 1997; Lockhart et al., 1997; Charusiri and Pum-Im, 2009; Ridd et al., 2011); (2) medium-grained sandstones and mangrove-bearing mudstones and coals deposited under tidally-influenced conditions in the Middle Miocene Malay Basin (Todd et al., 1997; $\underline{\text { Morley et }}$ al., 2011; Shoup et al., 2013); and (3) tide-influenced deltaic units (e.g. channels) comprising very fine- to fine-grained sandstone and mangrove-bearing mudstones in embayed areas in the Baram-Balabac Basin, NW Borneo (Hadley et al., 2006; Ainsworth et al., 2011; Collins et al., 2018b). This distribution is consistent with the preferential occurrence of tidal shoreline 
environments and mangroves within present-day embayed areas, such as the NE shoreline of the Gulf of Thailand and, in NW Borneo. The latter includes the Lupar embayment, which hosts the tide-dominated Rajang delta (Staub and Gastaldo, 2000), and Brunei Bay (e.g. Staub and Esterle, 1994; Nyberg and Howell, 2016; Collins et al., 2018b; Twilley et al., 2018). However, opencoastline systems in the Middle-Late Miocene overwhelmingly preserve evidence for reduced tidal influence, most notably: (1) a pronounced decrease in abundance of mangrove pollen and increase in freshwater pollen in shallow-marine strata after the Middle Miocene in the Cuu Long Basin (Chung et al., 2015); (2) a sharp reduction in terrestrial and mangrove-derived pollen and transition from tidally-influenced deltaic to shoreface-shelf deposition through the Middle Miocene in the Nam Con Son Basin, mostly due to increased sea level in the Middle Miocene thermal maximum (Morley et al., 2011); (3) overall decrease in abundance of mangrove pollen and extent of interpreted mangrove-bearing environments in the Middle-Late Miocene Gulf of Thailand (Shoup et al., 2013); and (4) storm-dominated, fluvial-influenced and tide-affected deposition in open coastline areas of the Middle-Late Miocene Baram-Balabac Basin (Lambiase et al., 2003; Hadley et al., 2006; Ainsworth et al., 2011; Collins et al., 2018b) (Collins et al., 2017b). In open-coastline settings of the Middle-Late Miocene, as well as lower modelled tidal potential, a large fetch and possible increased influence of typhoons (Collins et al., 2017b) would have increased the potential for wave and storm overprinting of higher frequency, lower magnitude tidal processes (e.g. Dott, 1983; Dott, 1996; Miall, 2015; Collins et al., 2018a; Collins et al., 2018b). Nonetheless, mixed wave- and tide-influenced, mangrove-bearing, open-coastline and deltaic strata are preserved in the Middle Miocene Cuu Long Basin, which are similar to the present day, mixed wave- and tide-influenced, mangrove-bearing Mekong delta, southern Vietnam (e.g. Ta et al., 2002a). 
Fig. 14. Evidence of tide-influenced deposition based on sedimentological and micropaleontological data, mainly from petroleum exploration wells, and comparison to base case tidal model results (Fig. 12) in South China Sea shelf basins. Rock-record data include grain size, cross lamination (ripples) and/or cross bedding interpreted to preserve evidence of tidal process (e.g. bidirectional palaeocurrents, scoop-shaped foresets, mudstone drapes), mangrove pollen acmes and the occurrence of paralic, mangrove-bearing coals and source rocks. Studied formations and key references for each basin are: (1) Upper Zhuhai (Zh) Formation, Pearl River Mouth Basin (Zheng and Deng, 2012); (2) Bach Ho (BH) and Con Son (CS) formations, Cuu Long Basin (Morley et al., 2011); (3) Dua (Du), Thong (Th) and Mang Cau (MC) formations, Nam Con Son Basin (Tin and Ty, 1995; Morley et al., 2011); (4) Sequences II-IV, Pattani Basin (Jardine, 1997; Lockhart et al., 1997); (5) Groups L-J and E, Malay Basin (Morley et al., 2011); (6) Arang (Ar) Formation, West Natuna Basin (Morley et al., 2011); (7) Nyalau (Ny) Formation, Balingian Province, Sarawak Basin (Amir Hassan et al., 2013; Amir Hassan et al., 2016); (8) 
${ }_{5}^{4} 1115$ Lambir (L) and Belait (B) formations, Baram Delta Province, Baram-Balabac Basin (Lambiase 61116 et al., 2003; Collins et al.).

\subsection{Early Cretaceous (Aptian-Albian) Lower Greensand Seaway, north-west Europe}

\subsubsection{Overview}

The Early Cretaceous Lower Greensand Group in Southeast England is well known for its tidal sandstone deposits (ㅅllen, 1982a); Bridges, 1982; Johnson and Levell, 1995; Wonham and

Elliott, 1996; Yoshida et al., 2004). The study area is very different to our previous (SCS)

example: it covers a much smaller area, it was part of a larger epicontinental sea and it was

entirely shallow water, far removed from coeval oceanic basins. The larger-scale (10-100s km)

basin physiography was determined by a series of precursor, west-east-trending, rift basins ( $c$.

50-100 km long and 10-30 km wide; e.g. Weald, Wessex and Channel basins) that were

initiated during the Early Cretaceous (e.g. Ziegler, 1990; Hawkes et al., 1998). These basins were initially (Berriasian-Barremian) filled by thick (100s m; up to ca $1 \mathrm{~km}$ ) alluvial plain successions (Wealden Group). These successions were succeeded by Aptian-Albian deposits that comprise shallow-marine sandstones (Lower Greensand Group) with exemplary evidence of tidal sedimentation (e.g. De Raaf and Boersma, 1977) overlain by offshore marine mudstones (Gault Clay Formation). Hence, the Aptian-Albian succession reflects overall marine transgression, which was accompanied by an overall increase in basin width, length, bathymetry and connectivity. Consequently, predicting tidal circulation in this setting is complicated by several uncertainties, most notably (1) variability in palaeobathymetry caused by the drowning of previously separate rift basins with differing initial water depths, (2) complex marine flooding of these basins, with competing marine incursions entering the Weald Basin through connections to 
three major marine water bodies during drowning: the Boreal Sea (to the north), proto-Atlantic Ocean (to the south-west), and Neotethys Ocean (to the south-east) (Fig. 15A-B). Palaeotidal modelling and comparison to the stratigraphic record, with emphasis on the Lower Greensand Group, has been used to understand these uncertainties across a range of different age, palaeobathymetric and palaeogeographic scenarios (Wells et al., 2010b).

\subsubsection{Geological Setting}

During the Early Cretaceous, an increase in eustatic sea level, and a waning of rift-related subsidence, resulted in the marine flooding and connection of several previously isolated continental rift basins (Fig. 15A-C). Many of these basins became connected as marine transgression flooded several relatively narrow (c. 10s $\mathrm{km}$ wide) seaways, which exploited preexisting structural lineaments, including basement-linked syn-rift faults (․ㅏawkes et al., 1998). Thus, the Weald and Paris basins were connected via a northwest-southeast-trending seaway along the major Pays de Bray Fault, while the Weald and Southern North Sea basins were connected across the London-Brabant Massif via the northeast-southwest-trending 'Bedfordshire Strait' (Ziegler, 1990). Transgression of the Wessex Basin exploited the major basin-bounding Purbeck-Isle of Wight Fault Zone (Gupta and Johnson, 2002).

The various sedimentary basins were infilled with highly diachronous, but broadly AptianAlbian age, glauconite-rich shallow-marine sandstones, informally referred to 'greensands'. The first of these shallow-marine sandstone units, the Lower Greensand Group (LGG), is the primary focus of this review. The term 'Lower Greensand Seaway' is used here to refer to an interconnected network of three main seaways of latest Aptian-Albian age, each one connecting 
with larger marine water bodies (i.e. Boreal, proto-Atlantic and Neothys; Fig. 15A-B). The LGG

stratigraphy and palaeogeography is supported by a robust ammonite biostratigraphic framework and contains unconformities of local-to-regional extent (Fig. 15D) (Bridges, 1982). Two stratigraphic intervals and associated phases of basin-fill deposition are considered below. The first phase of deposition (labelled 'FH' in Fig. 15D) is represented by the upper part of the fissicostatus-martinioides Zone, which comprises the Ferruginous Sands Formation (Isle of Wight, Wessex and Channel basins) (Ruffell, 1992) and the Hythe Formation (Weald Basin) (Bridges, 1982; Ruffell, 1992; Rawson, 2006). These deposits display negligible evidence of tidal currents, suggesting low tidal range (microtidal-low mesotidal) (Ruffell and Wach, 1991; Wells et al., 2010b). The second phase of deposition (labelled 'FSW' in Fig. 15E) is represented by the mid-to-upper part of the upper martinioides-lower tardefurcata Zone, and comprises several high-energy, shallow-marine sandstone units, most notably (1) the Woburn Sands Formation (in Leighton Buzzard) (Johnson and Levell, 1995; Wonham and Elliott, 1996; Yoshida et al., 2004); (2) the Folkestone Sands Formation (Weald Basin) (Allen, 1981a; Allen, $\underline{1981 b}$; Allen, 1982a; Bridges, 1982); and (3) the Sandrock Formation (Isle of Wight, Wessex and Channel basins) (Ruffell and Wach, 1991; Insole et al., 1998; Rawson, 2006) (Fig. 15D). These deposits all display compelling evidence of deposition by strong tidal currents within an inferred macro-tidal setting (Allen, 1982a; Johnson and Levell, 1995). Mud drape spacing in the Folkestone Sands has been interpreted to form spring-neap tidal bundles that were deposited in an ebb-dominated diurnal, or mixed, predominantly diurnal tidal regime (lllen, 1982a). The LGG succession is capped everywhere by offshore marine mudstones of the Gault Clay Formation, which transgressively onlaps the underlying tidal sandstones (Johnson and Levell, 
${ }_{5}^{4} 1183$ 1995). Palaeotidal modelling has focused on the two stratigraphic intervals outlined above ('FH' 6 and 'FSW' in Fig. 15D) (Wells et al., 2010b), as summarised below.
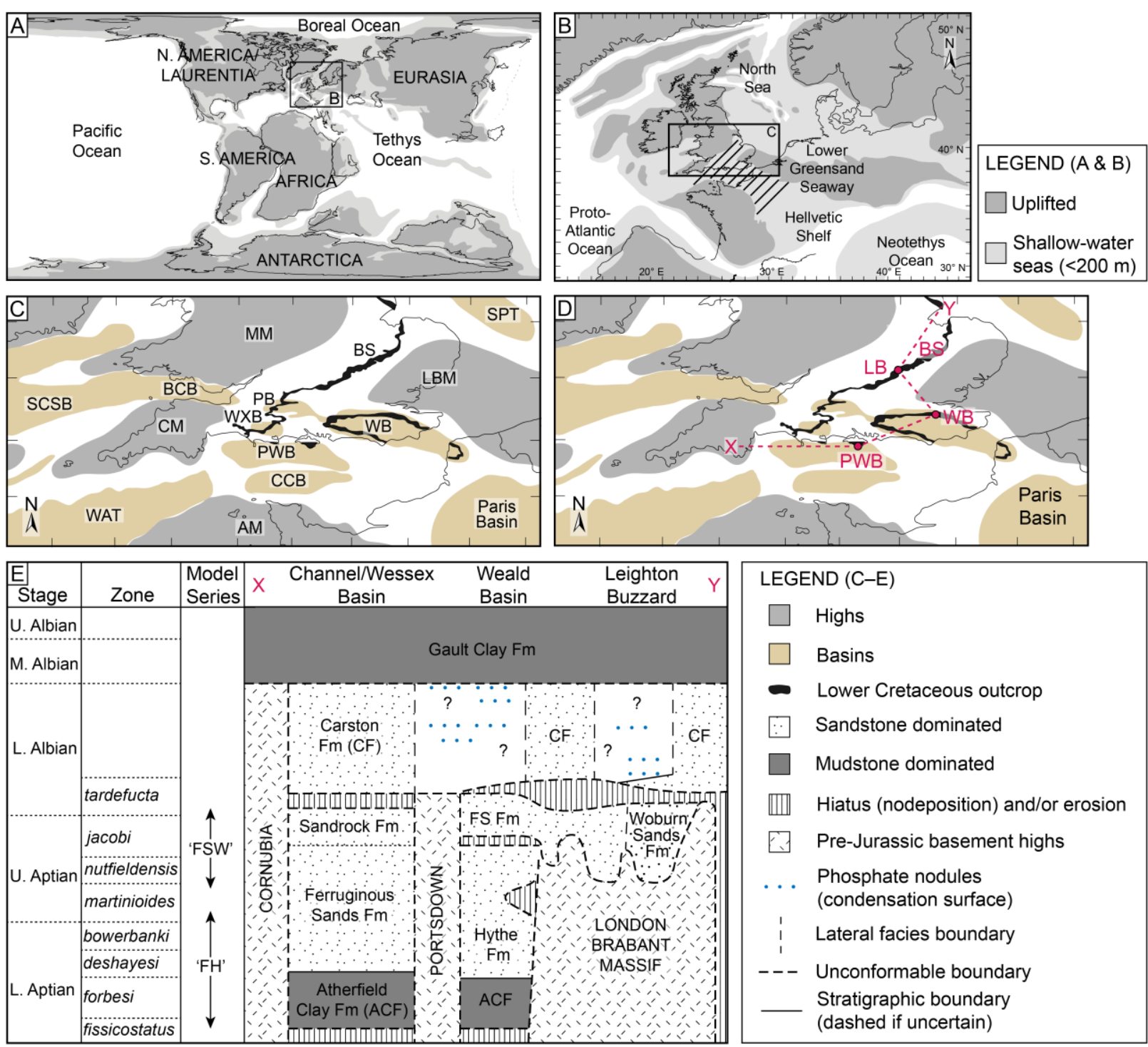

\begin{tabular}{|c|c|}
\hline \multicolumn{2}{|c|}{ LEGEND (C-E) } \\
\hline & Highs \\
\hline & Basins \\
\hline & Lower Cretaceous outcrop \\
\hline & Sandstone dominated \\
\hline & Mudstone dominated \\
\hline 凹监 & Hiatus (nodeposition) and/or erosion \\
\hline$\theta$ & Pre-Jurassic basement highs \\
\hline & $\begin{array}{l}\text { Phosphate nodules } \\
\text { (condensation surface) }\end{array}$ \\
\hline 1 & Lateral facies boundary \\
\hline--- & Unconformable boundary \\
\hline & $\begin{array}{l}\text { Stratigraphic boundary } \\
\text { (dashed if uncertain) }\end{array}$ \\
\hline
\end{tabular}

Fig. 15. Geological and stratigraphic framework of the Early Cretaceous 'Lower Greensand

Seaway', NW Europe. (A) Global Aptian palaeogeographic framework. (B) Aptian

palaeogeographic framework of northwest Eurasia. In A and B, darker grey are significant

uplifted highs and lighter grey shallow-water seas (<200 m depth). (C) Aptian palaeogeographic 
map of southern UK and northern France with significant uplifted highs in dark grey and basins in light brown. Basin abbreviations: BCB - Bristol Channel Basin; BS - Bedfordshire Strait; CCB - Central Channel Basin; PB - Pewsey Basin; PWB - Purbeck-Wright Basin; SCSB South Celtic Sea Basin; WAT - Western Approaches Trough; WB - Weald Basin. High abbreviations: AM - Armorcian Massif; CM - Cornubian Massif; LBM - London-Brabant Massif; MM - Midlands Massif. (D) Aptian palaeogeographic map illustrating key locations for the chronostratigraphic and lithostratigraphic framework of the Lower Greensand Group (section $\mathrm{X}-\mathrm{Y}$ in $\mathrm{E}$ ). Location abbreviations in addition to those labelled in $\mathrm{C}$ : $\mathrm{LB}$ - Leighton Buzzard. (E) Illustrative chronostratigraphic and lithostratigraphic section of the Lower Greensand Group in southern England. Two “'base case” palaeogeographies are considered (Fig. 16): 'FH' represents the upper part of the fissicostatus-martinioides Zone depositional sequence, corresponding to the Ferruginous Sands Formation on the Isle of Wight and the Hythe Formation in the Weald; 'FSW' represents the mid to upper part of the upper martinioides-lower tardefurcata Zone depositional sequence, corresponding to the Folkestone Sands Formation in the Weald, the Sandrock Formation on the Isle of Wight, and the Woburn Sands Formation around Leighton Buzzard. After Wells et al. (2010b), Yoshida et al. (2004) and references therein.

\subsubsection{Model Setup}

Regional-scale tidal simulations were forced with both astronomical and boundary tides for the four most significant tidal constituents $\left(\mathrm{M}_{2}, \mathrm{~S}_{2}, \mathrm{~K}_{1}\right.$, and $\left.\mathrm{O}_{1}\right)$ (Kantha and Clayson, 2000); each constituent was run independently for an 8-day period (simulated time), with a time step of 5 minutes, in order to reach a steady-state solution. Tidal amplitude and phase were calculated 
using harmonic analysis on the last 30 hours of the simulated free-surface height; tidal range is twice the total tidal amplitude values.

Tidal open boundary conditions for regional-scale tidal simulations were generated using a global-scale Lower Cretaceous (Aptian) palaeotidal model (Wells et al., 2010a) along the southern (Neo-Tethys) and western (proto-Atlantic) margins, and positioned oceanward of the shelf edge, in order to better resolve the propagation of the oceanic tidal wave onto the continental shelf and minimised boundary effects within the Lower Greensand Seaway. The plate-tectonic and palaeocoastline reconstructions were based on the Palaeogeographic Atlas Project (Paul Markwick, personal communication 2007), underpinned by ocean-floor ages (Müller et al., 1997) and further literature review (Wells et al., 2010a). Palaeobathymetry was estimated by reference to modern analogues (Wells et al., 2010a). The Aptian global palaeotidal model predicts low microtidal ranges in the proto-Atlantic $(<1 \mathrm{~m})$ and Boreal $(<0.5 \mathrm{~m})$ oceans, and higher diurnal-dominated microtidal (c. 1.5-2 m) ranges in the Neotethys (Wells et al., 2010a).

Modified versions of the published Lower Greensand Seaway palaeocoastline (Tyson and

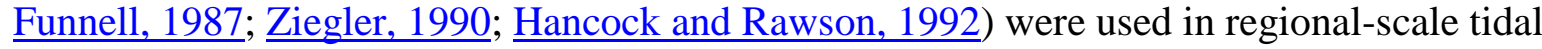
simulations of the Lower Greensand Seaway (Wells, 2008; Wells et al., 2010b). Maximum modelled water depths in the seaway are typically $25 \mathrm{~m}$ and do not exceed $75 \mathrm{~m}$ by analogy to sand-wave deposits in the present-day English Channel and Southern North Sea (Allen, 1982a;

Stride, 1982). Numerous sensitivity tests were performed on two 'base-case' palaeogeographies for (1) the upper part of the fissicostatus-martinioides Zone depositional sequence (the 'FH' 
series, Fig. 15E), referred to as FH1 (Fig. 16A-B), and (2) mid to upper part of the upper martinioides-lower tardefurcata Zone depositional sequence (the 'FSW' series, Fig. 15E), referred to as FSW1 (Fig. 16C-D). A key difference between the 'base case' scenarios for these two timeslices is widening of the oceanic connections, especially through the Paris Basin, in the upper martinioides-lower tardefurcata Zone due to transgression in the nutfieldensis Zone (Casey, 1961; Wells et al., 2010b).

Eight sensitivity analyses were performed for each 'base-case' palaeogeography (Wells et al., 2010b), of which four are discussed herein (Scenarios 2, 4, 6 and 8, using the numbering system of Wells et al. (2010b)): (1) closure of the Paris Basin connection to the Neotethys Ocean (Scenario 2: cases FH2 and FSW2; Fig. 17A, B); (2) connection through the Pewsey Basin to the proto-Atlantic Ocean (Scenario 4; FH4 and FSW4; Fig. 17C, D); (3) opening of all oceanic connections (Scenario 6; FH6 and FSW6; Fig. 17E, F); and (4) doubling the water depth between 0 and 200 m, whilst maintain the same palaeoshoreline (Scenario 8; FH8 and FSW8; Fig. 17G, H).

\subsubsection{Model Results}

Base-case simulations for both timeslices suggest propagation of two progressive tidal waves into the Lower Greensand Seaway: (1) a generally dominant tide from the Neotethys Ocean to the south-east, via the Paris Basin, and (2) a generally subordinate tide from the proto-Atlantic Ocean to the west and south-west, via Western Approaches Trough (Fig. 16). A connection to the Boreal Ocean to the north, via the 'Bedfordshire Strait' and North Sea (Fig. 15C, D), had not yet been established in either base-case simulation (Fig. 16). In the base-case simulation of the 
older timeslice (scenario FH1; Fig. 16A), a microtidal (c. 1-2 m) diurnal-dominated tidal regime in the Lower Greensand Seaway is predicted. The restricted connection between the seaway and Paris Basin is associated with funnelling, shoaling and amplification of tides in the northern Paris Basin, and decreased tidal inflow into the Weald Basin (e.g. Guillocheau et al., 2000). In the 'base-case' simulation of the younger timeslice (scenario FSW1; Fig. 16B), tides in the Lower Greensand Seaway are diurnal-dominated but higher than in scenario FH1: high mesotidal to low macrotidal in the western Weald and Leighton Buzzard -Bedfordshire Strait area, and mesotidal in the rest of the seaway. The simulation shows the northward-propagating tidal wave from the Neotethys Ocean being significantly amplified by funnelling and shoaling effects as the seaway narrows and shallows towards the northwest (Fig. 16B). Furthermore, Coriolis deflection to right steers the tidal wave into the funnel shaped 'Leighton Buzzard Trough', causing further amplification and formation of macrotidal conditions here (Fig. 16B).

Compared to the base-case simulations (Fig. 16), four sensitivity analyses (Scenarios 2, 4, 6 and

8) indicate the following effects on tides in the Lower Greensand Seaway:

(1) Scenarios FH2 and FSW2 represents closure of the Paris Basin connection to the Neotethys Ocean, and therefore loss of the dominant tidal inflow into the seaway. This substantially decreases modelled tidal range within the seaway in both timeslices, decreasing tidal range by up to c. $75 \%$ to microtidal in scenario FSW2 (Fig. 17A-B), and causing local increases in semi-diurnal tides (Fig. 18).

(2) Scenarios FH4 and FSW4 includes an additional connection to the proto-Atlantic Ocean through the Pewsey Basin, which decreases modelled tidal range within the seaway in both time-slices (Fig. 17C-D). Tidal range is decreased due to destructive interference of 
out-of-phase tidal waves, which enter from the Weald Basin from the Pewsey Basin and the Paris Basin in scenario FH4, and from the English Channel Basin and the Paris Basin in scenario FSW4 (Fig. 17C-D). Additionally, some tidal energy may outflow through the Pewsey Basin in both scenarios.

(3) Scenarios FH6 and FSW6 reflects opening of an additional oceanic connection through the Bedfordshire Strait (Fig. 15D) and first communication with the Boreal Sea, to the north. This results in decreased modelled tidal range across much of the LGS because the various tidal waves are not in phase, leading to destructive interference (Fig. 17E-F). Additionally, rather than being trapped, funnelled, and amplified within the seaway, the dominant incoming tide from the southeast may outflow via the additional connections. Tides in the seaway become more semi-diurnal influenced in scenario FH6 but remain diurnal dominated in scenario FSW6 (Fig. 18).

(4) Scenarios FH8 and FSW8 comprises a doubling the water depth between 0 and $200 \mathrm{~m}$, whilst maintaining the same palaeoshoreline. This significantly increases modelled tidal range in both timeslices, to high microtidal-mesotidal (c. 1.8-3 m) in scenario FH8 and macrotidal (c. 5-7 m) in scenario FSW8. This is partially due to enhanced inflow of tidal energy and shoaling caused by the larger change in water depth across the shelf. However, the ratio of diurnal to semi-diurnal tides changes in both time-slices, which suggests that regional physiography also had an important effect on tidal resonance (Fig. 18).

These scenarios illustrate that the regional-scale $(100 \mathrm{~s} \mathrm{~km})$ balance between tidal inflow and outflow has a first-order control on tides in smaller-scale $(10 \mathrm{~s} \mathrm{~km})$ areas and can supersede 
${ }_{5}^{4} 1305$ funnelling effects within physiographic constrictions, such as in straits and embayments.

91307 Figs. 16B, D, 17B, D, F, H) are consistently higher in the Lower Greensand Seaway than

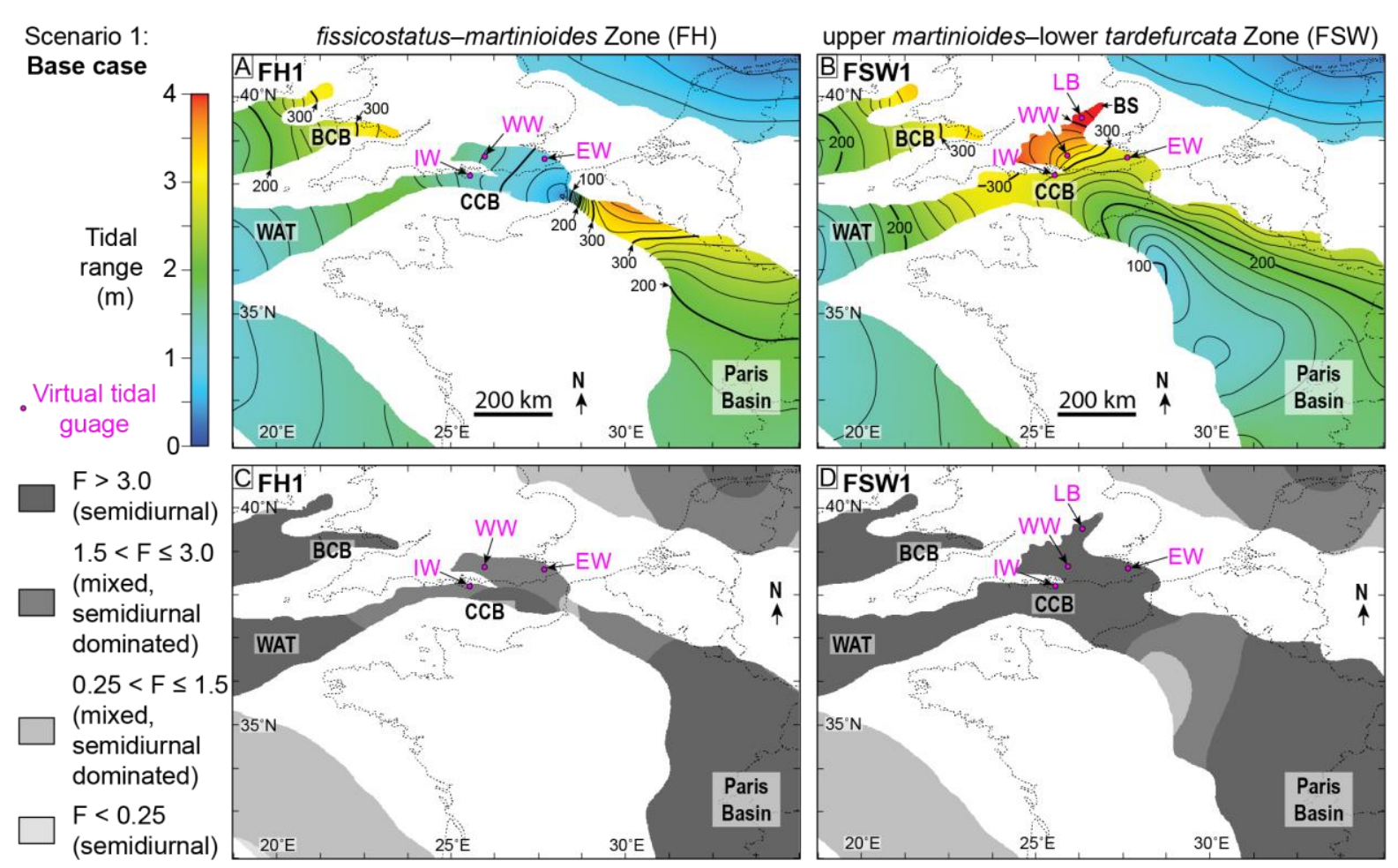


Fig. 16. Base case palaeotidal model results in the Early Cretaceous Lower Greensand Seaway

71319 for the fissicostatus-martinioides Zone (A, C) and upper martinioides-lower tardefurcata Zone 


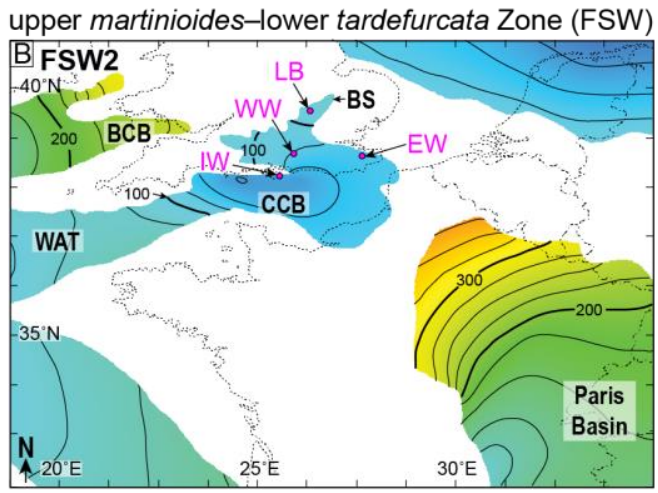

\section{Scenario 4: Pewsey Basin} connection open
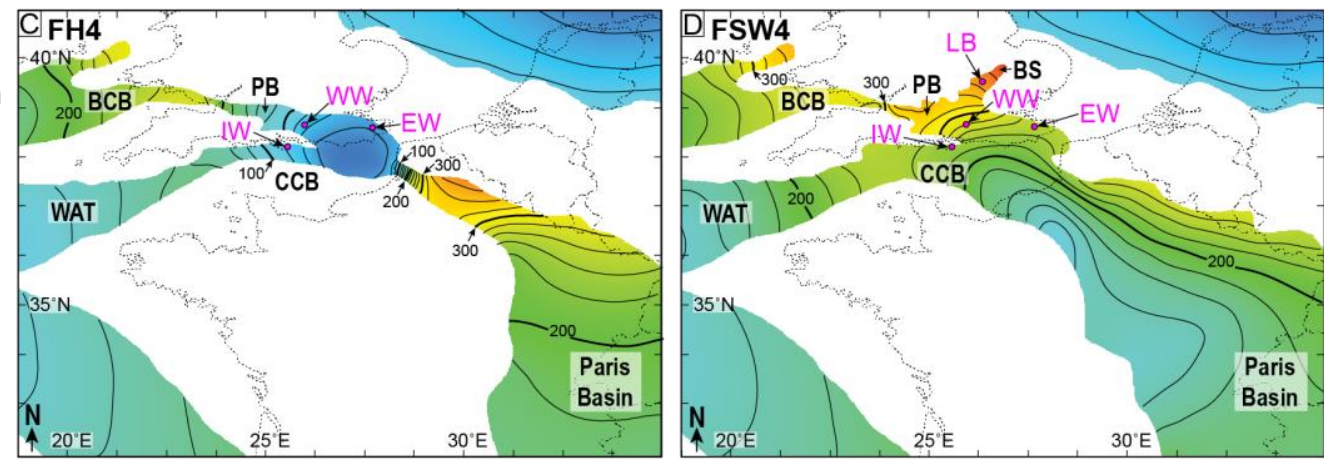

\section{Scenario 6: \\ All ocean} connections open
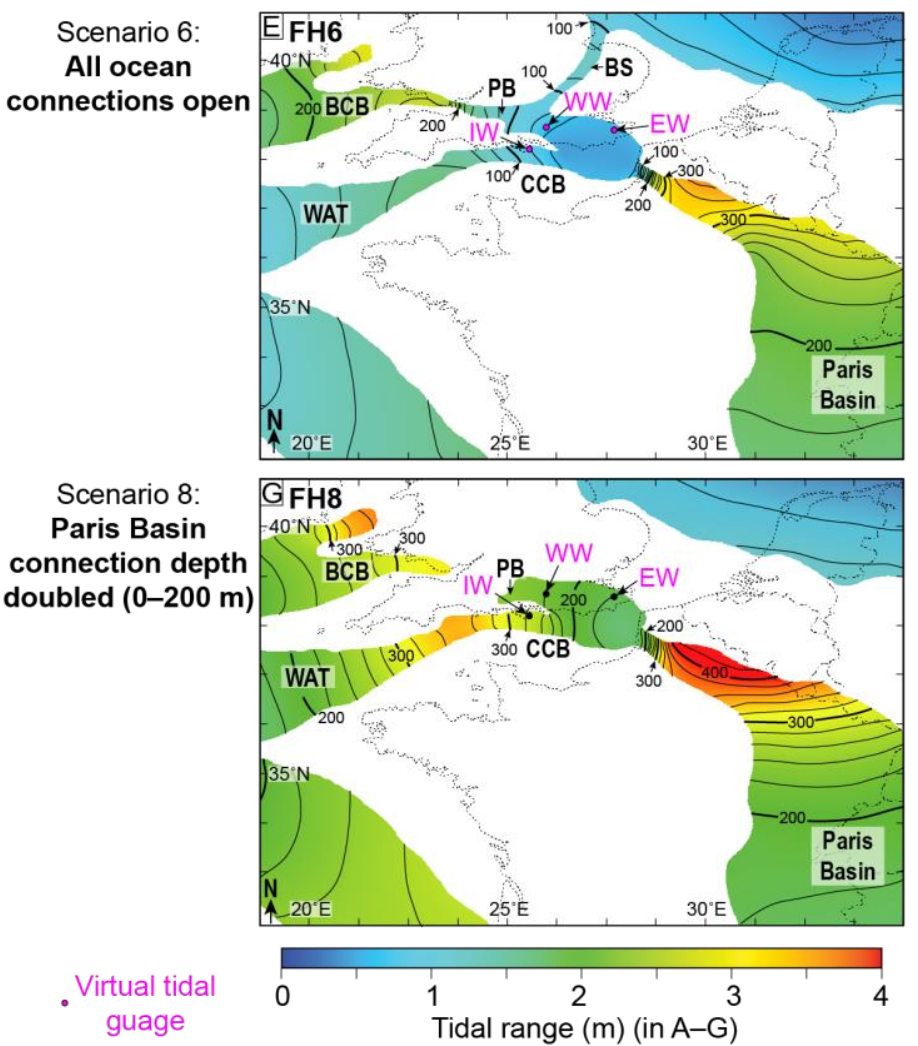
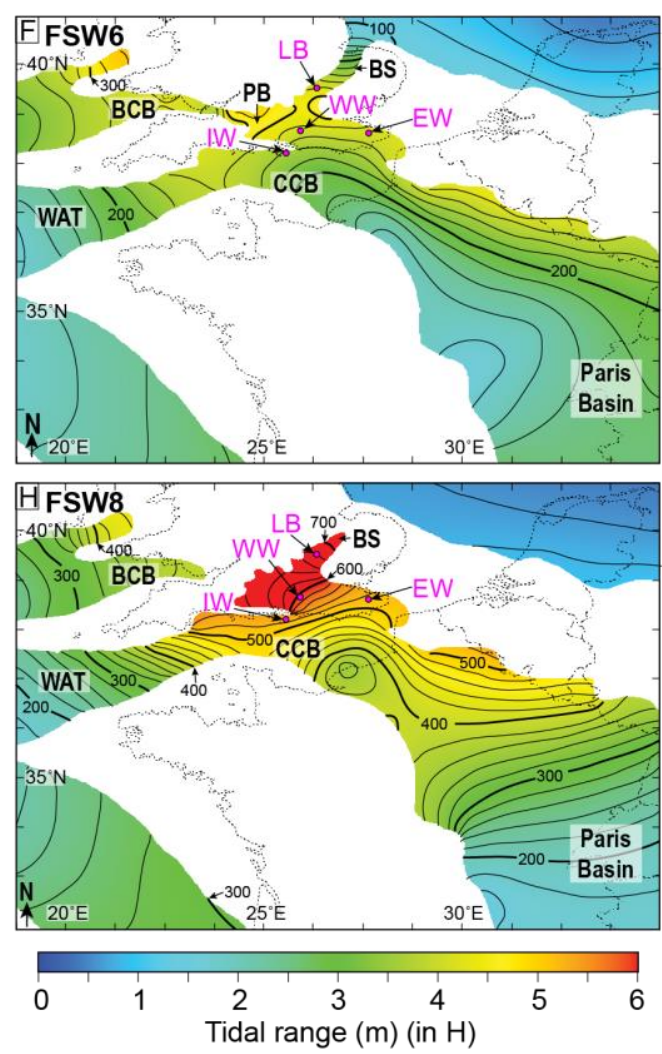
Fig. 17. Modelled tidal range for the four principal tidal constituents $\left(M_{2}+S_{2}+K_{1}+O_{1}\right)$ in sensitivity analyses of base-case reconstructions for the fissicostatus-martinioides Zone (A, C, E, G) and upper martinioides-lower tardefurcata Zone (B, D, F, H) timeslices in the Early Cretaceous Lower Greensand Seaway (respectively 'FH' and 'FSW' in Fig. 15D); tidal range contours are drawn for $20 \mathrm{~cm}$ intervals and bold, annotated contours every $100 \mathrm{~cm}$. Pink labelled dots show positions of 'virtual tidal gauges' in the East Weald Basin (EW), Isle of Wight (IW), Leighton Buzzard (LB) and West Weald Basin (WW).Basin abbreviations: CCB - Central Channel Basin; BCB - Bristol Channel Basin; BS - Bedfordshire Strait; CCB - Central Channel Basin; PB - Pewsey Basin; WAT - Western Approaches Trough. Modified from Wells et al. $\underline{(2010 b)}$. 

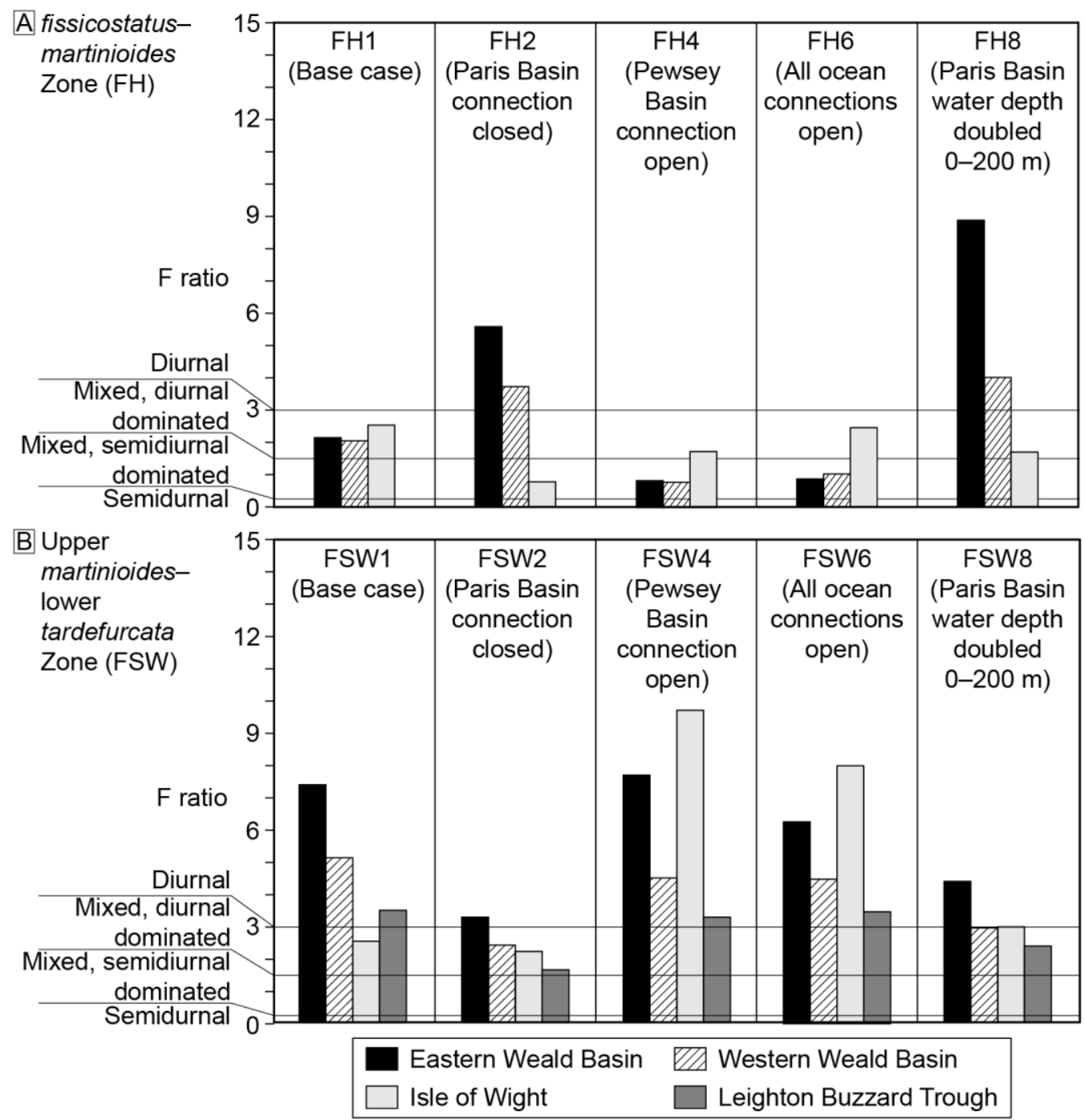

Fig. 18. Bar graphs of modelled tidal range at 'virtual tide gauge' locations (see Fig. 16 \& 17)

for base-case (Fig. 16) and sensitivity simulations (Fig. 17) for the fissicostatus-martinioides

Zone (A) and upper martinioides-lower tardefurcata Zone (B) timeslices (respectively 'FH' and 'FSW' in Fig. 15D). Modified from Wells et al. (2010b).

\subsubsection{Comparison with the Rock Record}

Modelled tides for the fissicostatus-martinioides Zone ('FH' in Fig. 15D) predict microtidal conditions across most models (FH2, FH4 and FH6 scenarios; Fig. 17A, C, E) and low mesotidal 
in scenario FH8 (Fig. 17G). These results are broadly consistent with the time-equivalent sedimentary record, which contains little evidence of tidal influence on deposition (see review in Wells et al. (2010b)). In the western Weald Basin, putative tidal deposits in the uppermost part of this interval (Hythe Formation) are of limited areal extent and contain no published evidence of bidirectional currents or mud drapes (Casey, 1961; Narayan, 1971; Bridges, 1982; Ruffell and Wach, 1991; Rawson, 2006). This comparison supports modest tidal amplification and high microtidal-low mesotidal tides in the western Weald Basin (Figs. 16A and 17). The comparison also suggests that the connection between the Lower Greensand Seaway and Paris Basin may have been wider, which decreases amplification within the strait and increases tidal inflow into the seaway (see scenario FH7 in Wells et al. (2010b)).

Modelled tides for the upper martinioides-lower tardefurcata Zone ('FSW' in Fig. 15D) consistently predict high mesotidal to low macrotidal conditions across all model scenarios (Figs 16B, 17D, F, H, 18B), except when the Paris Basin is not connected (Fig. 17B). Closure of the Paris Basin connection may have occurred for a short time during a global eustatic sea level fall in the jacobi Zone, as indicated by a minor non-depositional or erosional hiatus (Fig. 15D) (Casey, 1961). Tidal deposits are widespread throughout the seaway at this time, including the following: (1) mudstone draped cross-bedding and brackish ichnofauna in the Sandrock

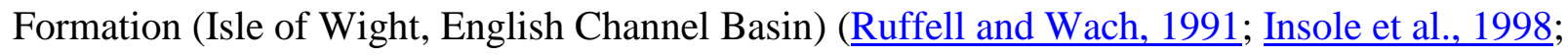
Rawson, 2006); (2) various combinations of large cross-sets (up to $15 \mathrm{~m}$ thick) with mudstone drapes (some double mudstone drapes), reactivation surfaces and bidirectional palaeocurrent directions, wavy-, flaser- and lenticular-bedded heterolithic toesets, and a shallow-marine ichnofauna in the Woburn Sands Formation ('Leigh Buzzard Trough') (Bridges, 1982; Johnson 
and Levell, 1995; Wonham and Elliott, 1996; Yoshida et al., 2004; Wells et al., 2010b), which

are interpreted to preserve large migrating bedforms in tide-dominated estuaries and marine embayments (e.g. Yoshida et al., 2004); and (3) compound cross-bedded sandstones with abundant mud drapes, reactivation surfaces, spring-neap tidal bundles, heterolithics and a shallow-marine ichnofauna in the Folkestone Sands Formation (Weald Basin), which are interpreted to preserve tidal sand waves formed in a shallow sea (Allen, 1982a; Bridges, 1982). These deposits record deposition under strong tidal currents, with probable mesotidal to macrotidal ranges $(\underline{\text { Allen, 1981b) }}$, which is supported by palaeotidal model results (Fig. 17B and 18). Furthermore, the predicted diurnal-dominated tidal regime in the LGS in all modelled scenarios (Fig. 18) matches the interpretation of diurnal-dominated spring-neap tidal bundles in the Folkestone Sands Formation (Allen, 1981a; $\underline{\text { Allen, 1982a). }}$

\subsection{Late Cretaceous (Turonian-Cenomanian), Bohemian Cretaceous Basin, Central Europe}

\subsubsection{Overview}

The Bohemian Cretaceous Basin (BCB) contains prominent tide-influenced shallow-marine sandstones of Turonian-to-early-Coniacian age (e.g. Jerzykiewicz and Wojewoda, 1986; Uličný, 2001; Uličný et al., 2009; Mitchell et al., 2010). The BCB was a slowly subsiding, transtensional basin that together with other, linked basins formed a large and shallow epicontinental sea across much of Europe (e.g. Ziegler, 1990; Mitchell et al., 2010). As with the LGS example presented above, the BCB was far removed from coeval oceanic basins; over a thousand kilometres from the Neotethys Ocean to the southeast and the Proto-Atlantic Ocean to the west (Fig. 19) (e.g.

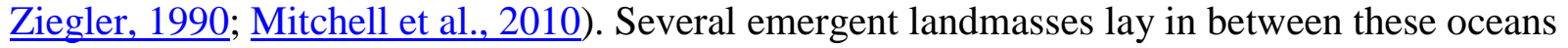


and the BCB (Fig. 19), such that boundary tides are likely to have been significantly blocked and

damped by seabed friction (Mitchell et al., 2010). However, funnelling and shoaling effects may have been important in local-scale straits (c. 10s km wide) within the basin (Fig. 20). In this context, two depositional models have been proposed for Turonian-to-early-Coniacian shallowmarine sandstones in the BCB. Early models interpreted the sandstones as the deposits of large offshore bedforms sculpted by storms and tides (cf. tidal sand banks or ridges) and accumulated in fault-bounded bathymetric depressions (e.g. Jerzykiewicz and Wojewoda, 1986). More recently, the sandstones were re-interpreted as the deposits of localised, top-truncated, coarsegrained deltaic shorelines that were reworked by tidal currents in the basin (Uličný, 2001; Uličný et al., 2009). Palaeotidal modelling has been used with two aims (Mitchell et al., 2010): (1) to understand how boundary tides from the Neotethys and Proto-Atlantic oceans were expressed as tidal circulation in the $\mathrm{BCB}$, by considering regional-scale (10-100s $\mathrm{km}$ ) basin physiography (Fig. 19); and (2) to assess whether modelled tidal bed shear stress was capable of generating the grain-size distributions, bedform types and palaeocurrent orientations observed at local-scale (1s-10s km) in the Turonian-to-early-Coniacian shallow-marine sandstones (Fig. 20).

\subsubsection{Geological Setting}

Turonian-to-early-Coniacian strata in the BCB were deposited shortly after peak eustatic flooding at the Cenomanian-Turonian boundary and the maximum extent of the Cretaceous shallow epicontinental sea in Europe (Fig. 19) (Hancock and Kauffman, 1979; Ziegler, 1990;

Miller et al., 2003). These strata record drowning of Cenomanian fluvio-estuarine deposits around the basin margin (Uličný and Špičáková, 1996), and the onset of open marine conditions throughout the $\mathrm{BCB}$. Turonian and early Coniacian strata contain eight basinward-thinning 
sandstone wedges ('TUR1-7' and 'CON1' genetic sequences of Uličný et al. (2009)), some of

which terminate against or show abrupt thickness changes across syn-depositional faults

(Jerzykiewicz and Wojewoda, 1986; Uličný et al., 2009). Each wedge consists of several tongues, and the basinward-lying part of each tongue contains a single, basinward-dipping set of thick (up to $80 \mathrm{~m}$ ), steeply dipping (up to $30^{\circ}$ ) foresets. Each tongue is interpreted to record the progradation of a coarse-grained, Gilbert-type delta from the basin margin, with delta topsets having been removed by later transgressive erosion (Uličný, 2001; Uličný et al., 2009). Tidal influence was pervasive, as indicated by: (1) cross-bedded, coarse-grained sandstones with bidirectional palaeocurrents oriented parallel to the basin axis, commonly perpendicular to the delta-front foresets that contain the cross-beds; (2) reactivation surfaces in cross-bed sets; and (3) mudstone, siltstone and silty sandstone drapes, which are sometimes paired, along the foresets of cross-beds (e.g. Jerzykiewicz and Wojewoda, 1986; Uličný, 2001; Uličný et al., 2009; Mitchell et al., 2010). A dataset combining outcrops and densely spaced boreholes provides good constraint on the basin-fill thickness and syn-depositional physiography of the BCB (Uličný et al., 2009), which contained islands with intervening, fault-bounded, local-scale (c. 10s km) straits (e.g. 'Elbe Strait' of Mitchell et al. (2010); Fig. 20). However, the physiography of many areas in the wider European epicontinental sea is poorly constrained (Ziegler, 1990). Consequently, modelled palaeobathymetric scenarios are similar for the $\mathrm{BCB}$, but differ by up to $100 \mathrm{~m}$ water depth in other basin centres in the epicontinental European seaway (Fig. 19B-C).

Palaeotidal modelling work on the BCB has focussed on Early to Middle Turonian deltaic to shallow-marine strata, which form the intermediate part of the 'TUR 2' genetic sequence of Uličný et al. (2009), and occur in three tectonically controlled depocenters: (1) the Lužice-Jizera 
${ }_{5}^{4} 1442$ Sub-basin in the eastern Elbe Strait, fed by sediment sourced from the Western Sudetic Island; 

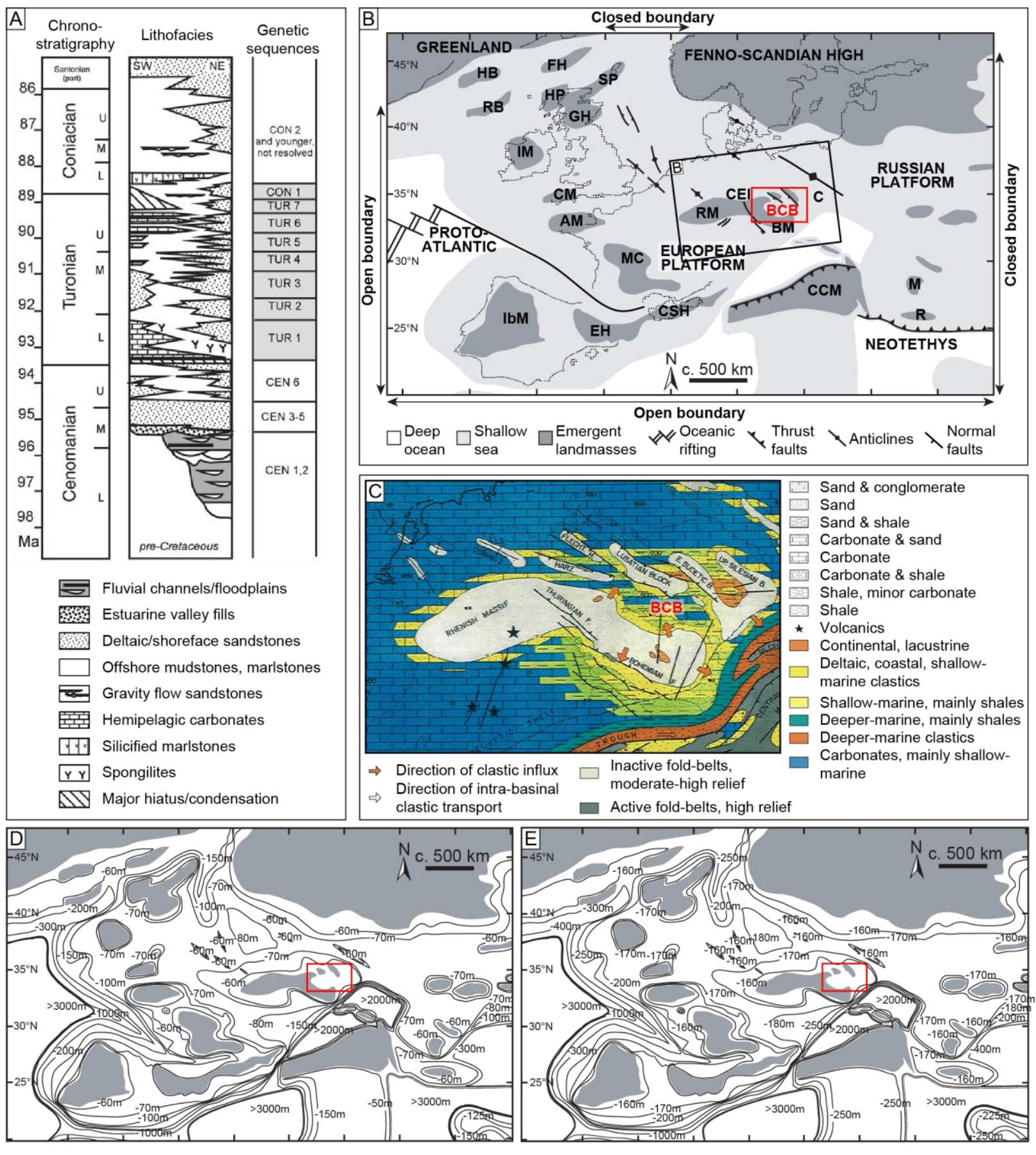

Fig. 19. (A) Stratigraphic chart showing the chronostratigraphy (modified after Ogg et al. (2004)), main lithofacies in the Lužice-Jizera Sub-basin (see Fig. 20A), genetic sequences recognized in this paper, and phases of basin evolution (after Uličný et al., 2009). (B) Regional 
palaeogeography for the Mid-Cretaceous European Epicontinental Sea (Ziegler, 1990; Dercourt et al., 2000; Golonka, 2004; Gil et al., 2006; Golonka et al., 2006; Golonka, 2007; Mitchell et al., 2010). The approximate outline of the Bohemian Cretaceous Basin (BCB) is shown in red. (c)

Gross depositional environmental map of central-western mainland Europe for the CenomanianTuronian (from Ziegler, 1990). (D-E Regional palaeobathymetries for palaeotidal modelling of the Mid-Cretaceous European Epicontinental Sea (MCEES), showing major contours for (D) minimum and (E) maximum depth scenarios (after Mitchell et al., 2010). Red box shows the position of the BCB. Abbreviations: $\mathrm{AM}=$ Amorican Massif; $\mathrm{BCB}=$ Bohemian Cretaceous Basin; $\mathrm{BM}=$ Bohemian Massif; $\mathrm{C}=$ Cracow Swell; $\mathrm{CM}=$ Cornubian Massif; $\mathrm{CCM}=$ Central Carpathian Massif; CSH = Corso-Sardinian High; EH = Ebro High; FH = Faeroe High; GH = Grampian High; HB = Hatton Bank; HP = Hebrides Platform; IbM = Iberian Massif; IM = Irish Massif; $\mathrm{M}=$ Moesia; $\mathrm{MC}=$ Massif Central; $\mathrm{SP}=$ Shetland Platform; $\mathrm{R}=$ Rodopes $; \mathrm{RB}=$ Rockall Bank; RM = Rhenish Massif.

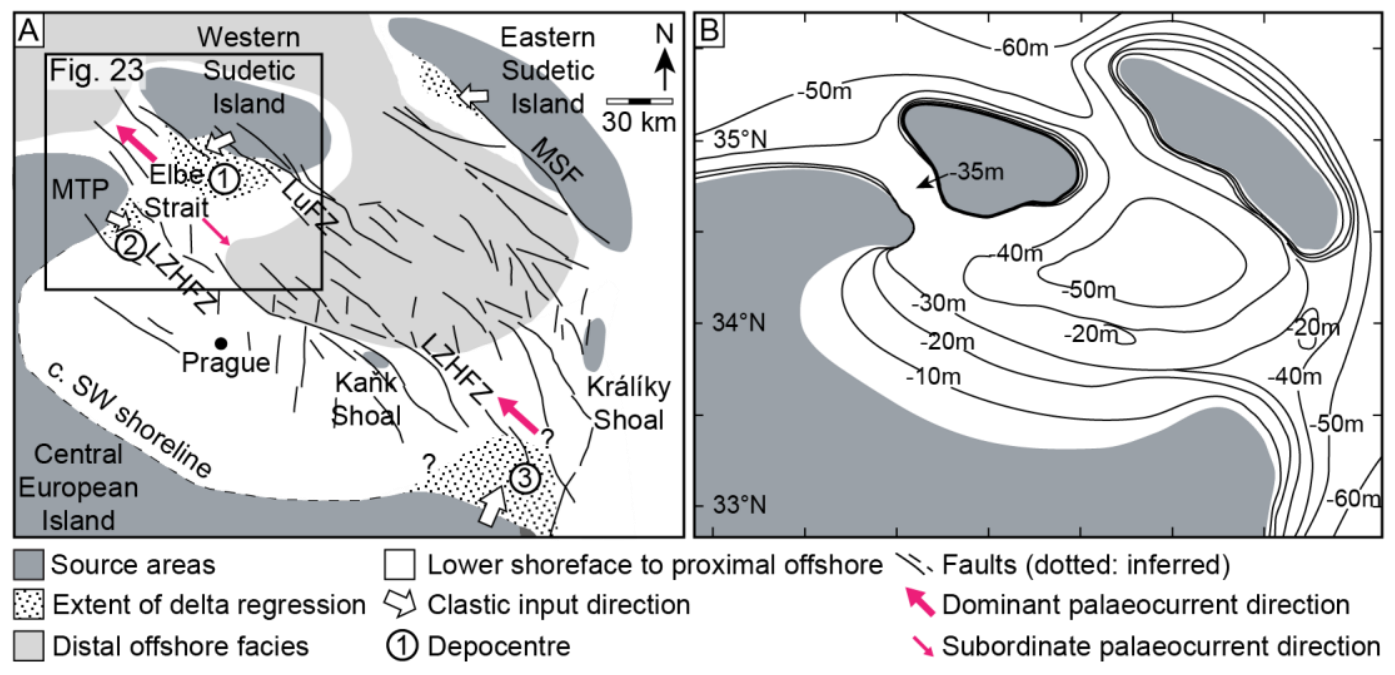

Fig. 20. Local scale palaeogeography (A) and palaeobathymetric (B) for the early Middle Turonian Bohemian Cretaceous Basin (onset of Collignoniceras woollgarii Zone). The extent of deltaic depocenters correspond to intermediate regression of the 'TUR 2' siliciclastic wedge (see Fi. 19A). Circled numbers (1) to (3) indicate the three main depocenters: (1) the Lužice-Jizera Sub-basin; (2) the Ohře Ramp; and (3) the Orlice-Žd'ár Sub-basin. MTP - Most-Teplice Palaeohigh; LuFZ - Lužice (Lausitz) Fault Zone; LZHFZ - Labe-Železné Hory Fault Zone. Modified after (Uličný et al., 2009). (B) Palaeobathymetric interpretation based on facies 
analysis of preserved outcrop and subsurface data (Uličný, 2001; Uličný et al., 2009). The heights of delta-front clinoforms suggests minimum depths of c. $35 \mathrm{~m}$ in the Elbe Strait, whereas a maximum depth of c. $50 \mathrm{~m}$ is estimated for the basin interior as inferred from trace fossil assemblages. After Mitchell et al. (2010).

\subsubsection{Model Setup}

Palaeotidal model simulations in the Mid-Cretaceous European Epicontinental Sea (MCEES) and $\mathrm{BCB}$ were forced with both astronomical and co-oscillating boundary tides with the four main tidal constituents $\left(\mathrm{M}_{2}, \mathrm{~S}_{2}, \mathrm{~K}_{1}\right.$ and $\left.\mathrm{O}_{1}\right)$. To reduce the impact of uncertain co-oscillating boundary tides in the $\mathrm{BCB}$, the regional-scale modelled domain covers much of the surrounding MCEES (Fig. 19). Open boundaries occur adjacent to the deep, expansive Proto-Atlantic and Neotethys oceans, whereas the boundaries adjacent to the extensive shallow seas of Arctic region and Russian Platform are unforced, because they are deemed unlikely to have had a significant tidal range (Fig. 19) (Wells et al., 2007a; Mitchell et al., 2010). The co-oscillating boundary tide is set in phase with the natural resonance at each respective boundary to give the maximum tidal potential in the seaway. This is determined by running a model with astronomical forcing, undertaking harmonic analysis of tidal amplitude time series collected at various points along the forced boundary, and interpolating the phase values at each point along the boundary so that the spacing between them matches the resolution of the mesh (Section 3.1.2) (Wells et al., 2007a; Mitchell et al., 2010).

Two sensitivity cases of tides in the MCEES were considered: (1) palaeobathymetric uncertainty was tested using two scenarios (Fig. 19D, E), and (2) resonance of different tidal constituents was tested by imposing different boundary tides weighted towards semi-diurnal $\left(\mathrm{M}_{2}, \mathrm{~S}_{2}\right.$; F-ratio 
${ }_{5}^{4} 1511$ of 0.1$)$ and diurnal components $\left(\mathrm{K}_{1}, \mathrm{O}_{1}\right.$; F-ratio of 10). All simulations included a spin-up period

71512 of five days and were run for a single spring-neap cycle lasting 14.8 days with a time step of 5

$1513 \mathrm{~min}$. These regional-scale tidal simulations were subsequently investigated on a more local scale

\subsubsection{Model Results}

On a regional scale, modelled tidal range in the interior of the MCEES is consistently microtidal to mesotidal (Fig. 21), which supports attenuation of the tidal wave by seabed friction and emergent landmasses as it propagated across the continental shelf (Shaw, 1964; Hallam, 1981;

Wells et al., 2005a; Mitchell et al., 2010). Tidal amplification forming macrotidal conditions is limited to embayments and straits. For example, macrotidal conditions are predicted on the southern margin of the Fenno-Scandian High (Fig. 21), but this only occurs with specific boundary and bathymetric conditions, consistent with the influence of tidal resonance (Fig. 7) (Wells et al., 2007a).

On a local scale within the $\mathrm{BCB}$, modelled tidal range also varies from microtidal to mesotidal, with elevated tidal ranges mainly restricted to the embayed western and southern margins (Fig. 21). Modelled values of maximum tidal bed shear stress are consistently elevated locally in palaeogeographic constrictions between islands, including the Elbe Strait (Fig. 22). Maximum bed shear stress values are slightly higher for the diurnal regime compared to the semidiurnal regime (Fig. 22B, D), and increase with increasing boundary tide magnitude (Fig. 22A-B). Water depth in the regional seaway also influences the predicted maximum bed shear stresses locally in the BCB: modelled values are higher in the minimum depth scenario for the semi- 
${ }_{5}^{4} 1534$ diurnal regime, but higher in the maximum depth scenario for the diurnal tidal regime (Fig. 22C,
D). This result suggests variations in resonance potential between boundary tide and

palaeobathymetry scenarios. However, this inference is not shown in the modelled tidal range

(Fig. 21) or explained by simple models of tidal resonance (e.g. Fig. 7), which indicate that

slower and shorter-wave semi-diurnal tides are typically closer to resonance in deeper domains

(Wells, 2008; Mitchell et al., 2010). Instead, these modelled bed shear stress patterns probably

result from relatively complex, constructive interaction between the different co-oscillating

boundary tides and the relative depths of the otherwise unchanged domains (Mitchell et al.,

2010).
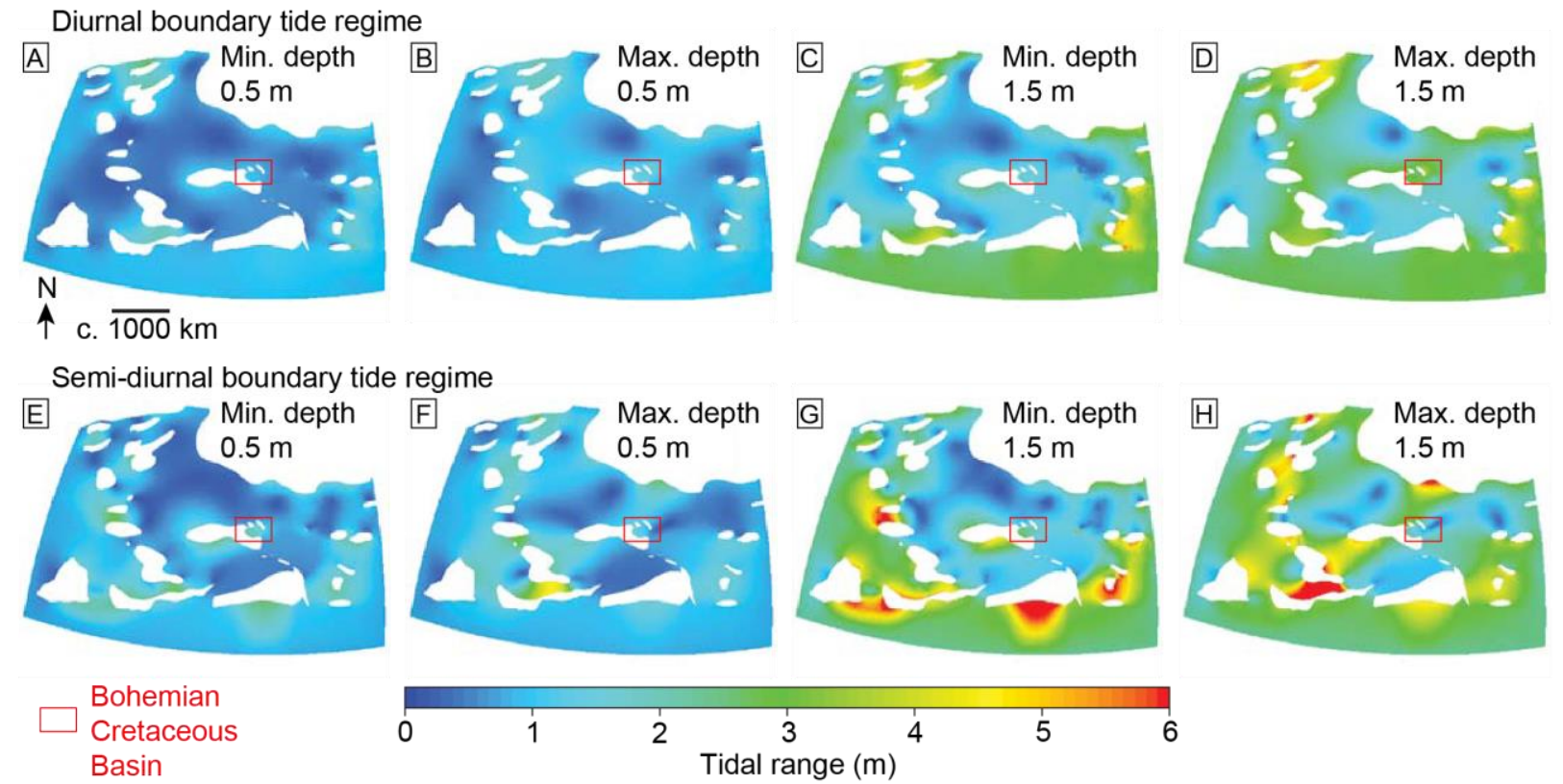

Tidal range $(m)$

Fig. 21. Modelled tidal range in the Mid-Cretaceous European Epicontinental Sea (MCEES) for eight sensitivity tests for co-oscillating diurnal (A-D) versus semi-diurnal $(\mathrm{E}-\mathrm{H})$ boundary tide regimes, $0.5 \mathrm{~m}(\mathrm{~A}, \mathrm{~B}, \mathrm{E}, \mathrm{F})$ versus $1.5 \mathrm{~m}(\mathrm{C}, \mathrm{D}, \mathrm{G}, \mathrm{H})$ boundary tidal range, and minimum (min.) $(\mathrm{A}, \mathrm{C}, \mathrm{E}, \mathrm{G})$ and maximum (max.) $(\mathrm{B}, \mathrm{D}, \mathrm{F}, \mathrm{H})$ regional palaeobathymetry in the MCEES. Fluidity consistently predicts a microtidal to mesotidal range in the interior of the seaway, 
suggesting attenuation of the boundary tidal waves across the continental shelf by bed friction and blocking by emergent landmasses. After Mitchell et al. (2010).

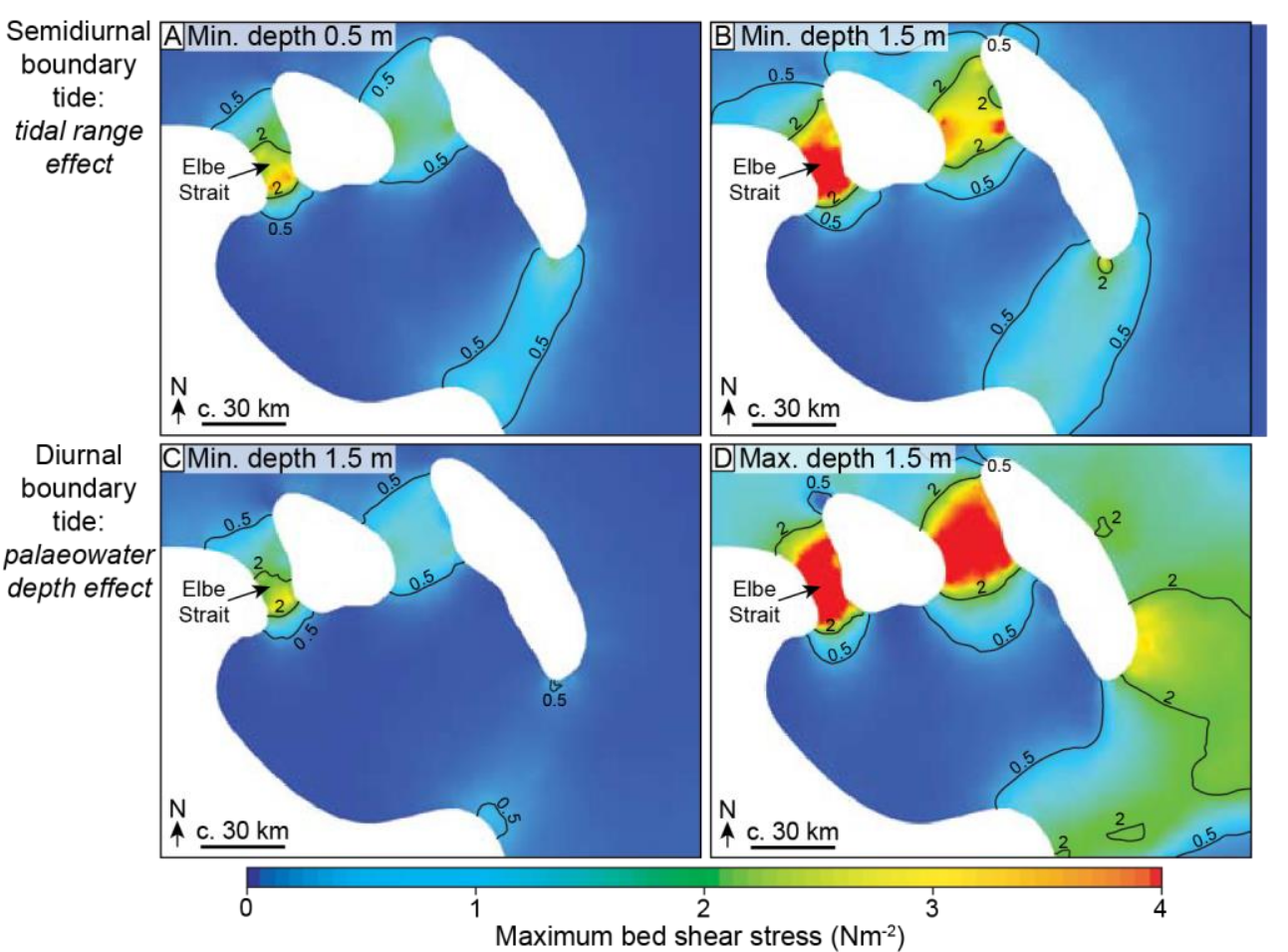

Fig. 22. Modeled maximum bed shear stress in the Bohemian Cretaceous Basin. The $0.5 \mathrm{Nm}^{-2}$ contours show the approximate minimum bed shear stress required for the formation of dunes in coarse sand (Fig. 10) (Harms et al., 1982), whereas $1.0 \mathrm{Nm}^{-2}$ is the approximate minimum bed shear stress required to form the observed scale of 3D dunes in coarse-grained sand in the Elbe Strait. Results for a $0.5 \mathrm{~m}$ (A) and $1.5 \mathrm{~m}$ (B) semi-diurnal boundary tide regime in the minimum (min.) depth regional palaeobathymetric domain (Fig. 19D) indicate that the modeled maximum bed shear stress is strongly dependent on the amplitude of the co-oscillating boundary tide.

Results for the $1.5 \mathrm{~m}$ diurnal boundary tide regime in (C) minimum and (D) maximum (max.) regional paleobathymetries indicate that the modeled maximum bed shear stress is strongly dependent on regional palaeobathymetry (Fig. 19D, E). After Mitchell et al. (2010).

\subsubsection{Comparison with the Rock Record}


At the regional scale, palaeotidal modelling demonstrates that it is plausible for boundary tides

from the Neotethys and Proto-Atlantic oceans to have propagated into the BCB and influenced water circulation here during the late Cretaceous, even allowing for uncertainty in the physiography and boundary tides of the European Mid-Cretaceous European Epicontinental Sea (Fig. 21). Modelled tidal range in the BCB is microtidal to mesotidal, due to attenuation and blocking of the boundary tidal waves as they propagated from the open ocean. These results are inconsistent with early interpretations of Turonian-to-early-Coniacian sandstones as large tidal bedforms (Jerzykiewicz and Wojewoda, 1986), which implies a macro-tidal regime (Stride, 1973; Stride, 1982). Modelled bed shear stress in the BCB is only sufficiently high to transport coarse sand where the shoreline is constricted along straits and embayments. These results support recent interpretations of a tide-influenced deltaic origin for the Turonian-to-earlyConiacian sandstones (Uličný, 2001; Uličný et al., 2009; Mitchell et al., 2010), in which fluviodeltaic sediment supplied laterally from the basin margins was reworked along the basin axis by strong, locally constricted tidal currents.

Within the Elbe Strait and northwestern Lužice-Jizera Sub-basin (Figs 20 \& 22), the early-tointermediate regressive part of the TUR 2 genetic sequence comprises an upward-coarsening, 20$35 \mathrm{~m}$-thick delta-front clinoform set that is dominated by coarse-grained sandstone. The dominant cross-bedding, including in gravelly sandstones to granule conglomerates, displays the following characteristics: (1) cross-sets $10 \mathrm{~cm}$ thick in the lower parts of the clinoform set and up to $30-40 \mathrm{~cm}$ thick in its upper parts; (2) tabular sets with abundant reactivation surfaces in the middle parts of the clinoform set; (3) silty, fine-grained to very fine-grained sandstone drapes occur locally on foresets; and (4) consistent WNW-directed palaeoflow in the lower to middle 
part and bi-directional trough cross-sets in the upper part of the clinoform set (Fig. 23) (Mitchell et al., 2010). These features indicate extensive reworking of the seabed by tidal currents with velocities in excess of 0.6 to $0.8 \mathrm{~ms}^{-1}$, equivalent to bed shear stresses in excess of c. $1.0 \mathrm{Nm}^{-2}$ (Fig. 10) (Harms et al., 1982; Southard and Boguchwal, 1990). All modelled scenarios with forced boundary conditions generated maximum bed shear stresses in excess of c. $2.0 \mathrm{Nm}^{-2}$ in the Elbe Strait (Fig. 22), which is capable of forming 3D dunes in coarse sand in up to c. $20 \mathrm{~m}$ water depths. Instantaneous bed shear stress vectors in all models show clear northwest- and southeast-directed bi-polarity in the Elbe Strait, in accordance with the flood and ebb of the tide, and consistent with recorded palaeocurrent directions (Mitchell et al., 2010). In contrast, maximum and mean bed shear stress vectors, which are time-averaged over each model run, lack a consistent pattern across the range of palaeogeographic sensitivity tests, and are instead highly sensitive to subtle changes in local palaeogeography (Mitchell et al., 2010). The range and variability of maximum and mean bed shear stress vectors in palaeogeographic sensitivity tests encompasses the dominant WNW-directed palaeocurrents from early-to-intermediate regression of the TUR 2 deltas in the Elbe Strait and northwestern Lužice-Jizera Sub-basin (Fig. 23; Uličný et al., 2009; Mitchell et al., 2010) and also the dominant southeast-directed palaeocurrents from late regression of the TUR 2 deltas in the central Lužice-Jizera Sub-basin (Uličný, 2001; Uličný et al., 2009), but there are insufficient data to constrain detailed local palaeogeography such that a dominant tidal palaeoflow direction can be confidently predicted from model output (Mitchell et al., 2010). This result demonstrates the limitation of paleotidal modelling for prediction at a higher resolution than available geological data can support. In addition, the outcrop-scale detail of the extensive current modification of delta-front clinoforms recorded by the sedimentary structures represents the time-integrated record of local tidal reworking during specific 
${ }_{5}^{4} 1612$ increments of delta progradation at specific locations, at higher spatial resolutions and potentially

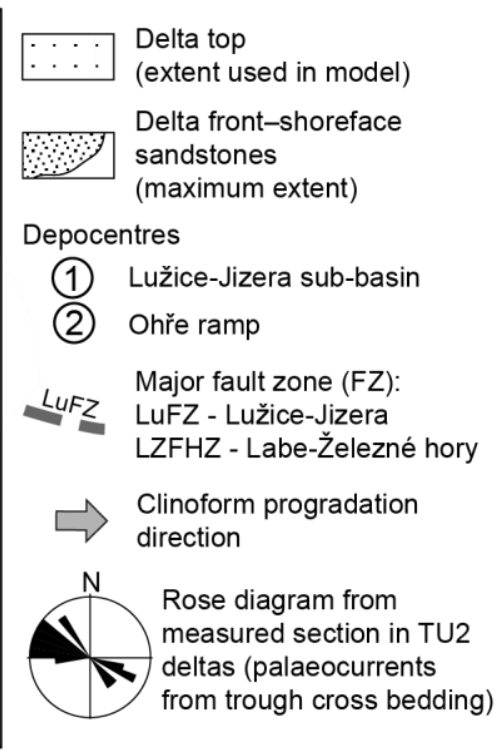

Fig. 23. Close-up view of the Elbe Strait area within the BCB (Fig. 20), showing the progradation extent and direction of sandy clinoforms (Voigt and Tröger, 1996; Uličný et al., 2009), and typical palaeocurrent rose diagrams for small-scale cross-sets in clinoforms recording intermediate regression of TUR 2 deltas. Circled numbers indicate (1) the Lužice-Jizera Subbasin; (2) the Ohře Ramp.

\section{DISCUSSION}

\subsection{Comparing Tidal Model and Rock Record Data}

The comparison of palaeotidal model to rock-record data involves the evaluation of different data types with contrasting dimensions and spatial-temporal scales (Fig. 24). This review has highlighted favourable comparisons between (1) palaeotidal model predictions of tidal range

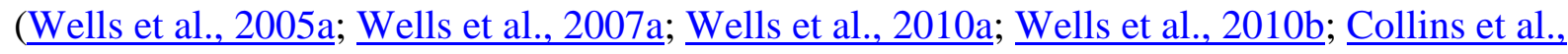


2017a; Collins et al., 2018a; Dean et al., 2019) and tidal bed shear stress (Mitchell et al., 2010;

Collins et al., 2017a; Collins et al., 2018a; Dean et al., 2019), with (2) the occurrence of tidallyinfluenced strata in the spatial and temporal domains of the modelled areas. However, the comparison of palaeotidal model results and the time-equivalent rock record is limited by several factors, in particular: (1) the spatial and temporal resolutions of the palaeogeographic data and related interpretations underpinning palaeotidal simulations (e.g. basin morphology, palaeobathymetry, gross depositional environments); and (2) the relationship between model outputs (e.g. palaeotidal range and bed shear stress) and interpretations of shoreline depositional processes and geomorphology based on rock-record observations. These issues are discussed below.

\subsubsection{Spatial and temporal resolution}

Palaeogeographic reconstructions underpinning palaeotidal simulations involve combining, simplifying and averaging multiple geological data types (e.g. sedimentological, biostratigraphic, seismic). Each data type contains uncertainties, especially the quality of age dating and geological interpretations (Markwick and Valdes, 2004). The resolution of geologic data used to underpin palaeogeographic maps is user defined and may vary depending on many factors, including available data and project aims. With increasing spatial extent, the minimum temporal resolution of the geologic data underpinning palaeogeographic maps generally coarsens, becomes more variable and forms a composite 'time-slice' rather than a single 'time plane' (Fig. 24A). 
Palaeotidal modelling provides areal (2D) and temporal data on three main parameters: (1) tidal

amplitude, (2) tidal range and (3) tidal bed shear stress (magnitude and direction of

instantaneous, mean and maximum values). In existing palaeotidal simulations, the maximum spatial resolution of computational meshes is on the order of $10 \mathrm{~km}$ and the temporal resolution is typically c. 2-5 Ma (Fig. 24B and C). However, the resolutions of model timeslices are often much broader and vary significantly on a case-by-case basis (Table 3). Rock record data is typically one-dimensional (e.g. stratigraphic logs, core and well data), occasionally twodimensional (e.g. outcrop panels, well-log correlation panels, seismic cross-sections and maps) and rarely three-dimensional (e.g. curvilinear and/or multiple outcrop panels, multiple and closely-spaced cores and wells, 3D seismic volumes) (Fig. 24B). Such data may lie at spatial resolutions much smaller than those of palaeotidal model meshes and model timeslices (e.g. individual stratigraphic logs, cores, wells and outcrop panels). It is possible to address the discrepancy in spatial scales between rock record data and palaeotidal models by combining rock record data from multiple locations, although such amalgamation of data should be carried out carefully so as not to obscure important local patterns (e.g. within the context of facies analysis carried out in the hierarchical stratigraphic framework of Vakarelov and Ainsworth (2013), as outlined below). For example, in paleotidal models of the Bohemian Cretaceous Basin (section 4.3), instantaneous bed shear stress provides a more reliable model output for comparison with rock-record paleocurrent data than values of mean and maximum bed shear stress collated over multiple tidal cycles (Mitchell et al., 2010).

Facies modelling aimed at deciphering the relative influence of tide, wave and fluvial processes involves analysis at a wide range of scales, from facies $(\mathrm{mm}-\mathrm{m})$ to systems tracts $(10-100 \mathrm{sm})$ 
(Van Wagoner et al., 1990; Walker and James, 1992; Posamentier and Walker, 2006; Hampson

et al., 2008). Vakarelov and Ainsworth (2013) have formalized this range for shoreline depositional systems into five stratigraphic hierarchical levels, each with different spatial resolutions and dimensions (Fig. 25): (1) facies (element), a component of a depositional element; (2) facies association (element set), a depositional environment; (3) parasequence (element complex assemblage), a facies model for part of a depositional system; (4) parasequence or parasequence set (element complex assemblage set), a depositional system model; and (5) a transgressive-regressive sequence or sequences, a depositional system evolution model. Comparing tidal model and rock-record data most often occurs at the facies, faciesassociation and parasequence levels, and possibly the parasequence-set level. This is due in part to data availability, but also because the variability in process dominance and preservation typically increases up the stratigraphic levels. For example, mixed energy depositional systems (parasequence set level and above) often comprise several depositional sub-environments (parasequence level) with varying degrees of tide, wave and/or fluvial influence (e.g. Ainsworth et al., 2011; Vakarelov and Ainsworth, 2013).

Deciphering the degree and extent of tidal influence is further complicated by incomplete stratigraphic preservation, including preservational bias. Tidal deposits may be preferentially preserved in a wide range of depositional environments and with variable significance. For example, such deposits are often widespread in coastal embayments, but geographically restricted elsewhere, such as in tidal inlets within larger barrier-lagoon systems. However, the maximum resolution of computational meshes used in palaeotidal modelling, especially for regional-scale studies, is significantly larger than the typical spatial dimensions of facies (mm- 
m) and facies associations (1-100s m) (Fig. 24B). Consequently, the comparison of model to

rock-record data may be biased by the preservation of tide-influenced deposits related to smallerscale spatial and temporal changes in tidal processes, especially for depositional systems with limited rock-record data and where data are selectively compared to model results. Hence, it is important to consider the potential for any preservational bias in the rock record regarding depositional processes. This could be highlighted by apparently unfavourable comparisons between model outputs and rock-record data.

For one- and two-dimensional stratigraphic data, interpretation of areal depositional morphology and up-scaling to the depositional system scale is typically guided by comparison to processbased interpretations of modern shoreline environments (Fig. 25B). Process-based classifications of modern shoreline systems are principally based on 2D areal morphology, ideally supported by data on hydrodynamics and sediment type (e.g. Coleman and Wright, 1975; Galloway, 1975; Hayes, 1979; Boyd et al., 1992; Hori and Saito, 2007; Ainsworth et al., 2011; Nyberg and Howell, 2016) and sedimentary facies characteristics (e.g. Ta et al., 2002a; Lambiase et al., 2003; Salahuddin and Lambiase, 2013; Fanget et al., 2014; Gugliotta et al., 2018). Hence, the 2D morphologies of end-member tide-, wave- and fluvial-dominated shorelines are embedded in ternary-process models of shoreline depositional systems (Ainsworth et al., 2011; Vakarelov and Ainsworth, 2013; Nyberg and Howell, 2016).

The morphological characteristics of tide-dominated shorelines typically display (1) complex and intricately branching networks of funnel-shaped (seaward-flaring) tidal channels, (2) elongate tidal bars (mainly subtidal but often with subaerial tops), which partly infill tidal channels and 
often extend seaward from channel mouths, and (3) more extensive ('land-fringing') intertidal

and supratidal areas with, depending principally on latitude, salt marsh or mangrove colonization (e.g. Ainsworth et al., 2011; Nyberg and Howell, 2016). Tide-dominated shorelines are more likely to be rugose to funnel shaped, and vice versa, whereas straighter shorelines are more likely to be wave-dominated, and vice versa (e.g. Fig. 2) (e.g. Ainsworth et al., 2011; Nyberg and Howell, 2016). These generalized relationships are useful but oversimplified, especially when they are an intrinsic component of algorithms for classifying modern shoreline process regime (Nyberg and Howell, 2016). For example, this relationship does not include quantifiable variations in tidal range, tidal prism and/or tidal bed shear with shoreline rugosity, or complex related feedbacks (e.g. D'Alpaos et al., 2010). A more rigorous, albeit ambitious, approach for determining the process regime along shorelines would be to compare measured values of tidal strength (bed shear stress), tidal range, wave strength, wave height and fluvial discharge (Harris et al., 2002) with those from numerical models, preferably including data assimilation.

The temporal resolution of rock-record data is highly dependent on the methodology of absolute dating and the degree of interpolation between control ages (Fig. 24C). For example, in the Cretaceous of the Western Interior Basin of North America, an estimated temporal resolution of c. $200 \mathrm{ka}$ has been achieved because high-resolution ammonite biozones have been calibrated to radiometric age dates (Obradovich, 1993) (Krystinik and DeJarnett, 1995). In contrast, a paucity of absolute age dates in the Miocene-Pliocene Baram Delta Province, and the vast majority of similar Tertiary delta provinces around the world, means biostratigraphic zones have a temporal resolution of $>1 \mathrm{Ma}$, based partly on correlation to adjacent basins with absolute ages (Sandal, 1996). 


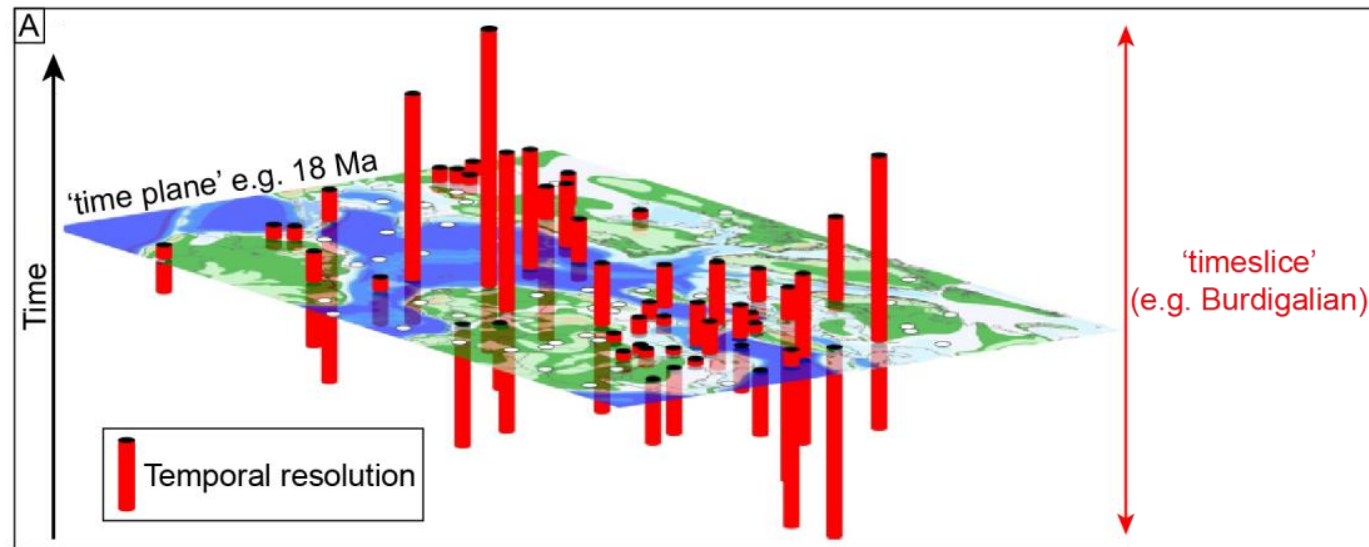

B Thickness/spatial resolution
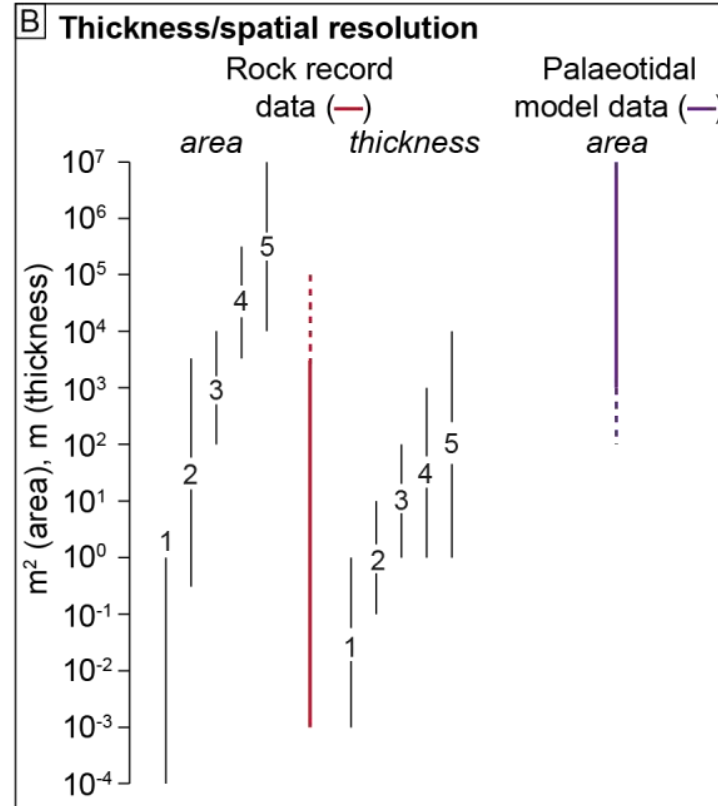
model data ( -$)$ C Temporal resolution

Fig. 24. Variable resolution of palaeogeographic, tidal modelling and rock record data. (A)

Illustration of the minimum temporal resolution of geologic data underpinning a

palaeogeographic 'timeslice' (after (after Markwick and Valdes, 2004). Each data point is assumed to represent a single observation of equivalent area, but the temporal resolution of each point is generally variable (red cylinders), due in part to imprecise or uncertain dating and correlation. Defining a timeslice instead of a time-plane maximizes data density. (B) 

81752 9 101753 11 121754 13 141755 ${ }^{15} 1756$ 16 171757 18 191758 20 211759
Thickness/spatial resolution of rock and model data. Rock data are differentiated by general versus exceptional dataset quality: in this context, exceptional being, for example, extensive and continuous outcrops or several tens of correlated cores and well logs. Numbers 1-5 represent the five hierarchical levels of rock data (or levels; e.g. Vakarelov and Ainsworth, 2013), showing varying areal and thickness scales (see full text and legend in the bottom panel). Tidal model data is area based. (C) Temporal resolution of rock and model data. The inset (bottom panel) shows (i) the five hierarchical levels of rock data (Vakarelov and Ainsworth, 2013); (ii) the most common methods of absolute rock dating include geomagnetic, isotopic, biostratigraphy (calibrated to absolute dates), and interpolation between dates; and (iii) data quality types. 
A Stratigraphic hierarchy and occurrence

. Element (E)/ Element set (ES)

Facies

2. Element complexes (EC) \& Element complex set (ECS) Facies association

3. Element complex assemblage (ECA) Parasequence

4. Element complex assemblage set (ECAS)

Parasequence/ parasequence set

5. Transgressiveregressive (T-R) sequence Depositional sequence
Spatial dimensionality

One dimensional Two dimensional (cross section)

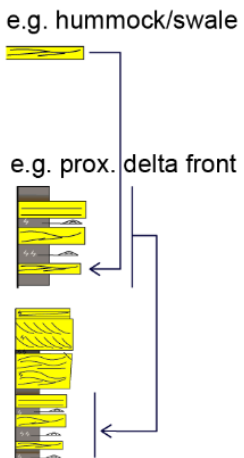

e.g. Wf-lobe EC
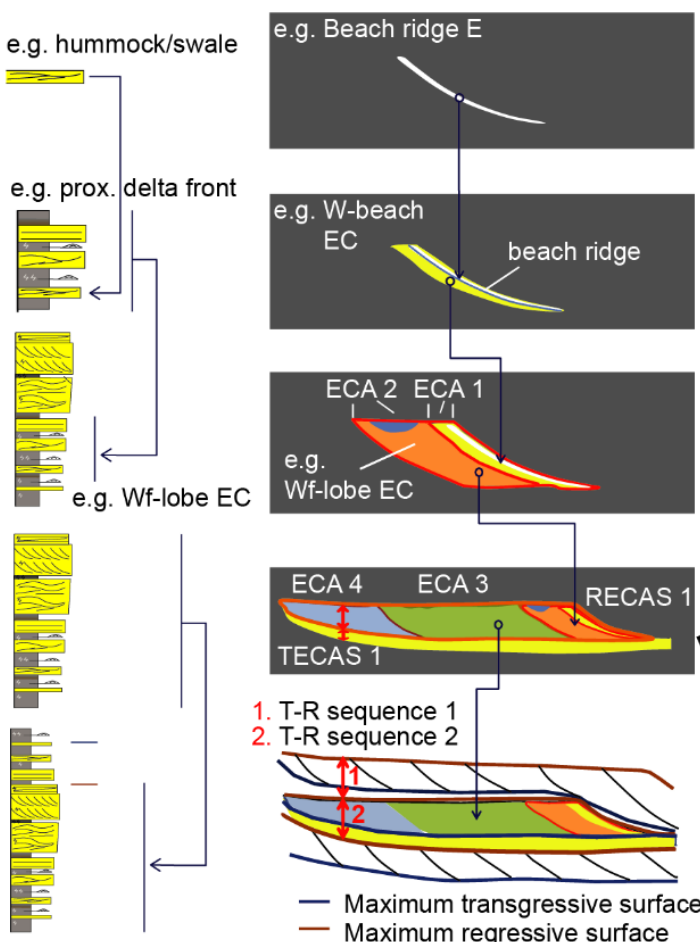

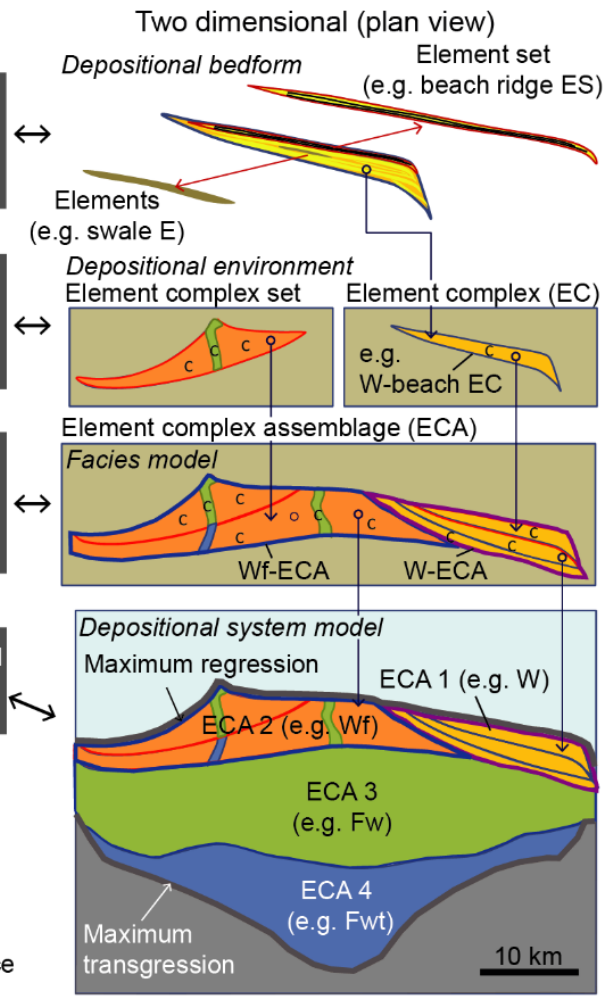

B 1. Classify data $\longrightarrow$
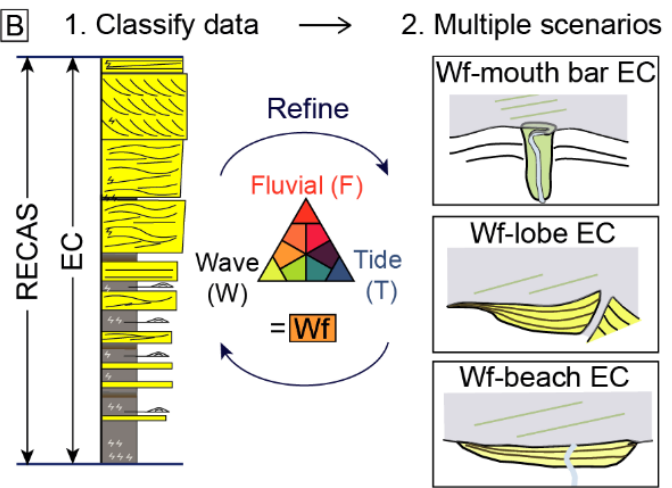

45

Fig. 25. Scale and methodology of process classification and depositional model reconstruction architectural classification based on one-dimensional thickness and two-dimensional crosssection and plan-view data. (B) Simplified workflow for determining process depositional model 


\subsubsection{Palaeotidal range and bed shear stress as proxies for depositional process regime}

It is common for sedimentological and stratigraphic analysis of tidal range in the rock record to be limited to differentiating microtidal, mesotidal and macrotidal regimes (Wells et al., 2005a). Methods proposed for more detailed interpretation of palaeotidal range suffer from several assumptions and limitations (Section 3.2). In the present-day, long-term tidal shoreline morphologies are related to the net exchange of water and sediment across the fluvial-to-marine transition zone, which is controlled by tidal range through its effect on the tidal prism (D'Alpaos et al., 2010). Furthermore, changes in tidal range and tidal prism impact the degree and physiography of tidal channelization, and vice versa (D'Alpaos et al., 2010). In mixed tide-wave systems, tidal range versus wave height is an approximate proxy for coastal energy regime and coastal morphology, especially for barrier islands (Hayes, 1979; FitzGerald, 1982; Davis and Hayes, 1984; Davis, 1994; FitzGerald et al., 1994; Anthony and Orford, 2002; McBride et al., 2013; Mulhern et al., 2017). However, coastal barrier morphologies in mixed tide-wave regimes are statistically indistinct from one another (Mulhern et al., 2017). Consequently, in ancient domains without quantitative information on both wave and tide processes, modelled palaeotidal range only indicates 'tidal potential'. Hence, coastlines with relatively high tidal ranges (i.e. high mesotidal to macrotidal) tend towards a 'higher potential' for tide dominance compared to coastlines with relatively low tidal ranges (microtidal to low mesotidal) and a 'lower tidal potential' (Wells et al., 2010a; Collins et al., 2018a). The precision of 'tidal potential' estimation is limited by the difficulties of quantifying tidal range from the rock record, and the complex relationships between tidal range, tidal dominance and shoreline morphology in the present-day. 
Tidal bed shear stress controls subaqueous sediment transport pathways and bedform distribution

(e.g. Stride, 1973; Pingree and Griffiths, 1979; Howarth, 1982; Hulscher et al., 1993; Ward et al.,

2015), but very few studies have compared tidal bed shear stress patterns to shoreline

morphology (e.g. Friedrichs, 1995; Coco et al., 2013). In models relating the tidal prism to equilibrium tidal channel physiography, the maximum bottom tidal shear stress equates to the critical threshold for incipient motion of sediment (D'Alpaos et al., 2010). At higher bed shear stresses, resultant bedform stability depends on the full range of flow conditions during transport and deposition (e.g. Baas et al., 2016). Consequently, modelled maximum palaeotidal bed shear stress, plotted as the equivalent transportable grain size based on critical bed shear stress thresholds, can be used as a proxy for tidal influence on sediment transport, bedform formation and shoreline morphology. This approximation is supported by favourable comparisons between model results and preserved sedimentary strata in earlier palaeotidal modelling case studies (Mitchell et al., 2010; Collins et al., 2017a; Collins et al., 2018a).

Bedform phase diagrams are predominantly based on laboratory experiments that use depthaveraged flow velocity or bed shear stress; narrow depth and grain size ranges; and the assumption that bedforms are in equilibrium with flow conditions (Figs. 10, 26A-B ) (Allen, 1968; Rubin and McCulloch, 1980; Allen, 1982b; Harms et al., 1982; Southard and Boguchwal, 1990; Baas et al., 2016). Bedform stability varies significantly with grain size and water depth, which has fundamental implications for comparison of modelled tidal bed shear stress and rock record data, and prediction of rock-record characteristics based on modelled tidal bed shear stress. For a given water depth, if the minimum available grain size during deposition ('rock grain size') is finer than the potential grain size transportable by maximum strength modelled 
${ }_{5}^{4} 1813$ tides ('model grain size'), the resultant bedform will be different from the equilibrium bedform

71814 (e.g. points V, X and Z; Fig. 26). For example, the resultant bedform may be in a different field 
50

B Current bedform stability (c. $20 \mathrm{~m}$ water depth) Model
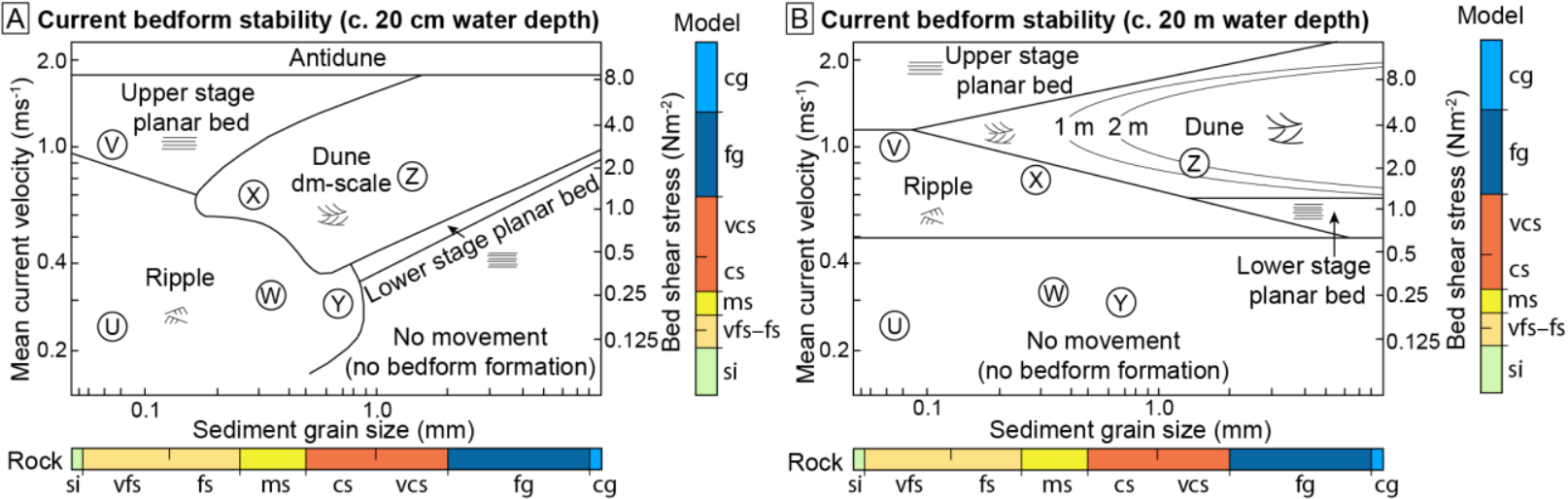

C Erosion vs. non-erosion (simplified Hjulström diagram*)

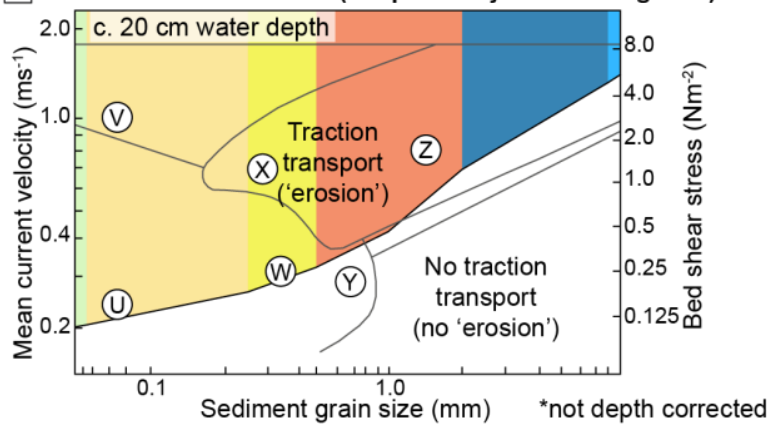

D.

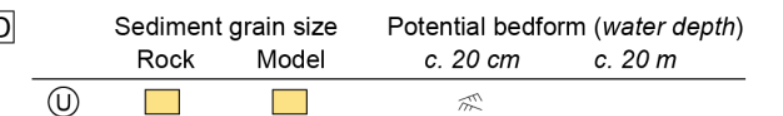

(v)

(W)

(X)

(Y)

(2)

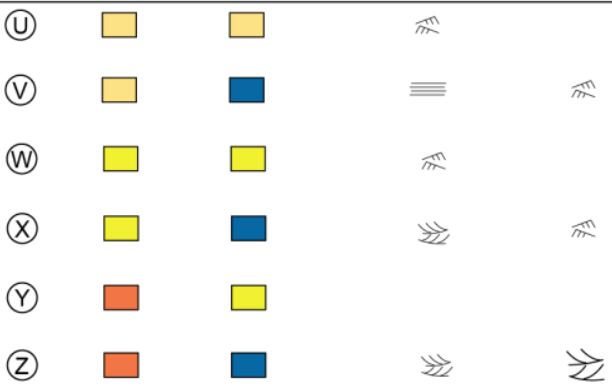

Fig. 26. The influence of current velocity, bed shear stress and sediment grain size on sediment traction, bedform stability and comparison of tidal model and rock-record data. (A) Bedform stability diagram, including bed shear stress, for unidirectional flow at c. $20 \mathrm{~cm}$ water depth (i.e. flume tank) (Harms et al., 1982; Mitchell et al., 2010). (B) Bedform stability diagram, including bed shear stress, for unidirectional flow at c. $20 \mathrm{~m}$ water depth (Rubin and McCulloch, 1980). (C) Simplified Hjulström diagram constructed by plotting sediment grain size to threshold bed shear stress for sediment entrainment (Berenbrock and Tranmer, 2008) (Hjulström, 1939). (D) Simplified table of various plotted positions $(\mathrm{U}-\mathrm{Z})$ on the bedform stability and simplified Hjulström diagrams $(\mathrm{A}-\mathrm{C})$ comparing the rock record grain size to modeled grain size and the depth dependence of potential bedform formation (or non-formation).

\subsection{Controls on Tidal Processes and Sedimentation}

\subsubsection{Basin Physiography}


The influence of regional-scale (100-1000s km) basin physiography on shoreline tides depends

on the overall physiographic setting and regional-scale physiography of the basin, and the influence of shelf width on tidal resonance.

Shoreline systems can be broadly subdivided into two physiographic categories. First, openocean systems directly face a typically large-scale $(1000 \mathrm{~s} \mathrm{~km})$ open ocean (e.g. modern Niger delta shelf facing the southern Atlantic Ocean). Second, partly enclosed systems face seas or oceans that are partly landlocked, have variable connectivity to an open ocean (s), and display a large variation in size (100s to 1000s km) (e.g. present-day North Sea). The case studies presented earlier (Section 4) are all partly enclosed systems.

For present-day open-ocean systems, there is no obvious systematic, qualitative relationship between tidal amplitude and latitude (e.g. Fig. 2). This is due to strong modification of tidal circulation by rotational, funnelling, shoaling and resonance effects, especially in shallower bathymetric areas and shoreline constrictions (Allen, 1997; Wells, 2008; Dalrymple and Padman, 2015). These effects are complicated and difficult to predict. However, numerical tidal modelling, such as shown here with Fluidity, integrates these effects and provides more rigorous and quantitative predictions of tidal potential in modern and ancient, open-ocean systems.

For partly enclosed systems, the foremost control on shoreline tides is the balance between the amount of tidal energy entering and exiting the basin (Fig. 27). Tidal potential is highest when tidal inflow exceeds outflow. Tidal inflow is mainly controlled by the angle between the basin entrance and tidal flow in the adjacent open ocean, which principally depends on latitude and Coriolis rotation (Leeder, 2011), and the physiography of the basin entrance (Fig. 27A). Tidal 
${ }_{5}^{4} 1869$ inflow will be relatively high where open-ocean tides flow directly towards the basin entrance, 


\section{Regional-scale (100-1000s km) controls on tides (partly-enclosed basins)}

A Inflow physiography

Wide and deep

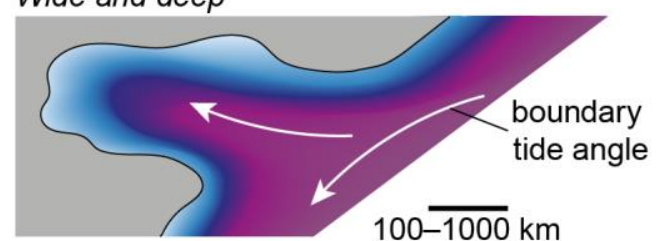

Unobstructed

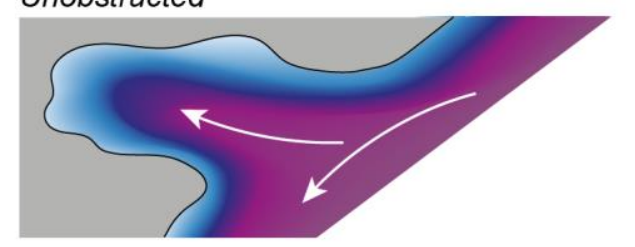

Narrow and shallow

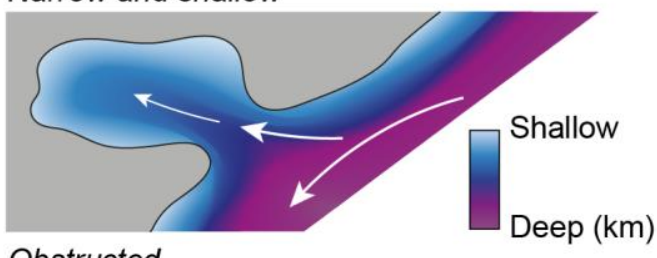

Obstructed

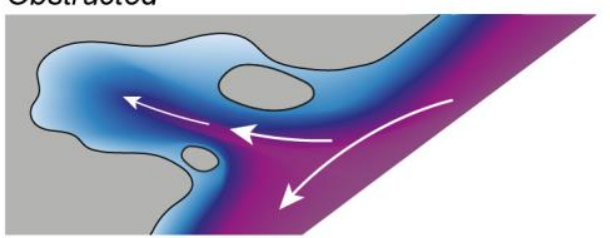

B Outflow configuration

Blind gulf

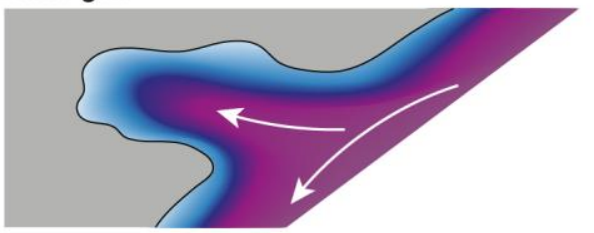

Open gulf or strait

Multiple outflows
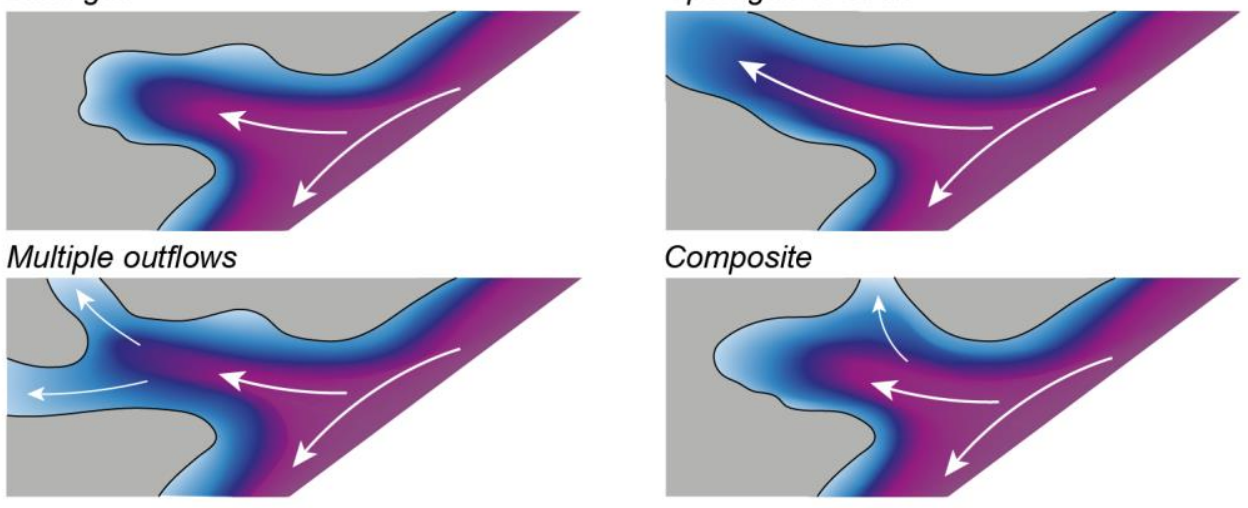

Composite

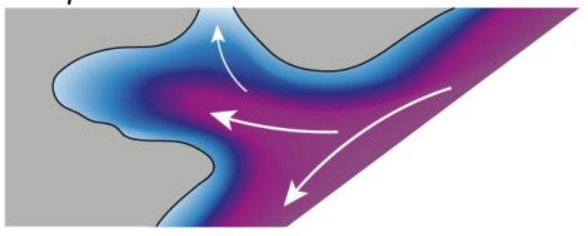

Fig. 27. Regional-scale (100-1000s km) basin physiographic controls on tidal energy potential in inflow physiography on tidal inflow includes the width, depth and degree of obstruction of the main tidal inflow position to the basin. Larger, thicker arrows indicate higher inflow. (B) The control of outflow physiography on tidal outflow includes the number, width, depth and degree of obstruction of main tidal outflow positions and their configuration with respect to the main tidal inflow positions and boundary tide pathway.

\subsubsection{Tidal resonance on continental shelves}

Funnelling, shoaling and resonance effects across continental shelves are important secondary controls on tides. Analysis of modern tides suggests that the relative importance of tides 
${ }_{5}^{4} 1900$ increases with shelf width perpendicular to the coastline (e.g. Redfield, 1958; $\underline{\text { Cram, 1979; }}$

Howarth, 1982; Ainsworth et al., 2011). For example, analysis of 110 shoreline profiles

surrounding Australia and 9 other global systems indicates that most wave-dominated systems

have shelf widths perpendicular to the coastline of $<75 \mathrm{~km}$, whereas most tide-dominated systems have shelf widths $>75 \mathrm{~km}$ (Heap et al., 2004; Ainsworth et al., 2011). This is principally due to an increase in tidal resonance (Howarth, 1982; Ainsworth et al., 2011) and shoaling effects, assuming sea-bed friction is ignored (Allen, 1997). Consequently, a $75 \mathrm{~km}$ shelf width is an approximate cut-off for high tidal resonance potential $(>75 \mathrm{~km})$ in predictive shoreline process models (Fig. 7).

However, it is important to consider potential variability in this relationship for ancient domains related to resonance theory, shelf width and regional controls. Simple resonance theory for straight, laterally extensive shelves with a boundary tide perpendicular to the shelf (Section 2.3) indicates that maximum tidal resonance occurs when shelf width is one-quarter the tidal wavelength (and for widths 3/4, 5/4, etc.) (Fig. 3A and 28A-B). This is equivalent to several hundred kilometres for the dominant $\mathrm{M}_{2}$ and diurnal $\mathrm{K}_{1}$ tides (Fig. 3B) (e.g. Proudman, 1953; Howarth, 1982). In general, an increase in resonance potential with shelf width below onequarter tidal wavelength is partly offset by an increase in frictional drag (Fig. 28A-B). However, the relationship between shelf width, tidal range and tidal dominance (Nyberg and Howell, 2016) varies globally due to changes in the following controls (Fig. 28C): (1) the relative amplitude of semi-diurnal to diurnal tidal constituents, which have significantly different wavelengths (e.g. Kowalik and Luick, 2013); (2) the geometry of continental shelves; (3) the incidence angle of tides and tidal flow patterns, which partly relates to latitude and Coriolis rotation; and (4) 
${ }_{5}^{4} 1923$ frictional effects, which may exceed tidal amplification across wide shelves and seaways.

91925 sea level changes related to global eustasy, isostatic adjustment, and tectonic subsidence and

Local-scale (10-100s $\mathrm{km})$ controls on continental shelf tidal resonance A Straight shelf (simple resonance scenario)

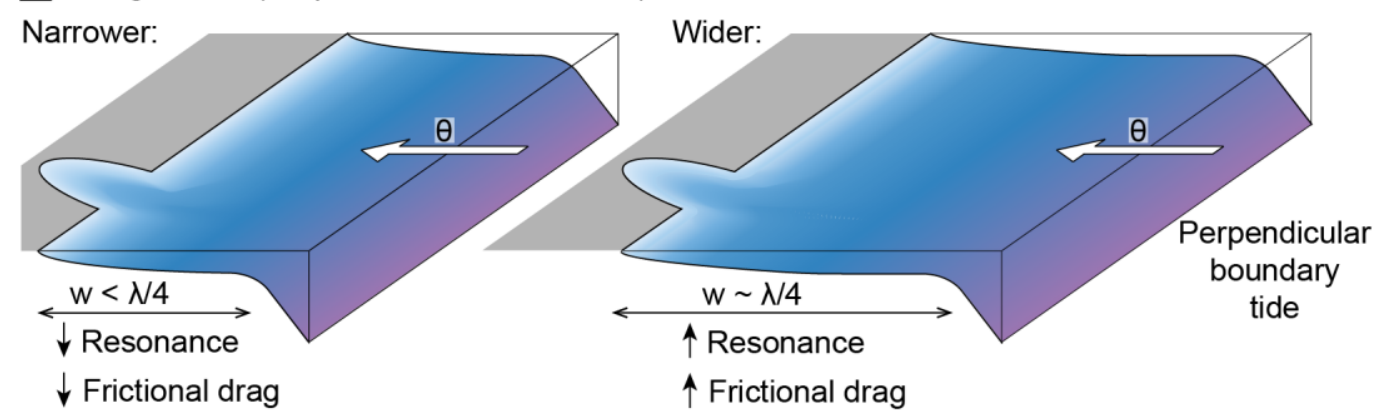

B Curvilinear shelf (real-world resonance scenario)
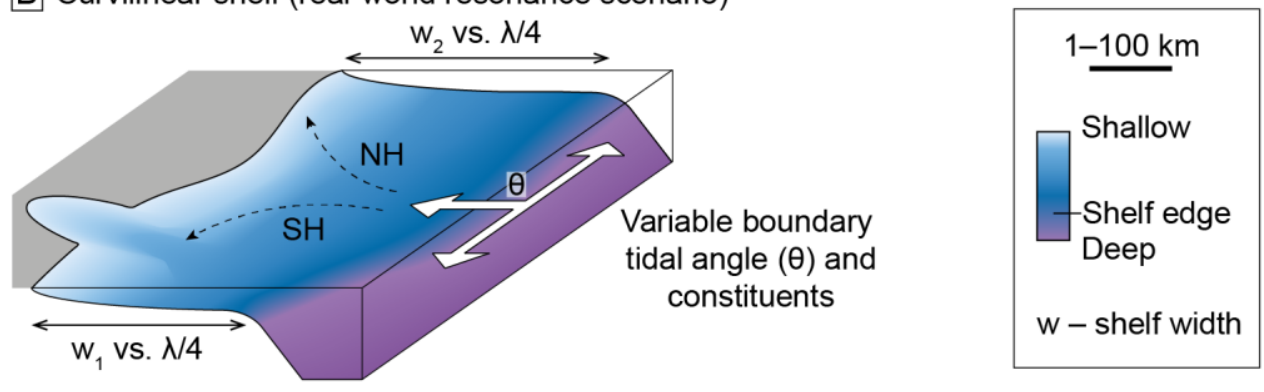
Fig. 28. Local-scale (10-100s km) controls on continental shelf tidal resonance. (A-B) Simple resonance scenario for a straight shelf, perpendicular boundary tide and uniform shelf width (w), where maximum tidal resonance occurs when shelf width is one-quarter the tidal wavelength $(\lambda)$ (cf. Fig. 3) (after Howarth, 1982). (C) A more realistic resonance scenario for a curvilinear shelf, variable angle $(\theta)$ and dominant tidal constituent of the boundary tide, Coriolis rotation and variable shelf width $\left(\mathrm{w}_{1}\right.$ versus $\left.\mathrm{w}_{2}\right)$ compared to one-quarter the tidal wavelength. $\mathrm{NH}=$ Northern Hemisphere. $\mathrm{SH}=$ Southern Hemisphere.

\subsubsection{Shoreline Geometry}

Funnelling, shoaling and resonance effects in shoreline embayments are tertiary controls on tides (e.g. Slingerland, 1986; Dalrymple, 1992; Wells et al., 2007a; Ainsworth et al., 2011). Protection from wave processes along embayed shorelines also increases the relative strength of tide and fluvial processes (e.g. Ainsworth et al., 2008; Ainsworth et al., 2011; Plink-Björklund, 2012). Consequently, increased shoreline rugosity is used as a proxy for increased tidal influence and decreased wave influence in predictive shoreline process models (Fig. 2) (Ainsworth et al., 2008; Ainsworth et al., 2011). However, as outlined below, modern tides and palaeotidal modelling suggest that tidal amplification in coastal embayments is variable and depends on the balance between tidal amplification, due to funnelling, shoaling and/or resonance effects, and frictional damping.

Modern river-linked embayments (e.g. estuaries and interdistributary bays) are typically

classified as either hyposynchronous, where tidal range decreases landward because frictional damping exceeds tidal amplification, or hypersynchronous, where tidal range initially increases landward due tidal amplification exceeding frictional damping, before decreasing to the tidal limit (e.g. Godin, 1999; Dalrymple and Choi, 2007). The degree of tidal amplification versus 
frictional damping can vary between adjacent embayments and show complex patterns within embayments, as seen along eastern North America and western India (Fig. 29). Differentiating between ancient hypersynchronous and hyposynchronous embayments is difficult and requires interpretation of the process balance and extent of turbidity maximum zone in the fluvial-tomarine transition zone (e.g. Gugliotta et al., 2016a). However, palaeotidal modelling can reveal spatial and temporal variations in tidal processes within ancient embayments. For example, as the entrance to the palaeo-Gulf of Thailand became wider and deeper during the Miocene, greater tidal inflow and reduced frictional damping shifted the tidal maxima landward (Fig. 12).

The relative strength of tidal amplification versus frictional damping depends on several factors:

(1) The geometry and bathymetry of the embayment, especially its sinuosity (e.g. $\underline{\text { Slingerland, 1986; }}$ Allen, 1997). Frictional effects will be higher in more sinuous and rapidly shallowing embayments compared to straighter, gently shallowing embayments (Fig. 29, 30A).

(2) The geometry and bathymetry of the embayment entrance impacts inflow and outflow of tidal energy. A narrower, shallower and obstructed entrance increases dissipation and reflection of tidal energy (e.g. Chesapeake Bay), whereas a wider, deeper and unobstructed entrance permits greater tidal inflow (e.g. Bay of Fundy) (Figs. 29, 30C).

(3) The angle between the embayment axis and incoming tide influences tidal inflow. Tidal inflow increases and frictional effects decrease when the incoming tide is more parallel to the embayment axis (Fig. 30B).

(4) Embayment physiography and the dominant tidal constituent control the resonance potential of embayment tides (Section 2.3). 
Hyposynchronous embayments are more likely if the tidal inflow and resonance potential are 9 low and frictional drag potential is high (Fig. 29A). Hypersynchronous embayments are more 
Fig. 29. Tides in shoreline embayments. (A) A hyposynchronous system in which frictional damping exceeds amplification of tides due to funneling, shoaling and resonance effect, resulting in a seaward to landward decrease in tidal range and tidal current speed. (B) A hypersynchronous system in which tidal amplification exceeds friction, causing a seaward-to-landward increase in tidal range and current speed, before friction causes tidal range and current speed to decrease to zero at the tidal limit (after Dalrymple and Choi, 2007). (C, D) Modeled tidal range from FES 2012 for north-east America (C) and north-west India (D) illustrating the varying relationship between tidal range and position within adjacent embayments: (1) hyposynchronous Chesapeake Bay; (2) moderately hypersynchronous Long Island Sound; (3) strongly hypersynchronous Bay of Fundy; (4) strongly hypersynchronous St. Lawrence River mouth; (5) strongly hyposynchronous Gulf of Khambhat; and (6) complex hyposynchronous and hypersynchronous Gulf of Kutch.

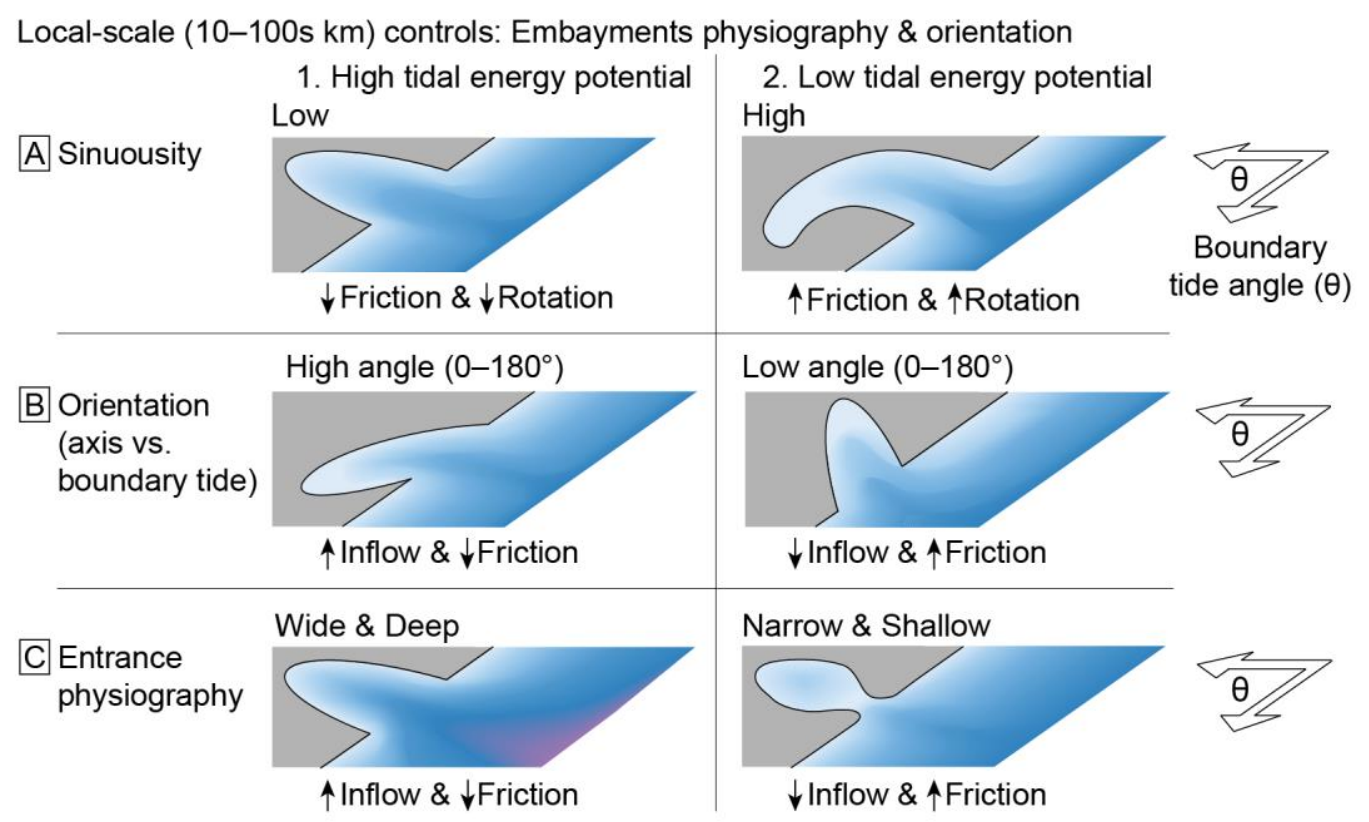

Fig. 30. Physiographic controls on tides in shoreline embayments. A schematic matrix includes the influence of (A) shoreline geometry, for example, sinuosity and rugosity, (B) the relative orientation of the embayment axis and incoming tide, and $(\mathrm{C})$ the physiography of the embayment entrance, on (1) high versus (2) low tidal energy potential within the embayment. Note this matrix excludes the influence of wave or fluvial processes. 
92013 The original process-based, decision tree hierarchy for predicting shoreline-shelf systems uses a 11

\subsection{Modified decision tree for prediction of shoreline processes} sequential procedure (Ainsworth et al., 2011) (Fig. 7A) of assessing tidal resonance potential, wave versus fluvial effectiveness, low versus high A/S, shoreline morphology (relative degree of rugosity), and coastal process dominance. Our evaluation proposes replacing this procedure with one that uses two decision trees, reflecting low and high wave energy potential, respectively. The procedure for using each decision tree comprises the following hierarchy (compare Figs. 7A and 31): (1) wave energy potential, (2) tidal energy potential, (3) shelf tidal resonance potential, (4) fluvial potential, and (5) shoreline geometry. The justification for this revision is outlined below, based on the preceding review of tidal theory, the physiographic influence on modern tides and present-day shoreline process regimes (e.g. Nyberg and Howell, 2016), and the physiographic controls on tides highlighted by palaeotidal modelling studies and the corresponding stratigraphic record with preserved tidal influence.

The dominance of wave-dominated process regimes along present-day depositional shorelines (Fig. 6) (Nyberg and Howell, 2016) supports this being the first-order control on shoreline process regime (hierarchical query \#1 in Fig. 31). In modern systems, the height and strength of wind-generated surface waves are primarily controlled by the speed, duration and fetch of the wind (e.g. Allen, 1997). Wave dominance also depends on the frequency of larger-magnitude storms. In ancient domains, determining the speed and duration of wind, and the effect on wave processes, would ideally require sophisticated analyses integrating palaeogeographic reconstructions and numerical climate and wave modelling. More generally, predicting wave 
energy potential along ancient shorelines relies on larger scale palaeogeographic reconstructions.

If a system is open to a large water body or ocean, wave fetch and consequently wave potential would be relatively high. Any protection that restricts access to oceanic waves will lower wave potential (e.g. Ainsworth et al., 2011). Protection from ocean waves may be tectonic (e.g. emergent fault blocks, tectonically controlled seaways) or depositional (e.g. rugose coastal morphology, depositional headland, barrier islands, asymmetric deltas).

The tidal energy potential of a basin (hierarchical query \#2 in Fig. 31) is dependent on whether the basin is adjacent to an open ocean or partly enclosed. For open-ocean basins, tidal energy potential is assumed to be relatively high, given the relative lack of dissipation effects compared to partly enclosed systems. However, the absolute amount and distribution of tidal energy in an open ocean basin is related to its size, geometry and latitudinal distribution. For partly-enclosed systems, the tidal energy potential depends on the balance of tidal inflow versus outflow, which is controlled by: (1) the relative orientation of the partly enclosed basin and incoming tide; (2) the physiography of the basin entrance; and (3) the number, position and physiography of outflow positions (Fig. 27). Tidal resonance may also be important in partly enclosed systems of certain depth and geometry (Fig. 4).

Shelf resonance potential (hierarchical query \#3 in Fig. 31) is related to shelf width and the dominant tidal constituent of the incoming tide (Figs. 3, 28). Analysis of modern shoreline processes suggest a cut-off of c. $75 \mathrm{~km}$ between mainly tide-dominated $(>75 \mathrm{~km})$ and wavedominated $(<75 \mathrm{~km}$ ) systems (Ainsworth et al., 2011). However, tides only dominate on c. 50\% of depositional shorelines associated with shelf widths of $>75 \mathrm{~km}$, with $47 \%$ being wave 
dominated (Fig. 6) (Nyberg and Howell, 2016). This suggests that a more representative shelf width threshold may be even higher, which would be closer to the theoretical shelf width for resonance of the typically dominant semi-diurnal $\mathrm{M}_{2}$ or diurnal $\mathrm{K}_{1}$ tidal components (Figs. 3, 28). However, without a more accurate and globally applicable cut-off value, the $75 \mathrm{~km}$ cut-off is retained in the proposed process prediction decision tree (Fig. 31). Nevertheless, this should be critically assessed on a case-by-case basis, considering other local geological factors.

Assessing fluvial potential (hierarchical query \#4 in Fig. 31) relies on (1) measured or inferred drainage area, hinterland relief and rock types (e.g. Milliman and Syvitski, 1992; Syvitski and Milliman, 2007\{Sømme, 2009\#1471); (2) paleoclimate and its effects on water and sediment discharge (ㅂovius, 1998; Syvitski et al., 2003; Milliman and Farnsworth, 2011), and/or (3) observational evidence of fluvial influence in the rock record (Bhattacharya and Walker, 1992; MacEachern and Bann, 2008; Ainsworth et al., 2016). In general, large drainage basins would have higher fluvial potential than smaller drainage basins. However, an exception may be river systems with short, steep drainage basins subject to high rainfall storms, which often preserve river-influenced shoreline deposits (e.g. Bhattacharya and MacEachern, 2009; Collins et al., 2017b). The overwhelming dominance of wave- and tide-dominated shoreline morphologies along present-day coastlines indicates effective reworking of riverine sediment by marine processes (Fig. 6). However, sedimentary dynamics and deposition may still be dominated by river floods, even in deltas with lobate-to-cuspate geometries typical of wave dominance (Rodriguez et al., 2000; Fielding et al., 2005; Gani and Bhattacharya, 2007). Consequently, for ancient shoreline systems, any information suggesting a closely adjacent river system may 
suggest relatively high potential for river-influenced sedimentary dynamics and deposition (Fig. 31).

Shoreline geometry (hierarchical query \#5 in Fig. 31) mainly relates to the degree of rugosity, recognizing that tides are commonly amplified in many present-day embayments and along embayed shorelines. However, embayments along present-day shorelines and those in palaeotidal simulations are not exclusively tide dominated (e.g. Figs. 6, 9, 31; cf. Fig. 2). The balance of tidal amplification and frictional damping depends on the physiography and orientation of the embayment (Fig. 30). Tides may also undergo excess frictional damping compared to amplification, due to funnelling, shoaling and/or resonance). Embayed shorelines are also inevitably more protected from direct wave processes. However, wave processes may still be dominant along the back of moderately embayed shorelines, especially adjacent to embayment mouths with access to open ocean waves (Fig. 31). In fluvially linked embayments, river processes may dominate over tides and waves (e.g. Dalrymple and Choi, 2007). Therefore, shoreline geometry can have a variable potential influence on depositional processes.

The A/S ratio of a shoreline-self system is a widely-used theoretical concept that links tectonics, eustatic sea-level change and sediment supply (Muto and Steel, 1997), and features prominently in the original process-based decision tree of Ainsworth et al. (2011) (hierarchical query \#3 in Fig. 7A). A/S ratio has been removed from our revised predictive decision tree (Fig. 30) due to limitations with the concept. For example, identifying relatively 'high' and 'low' A/S ratio relies on generalized relationships between $\mathrm{A} / \mathrm{S}$ ratio and sequence stratigraphic systems tracts, which in turn relies on extensive datasets for sequence stratigraphic and/or shoreline trajectory analysis 
(Ainsworth et al., 2008). Quantification of 'high' versus 'low' A/S ratios also relies upon sufficient well log, core and/or outcrop data to calculate the thickness of a sedimentary unit to approximate accommodation and the sand-to-shale ratio and approximate coarse sediment supply rate (Ainsworth, 2003; Ainsworth, 2005; Ainsworth et al., 2008). However, even if sufficient data are available, the exact ratios for 'high' and 'low' A/S regimes are yet to be determined. The reliance on available data and interpretations seriously limits the applicability of the A/S ratio for predicting shoreline processes in ancient systems with limited data. Furthermore, the A/S ratio is a subordinate control on tides compared to the tidal energy potential of a basin, shelf tidal resonance potential and shoreline geometry. Process changes relating to A/S ratio only apply for moderately- to highly-embayed shorelines and relate to inferred changes to shoreline geometry (Section 1.2) (Ainsworth et al., 2011).

In contrast to the three-tier process prediction scheme used in the original process-based decision tree of $\{$ Ainsworth, $2011 \# 345 @$ @author-year\} (Figs. 5A, 7A), we propose a two-tier process prediction scheme that is limited to the primary and secondary processes (Figs. 5B, 31). Analysis of modern shorelines suggests the thresholds for process classification in a three-tier scheme are ambiguous (e.g. Fig. 6) (Nyberg and Howell, 2016). While a three-tier scheme has the superficial appearance of greater precision (Figs. 5A, 7) (Ainsworth et al., 2011), it requires definitive process classification and quantitative analysis of sedimentary structures that is rarely, if ever, available. At present, the range of mixed process sedimentary structures and variability between different modern and ancient depositional systems are not yet fully documented or understood, leading to ambiguities in the process interpretations of several sedimentary structures (Section 2.2) (e.g. Ainsworth et al., 2011; Dashtgard et al., 2012; Legler et al., 2014; Gugliotta et al., 
${ }_{5}^{4} 2125$ 2016a; Gugliotta et al., 2016b; Jablonski and Dalrymple, 2016; Rossi and Steel, 2016). A more

72126 holistic framework for interpreting mixed process deposition and preservation would also

8

${ }_{10}^{9} 2127$ include the effect of grain size availability on sedimentary facies characteristics and preservation, 
1. Wave energy potential potential

4. Fluvial potential

5. Shoreline geometry

\section{Shoreline-shelf} process regime

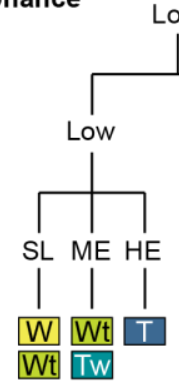

B High wave energy potential:

1. Wave energy potential

Fig. 31. Proposed revision to decision trees for predicting shoreline process dominance (cf. Error! Reference source not found.7A) (after Ainsworth et al., 2011) for systems with (A) low wave energy potential, and (B) high wave energy. The two decision trees each include five hierarchical queries: (1) wave energy potential of the basin; (2) tidal energy potential of the 
basin; (3) shelf tidal resonance potential; (4) fluvial potential; and (5) shoreline geometry. Key to color coding is shown in the inset. Shoreline geometry abbreviations: SL-straight/lobate; MEmoderately embayed; HE-highly embayed

\section{CONCLUSIONS}

Palaeotidal modelling investigations, integrating comparisons to the equivalent stratigraphic record, indicate that numerical tidal modelling can demonstrate the potential sensitivity of tides to physiographic uncertainty and potential influence of tidal processes along ancient shorelines. Present-day global tidal measurements, and the spatio-temporal sensitivity of modelled ancient tides, indicate the following physiographic controls on tidal processes: (1) regional physiography (100-1000 km-scale) controls tidal inflow versus outflow in partly-enclosed oceans and seas; (2) shelf physiography (10-100 km-scale), latitude, and the boundary tide orientation and dominant tidal constituent control shelf tidal resonance; and (3) embayment physiography (1-10 km-scale), especially at the entrance, and the relative orientation of the incoming tide, control tidal amplification (funnelling and shoaling) versus frictional effects in shoreline embayments.

However, validation of palaeotidal simulations using the rock record is limited by the difficulty in determining ancient tidal range from stratigraphic data and variability in the relationship between bed shear stress, grain size and bedforms (and primary sedimentary structures).

The overwhelming dominance of waves along modern shorelines indicates existing predictive models for shoreline process regime overstate the role of tides relative to waves. This supports the proposed revised model for classifying and predicting modern and ancient shoreline process regimes, capturing the relative influence of fluvial, tide and wave processes. Our revised model includes the first-order control of wave fetch and associated meteorological conditions, and 
${ }_{5}^{4} 2162$ improved understanding of physiographic controls on tides from numerical tidal modelling. 
${ }_{49}^{48} 2182$ Supplementary Fig. 1. Global map of modern tidal bed shear stress calculated from (A) tidal 50

512183 modelling using Fluidity and (B) tidal velocity magnitude from FES2014. C) Difference in 52

${ }_{54}^{53} 2184$ maximum tidal bed shear stress between (A) Fluidity and (B) FES2014; Blue indicates FES2014 55 562185 has a higher maximum tidal bed shear stress. 


\section{REFERENCES CITED}

Abieda, H.S., Harith, Z.Z.T. and Rahman, A.H.A., 2005. Depositional controls on petrophysical properties and reservoir characteristics of Middle Miocene Miri Formation sandstones, Sarawak. Bulletin of the Geological Society of Malaysia, 5: 63-75.

Ainsworth, R.B., 2003. Sequence stratigraphic-based analysis of depositional connectivity using 3-D reservoir modelling techniques, University of Liverpool, UK, $310 \mathrm{pp}$.

Ainsworth, R.B., 2005. Sequence stratigraphic-based analysis of reservoir connectivity: influence of depositional architecture - a case study from a marginal marine depositional setting. Petroleum Geoscience, 11: 257-276.

Ainsworth, R.B., Flint, S.S. and Howell, J.A., 2008. Predicting coastal depositional style: influence of basin morphology and accommodation to sediment supply ratio within a sequence stratigraphic framework. In: G.J. Hampson, R.J. Steel, P.M. Burgess and R.W. Dalrymple (Editors), Recent Advances in Models of Siliclastic Shallow-Marine Stratigraphy. SEPM Special Publication, pp. 237-263.

Ainsworth, R.B., Hasiotis, S.T., Amos, K.J., Krapf, C.B., Payenberg, T.H., Sandstrom, M.L., Vakarelov, B.K. and Lang, S.C., 2012. Tidal signatures in an intracratonic playa lake. Geology, 40: 607-610.

Ainsworth, R.B., Vakarelov, B.K., Lee, C., MacEachern, J.A., Montgomery, A.E., Ricci, L.P. and Dashtgard, S.E., 2015. Architecture and evolution of a regressive, tide-influenced marginal marine succession, Drumheller, Alberta, Canada. Journal of Sedimentary Research, 85: 596-625.

Ainsworth, R.B., Vakarelov, B.K., MacEachern, J.A., Nanson, R.A., Lane, T.I., Rarity, F. and Dashtgard, S.E., 2016. Process-Driven Architectural Variability In Mouth-Bar Deposits: A Case Study From A Mixed-Process Mouth-Bar Complex, Drumheller, Alberta, Canada. Journal of Sedimentary Research, 86: 512-541.

Ainsworth, R.B., Vakarelov, B.K. and Nanson, R.A., 2011. Dynamic spatial and temporal prediction of changes in depositional processes on clastic shorelines: Toward improved subsurface uncertainty reduction and management. AAPG Bulletin, 95: 267-297.

Allen, G.P. and Chambers, J.L.C., 1998. Sedimentation in the modern and Miocene Mahakam Delta. Indonesian Petroleum Association, Jakarta, 236 pp.

Allen, G.P. and Posamentier, H.W., 1993. Sequence stratigraphy and facies model of an incised valley fill; the Gironde Estuary, France. Journal of Sedimentary Research, 63: 378-391.

Allen, J., 1981a. Lower Cretaceous tides revealed by cross-bedding with mud drapes. Nature, 289: 579.

Allen, J.R.L., 1968. Current Ripples: their relation to patterns of water and sediment motion. North Holland, Amsterdam, 433 pp.

Allen, J.R.L., 1981b. Palaeotidal speeds and ranges estimated from cross-bedding sets with mud drapes. Nature, 293: 394-396.

Allen, J.R.L., 1982a. Mud drapes in sand-wave deposits: a physical model with application to the Folkestone Beds (early Cretaceous, southeast England). Philosophical Transactions of the Royal Society of London A: Mathematical, Physical and Engineering Sciences, 306: 291345. 
Allen, J.R.L., 1982b. Sedimentary structures, their character and physical basis, 1. Elsevier, Amsterdam, 592 pp. Sedimentology, 31: 63-81.

Allen, P.A., 1997. Earth Surface Processes. Blackwell Scientific Publications, Oxford, U.K., 404 pp.

Amir Hassan, M.H., Johnson, H.D., Allison, P.A. and Abdullah, W.H., 2013. Sedimentology and stratigraphic development of the upper Nyalau Formation (Early Miocene), Sarawak, Malaysia: A mixed wave- and tide-influenced coastal system. Journal of Asian Earth Sciences, 76: 301-311.

Amir Hassan, M.H., Johnson, H.D., Allison, P.A. and Abdullah, W.H., 2016. Sedimentology and stratigraphic architecture of a Miocene retrogradational, tide-dominated delta system: Balingian Province, offshore Sarawak, Malaysia. In: G.J. Hampson, A.D. Reynolds, B. Kostic and M.R. Wells (Editors), Sedimentology of Paralic Reservoirs: Recent Advances. Special Publications. Geological Society of London, London, UK, pp. SP444.12, 36 p.

Anderton, R., 1976. Tidal-shelf sedimentation: an example from the Scottish Dalradian. Sedimentology, 23: 429-458.

Anderton, R., 1985. Clastic facies models and facies analysis. In: P.J. Brenchley and B.P.J. Williams (Editors), Sedimentology Recent Developments and Applied Aspects. Special Publication 18. Geological Society, London, pp. 31-47.

Androsov, A., Kagan, B., Romanenkov, D. and Voltzinger, N., 2002. Numerical modelling of barotropic tidal dynamics in the strait of Messina. Advances in Water Resources, 25: 401-415.

Anthony, E.J. and Orford, J.D., 2002. Between wave-and tide-dominated coasts: the middle ground revisited. Journal of Coastal Research, 36: 8-15.

Anthony, E.J., Oyédé, L.M. and Lang, J., 2002. Sedimentation in a fluvially infilling, barrierbound estuary on a wave- dominated, microtidal coast: the Ouémé River estuary, Benin, west Africa. Sedimentology, 49: 1095-1112.

Archer, A.W., 1995. Modeling of cyclic tidal rhythmites based on a range of diurnal to semidiurnal tidal-station data. Marine Geology, 123: 1-10.

Archer, A.W., Kvale, E.P. and Johnson, H.R., 1991. Analysis of modern equatorial tidal periodicities as a test of information encoded in ancient tidal rhythmites. In: S. DG, R. GE, Z. BA and R. RA (Editors), Clastic Tidal Sedimentology. Memoir of the Canadian Society of Petroleum Geologists, pp. 189-196.

Arnott, R.W.C. and Southard, J.B., 1990. Exploratory flow-duct experiments on combined-flow bed configurations, and some implications for interpreting storm-event stratification. Journal of Sedimentary Research, 60: 211-219.

Avdis, A., Candy, A.S., Hill, J., Kramer, S.C. and Piggott, M.D., 2018. Efficient unstructured mesh generation for marine renewable energy applications. Renewable Energy, 116: 842856.

Baas, J.H., Best, J.L. and Peakall, J., 2016. Predicting bedforms and primary current stratification in cohesive mixtures of mud and sand. Geological Society of London Journal, 173: 1245.

Banks, N., 1973. Tide- dominated offshore sedimentation, Lower Cambrian, north Norway. Sedimentology, 20: 213-228. 
Barckhausen, U., Engels, M., Franke, D., Ladage, S. and Pubellier, M., 2014. Evolution of the South China Sea: Revised ages for breakup and seafloor spreading. Marine and Petroleum Geology, 58: 599-611.

Barckhausen, U. and Roeser, H.A., 2004. Seafloor spreading anomalies in the South China Sea revisited. In: P. Clift, W. Kuhnt, P. Wang and D. Hayes (Editors), Continent-Ocean Interactions Within East Asian Marginal Seas. Geophysical Monograph Series. AGU, Washington, DC, pp. 121-125.

Basilici, G., de Luca, P.H.V. and Poiré, D.G., 2012. Hummocky cross-stratification-like structures and combined-flow ripples in the Punta Negra Formation (Lower-Middle Devonian, Argentine Precordillera): A turbiditic deep-water or storm-dominated prodelta inner-shelf system? Sedimentary Geology, 267-268: 73-92.

Belderson, R., Johnson, M., Kenyon, N. and Stride, A., 1982. Bedforms. In: A.H. Stride (Editor), Offshore tidal sands: processes and deposit. Chapman and Hall, pp. 27-57.

Berenbrock, C. and Tranmer, A.W., 2008. Simulation of flow, sediment transport, and sediment mobility of the lower Coeur d'Alene River, Idaho. 2328-0328, U.S. Geological Survey, Reston, Virginia.

Bhattacharya, J.P. and Giosan, L., 2003. Wave-influenced deltas: Geomorphological implications for facies reconstruction. Sedimentology, 50: 187-210.

Bhattacharya, J.P. and MacEachern, J.A., 2009. Hyperpycnal Rivers and Prodeltaic Shelves in the Cretaceous Seaway of North America. Journal of Sedimentary Research, 79: 184-209.

Bhattacharya, J.P. and Walker, R.G., 1992. Deltas. In: R.G. Walker and N.P. James (Editors), Facies Models: Response to Sea-Level Change. Geological Association of Canada, St. John's, NL, pp. 157-177.

Boersma, J. and Terwindt, J., 1981. Neap-spring tide sequences of intertidal shoal deposits in a mesotidal estuary. Sedimentology, 28: 151-170.

Boersma, J.R., 1969. Internal structure of some tidal mega-ripples on a shoal in the Westerschelde estuary, the Netherlands: report of a preliminary investigation. Geologie en Mijnbouw (Netherlands Journal of Geosciences), 48: 409-414.

Boyd, R., Dalrymple, R.W. and Zaitlin, B.A., 1992. Classification of clastic coastal depositional environments. Sedimentary Geology, 80: 139-150.

Boyd, R., Dalrymple, R.W. and Zaitlin, B.A., 2006. Estuarine and incised-valley facies models. In: H.W. Posamentier, Walker, R.G. (Editor), Facies Models Revisited. SEPM Special Publication, pp. 171-234.

Briais, A., Patriat, P. and Tapponnier, P., 1993. Updated interpretation of magnetic anomalies and seafloor spreading stages in the south China Sea: Implications for the Tertiary tectonics of Southeast Asia. Journal of Geophysical Research, 98: 6299-6328.

Bridges, P.H., 1982. Ancient offshore tidal deposits. In: A.H. Stride (Editor), Offshore Tidal Sands, Processes and Deposits. Chapman \& Hall, London, UK, pp. 172-192.

Buatois, L.A., Santiago, N., Herrera, M., Plink-Björklund, P., Steel, R.J., Espin, M. and Parra, K., 2012. Sedimentological and ichnological signatures of changes in wave, river and tidal influence along a Neogene tropical deltaic shoreline. Sedimentology, 59: 15681612.

Burgess, P.M. and Hovius, N., 1998. Rates of delta progradation during highstands: consequences for timing of deposition in deep-marine systems. Journal of the Geological Society, 155: 217-222. 
Caldwell, P., Merrfield, M. and Thompson, P., 2015. Sea level measured by tide gauges from global oceans-the Joint Archive for Sea Level holdings (NCEI Accession 0019568), Version 5.5. National Oceanographic Data Center, NOAA. Dataset. 2015.

Carrère, L., Lyard, F., Cancet, M. and Guillot, A., 2015. FES 2014, a new tidal model on the global ocean with enhanced accuracy in shallow seas and in the Arctic regio, EGU General Assembly 2015, Vienna, Austria.

Casey, R., 1961. The stratigraphical palaeontology of the Lower Greensand. Palaeontology, 3: 487-621.

Čech, S. and Uličný, D., 1996. Bohemian-Saxonian Cretaceous Basin-Overview. In: T. Voigt (Editor), Stratigraphy and Facies of the Bohemian-Saxonian Cretaceous Basin. Field Trip Guide, Fifth International Cretaceous Symposium. Freiberg University of Mining and Technology, Freiberg, pp. 1-8.

Chamberlain, E.L., Törnqvist, T.E., Shen, Z., Mauz, B. and Wallinga, J., 2018. Anatomy of Mississippi Delta growth and its implications for coastal restoration. Science advances, 4: eaar4740.

Charusiri, P. and Pum-Im, S., 2009. Cenozoic Tectonic Evolution of Major Sedimentary Basins in Central, Northern, and the Gulf of Thailand. Bulletin of Earth Science Technology, 2: 40-61.

Chen, S., Steel, R.J., Dixon, J.F. and Osman, A., 2014. Facies and architecture of a tidedominated segment of the Late Pliocene Orinoco Delta (Morne L'Enfer Formation) SW Trinidad. Marine and Petroleum Geology, 57: 208-232.

Choi, K.S., Dalrymple, R.W., Chun, S.S. and Kim, S.-P., 2004. Sedimentology of modern, inclined heterolithic stratification (IHS) in the macrotidal Han River delta, Korea. Journal of Sedimentary Research, 74: 677-689.

Chung, N.H., Quang, C.D. and Tham, N.T., 2015. A Review of Tertiary Palynomorph Assemblage in Cuu Long Basin: Case Study of Palynomorphs in Miocene-Oligocene Sediments. International Journal of Sciences: Basic and Applied Research, 24: 103-111.

Clifton, H.E., 1983. Discrimination between subtidal and intertidal facies in Pleistocene deposits, Willapa Bay, Washington. Journal of Sedimentary Research, 53: 353-369.

Coates, L. and MacEachern, J.A., 2007. The ichnological signatures of river-and wavedominated delta complexes: differentiating deltaic and non-deltaic shallow marine successions, Lower Cretaceous Viking Formation and Upper Cretaceous Dunvegan Formation, west-central Alberta. In: J.A. MacEachern, K.L. Bann, M.K. Gingras and S.G. Pemberton (Editors), Applied Ichnology. Short Course Notes 52. SEPM, Tulsa, Oklahoma, pp. 227-254.

Coco, G., Zhou, Z., van Maanen, B., Olabarrieta, M., Tinoco, R. and Townend, I., 2013. Morphodynamics of tidal networks: Advances and challenges. Marine Geology, 346: 116.

Coleman, J.M. and Wright, L.D., 1975. Modern river deltas: variability of processes and sand bodies. In: M.L. Broussard (Editor), Deltas: Models for Exploration. Houston Geological Society, Houston, Texas, pp. 99-149.

Collins, D.S., Avdis, A., Allison, P.A., Johnson, H.D., Hill, J., Piggott, M.D., Amir Hassan, M.H. and Damit, A.R., 2018a. Controls on Tidal Sedimentation and Preservation: Insights from Numerical Tidal Modelling in the Late Oligocene-Miocene South China Sea, Southeast Asia. Sedimentology, Accepted; In Press. 
Collins, D.S., Avdis, A., Allison, P.A., Johnson, H.D., Hill, J., Piggott, M.D., Hassan, M.H.A. and Damit, A.R., 2017a. Tidal dynamics and mangrove carbon sequestration during the Oligo-Miocene in the South China Sea. Nature Communications, 8: 15698.

Collins, D.S., Johnson, H.D., Allison, P.A. and Damit, A.R., 2018b. Mixed Process, HumidTropical, Shoreline-Shelf Deposition: Middle Miocene-Modern Baram Delta Province, North-West Borneo. Journal of Sedimentary Research, 88: 399-430.

Collins, D.S., Johnson, H.D., Allison, P.A., Guilpain, P. and Damit, A.R., 2017b. Coupled 'storm-flood' depositional model: Application to the Miocene-Modern Baram Delta Province, north-west Borneo. Sedimentology, 64: 1203-1235.

Collins, D.S., Johnson, H.D. and Baldwin, C.T., 2020. Architecture and preservation in the fluvial to marine transition zone of a mixed- process humid- tropical delta: Middle Miocene Lambir Formation, Baram Delta Province, north- west Borneo. Sedimentology, 67: 1-46.

Collinson, J. and Mountney, N.P., 2019. Sedimentary Structures. Dunedin Academic Press Ltd, $320 \mathrm{pp}$.

Colombera, L. and Mountney, N.P., 2020a. Accommodation and sediment- supply controls on clastic parasequences: A meta- analysis. Sedimentology, 67: 1667-1709.

Colombera, L. and Mountney, N.P., 2020b. On the geological significance of clastic parasequences. Earth-Science Reviews, 201: 103062.

Colombera, L., Mountney, N.P. and McCaffrey, W.D., 2012. A relational database for the digitization of fluvial architectureconcepts and example applications. Petroleum Geoscience, 18: 129-140.

Comblen, R., Legrand, S., Deleersnijder, E. and Legat, V., 2009. A finite element method for solving the shallow water equations on the sphere. Ocean Modelling, 28: 12-23.

Cooper, J., 2001. Geomorphological variability among microtidal estuaries from the wavedominated South African coast. Geomorphology, 40: 99-122.

Cooper, J.A.G., 1993. Sedimentation in a river dominated estuary. Sedimentology, 40: 979-1017.

Cram, J.M., 1979. The influence of continental shelf width on tidal range: paleoceanographic implications. The Journal of Geology, 87: 441-447.

Cummins, P.F. and Thupaki, P., 2018. A note on evaluating model tidal currents against observations. Continental Shelf Research, 152: 35-37.

Cushman-Roisin, B., 1994. Introduction to Geophysical Fluid Dynamics. Prentice Hall, New Jersey, $320 \mathrm{pp}$.

Cushman-Roisin, B. and Beckers, J.-M., 2011. Introduction to Geophysical Fluid Dynamics: Physical and Numerical Aspects. International Geophysics Series. Academic Press, Cambridge, MA, 875 pp.

D'Alpaos, A., Lanzoni, S., Marani, M. and Rinaldo, A., 2010. On the tidal prism-channel area relations. Journal of Geophysical Research: Earth Surface, 115: F01003.

d'Anglejan, B. and Brisebois, M., 1978. Recent sediments of the St. Lawrence middle estuary. Journal of Sedimentary Research, 48: 951-964.

Dalrymple, R.W., 1992. Tidal depositional systems. In: R.G. Walker and N.P. James (Editors), Facies Models: Response to Sea Level Change. Geological Association of Canada, St. John's, Newfoundland, pp. 195-218.

Dalrymple, R.W., 2006. Incised valleys in time and space: an introduction to the volume and an examination of the controls on valley formation and filling. In: R.W. Dalrymple, D.A. 

Publication, pp. 5-12.

Dalrymple, R.W., 2010. Interpreting sedimentary successions: facies, facies analysis and facies models. In: N.P. James and R.W. Dalrymple (Editors), Facies Models 4. Geological Association of Canada, pp. 3-18.

Dalrymple, R.W., Baker, E.K., Harris, P.T. and Hughes, M.G., 2003. Sedimentology and stratigraphy of a tide-dominated, foreland-basin delta (Fly River, Papua New Guinea). In: F.H. Sidi, D. Nummedal, P. Imbert, H. Darman and H.W. Posamentier (Editors), Tropical Deltas of Southeast Asia-Sedimentology, Stratigraphy, and Petroleum Geology. SEPM Spec. Publ., pp. 147-173.

Dalrymple, R.W. and Choi, K., 2007. Morphologic and facies trends through the fluvial-marine transition in tide-dominated depositional systems: A schematic framework for environmental and sequence-stratigraphic interpretation. Earth-Science Reviews, 81: 135-174.

Dalrymple, R.W., Knight, R., Zaitlin, B.A. and Middleton, G.V., 1990. Dynamics and facies model of a macrotidal sand- bar complex, Cobequid Bay-Salmon River Estuary (Bay of Fundy). Sedimentology, 37: 577-612.

Dalrymple, R.W., Kurcinka, C.E., Jablonski, B.V.J., Ichaso, A.A. and Mackay, D.A., 2015. Deciphering the relative importance of fluvial and tidal processes in the fluvial-marine transition. In: P.J. Ashworth, J.L. Best and D.R. Parsons (Editors), Fluvial-Tidal Sedimentology. Developments in Sedimentology. Elsevier, pp. 3-45.

Dalrymple, R.W., Mackay, D.A., Ichaso, A.A. and Choi, K.S., 2012. Processes, morphodynamics, and facies of tide-dominated estuaries. In: R.A.J. Davis and R.W. Dalrymple (Editors), Principles of Tidal Sedimentology. Springer, New York, pp. 79108.

Dalrymple, R.W. and Padman, L., 2015. Tides at high latitudes, AAPG Hedberg Research Conference, Latitudinal Controls on Stratigraphic Models and Sedimentary Concept. AAPG Search and Discovery Article \#120178, Banff.

Dalrymple, R.W. and Rhodes, R.N., 1995. Estuarine dunes and bars. In: P. G.M.E. (Editor), Geomorphology and Sedimentology of Estuaries. Developments in Sedimentology. Elsevier, Amsterdam, pp. 359-422.

Dalrymple, R.W., Zaitlin, B.A. and Boyd, R., 1992. Estuarine facies models: conceptual basis and stratigraphic implications: perspective. Journal of Sedimentary Petrology, 62: 11301146.

Dashtgard, S.E., MacEachern, J.A., Frey, S.E. and Gingras, M.K., 2012. Tidal effects on the shoreface: towards a conceptual framework. Sedimentary Geology, 279: 42-61.

Davis, R.A., 1994. Barrier island systems - a geologic overview. In: R.A. Davis Jr (Editor), Geology of Holocene barrier island systems. Springer, Heidelberg, pp. 1-46.

Davis, R.A., 2012. Tidal signatures and their preservation potential in stratigraphic sequences. In: R.A. Davis and R.W. Dalrymple (Editors), Principles of Tidal Sedimentology. Springer, New York, pp. 35-55.

Davis, R.A. and Hayes, M.O., 1984. What is a wave-dominated coast? Marine Geology, 60: 313329.

De Boer, P.L., Oost, A. and Visser, M., 1989. The diurnal inequality of the tide as a parameter for recognizing tidal influences. Journal of Sedimentary Research, 59: 912-921. 
De Boer, P.L., Van Gelder, A. and Nio, S.D., 1988. Tide-influenced Sedimentary Environments and Facies. Reidel, Dordrecht, 530 pp. examples from Western Europe). Geologie en Mijnbouw, 50.

De Raaf, J., Reading, H. and Walker, R., 1965. Cyclic sedimentation in the Lower Westphalian of no Devon, England. Sedimentology, 4: 1-52.

De Raaf, J.F.M. and Boersma, J.R., 1977. Tidal deposits and their sedimentary structures (seven examples from Western Europe). Geologie en Mijnbouw, 50: 479-504.

de Vries Klein, G., 1977. Tidal circulation model for deposition of clastic sediment in epeiric and mioclinal shelf seas. Sedimentary Geology, 18: 1-12.

Dean, C.D., Collins, D.S., van Cappelle, M., Avdis, A. and Hampson, G.J., 2019. Regional-scale paleobathymetry controlled location, but not magnitude, of tidal dynamics in the Late Cretaceous Western Interior Seaway, USA. Geology, 47: 1083-1087.

Defant, A., 1961. Physical Oceanography, 11. Pergamon, New York, 598 pp.

Dercourt, J., Gaetani, M., Vrielynck, B., Barrier, E., Biju-Duval, B., Brunet, M.-F., Cadet, J.P., Crasquin, S. and Sandulescu, M., 2000. Atlas Peri-Tethys Palaeogeographical Maps, IXX. CCGM/CGMW, 269 pp.

Dott, R.H., 1983. Episodic Sedimentation-How Normal Is Average? How Rare Is Rare? Does It Matter? Journal of Sedimentary Petrology, 53: 5-23.

Dott, R.H., 1996. Episodic event deposits versus stratigraphic sequences - shall the twain never meet? Sedimentary Geology, 104: 243-247.

Dott, R.H. and Bourgeois, J., 1982. Hummocky stratification: significance of its variable bedding sequences. Geological Society of America Bulletin, 93: 663-680.

Doust, H. and Sumner, H.S., 2007. Petroleum systems in rift basins - a collective approach in Southeast Asian basins. Petroleum Geoscience, 13: 127-144.

Dumas, S. and Arnott, R.W.C., 2006. Origin of hummocky and swaley cross-stratification-The controlling influence of unidirectional current strength and aggradation rate. Geology, 34: 1073-1076.

Egbert, G.D., Ray, R.D. and Bills, B.G., 2004. Numerical modeling of the global semidiurnal tide in the present day and in the last glacial maximum. Journal of Geophysical Research: Oceans, 109.

Ericksen, M.C. and Slingerland, R., 1990. Numerical simulations of tidal and wind-driven circulation in the Cretaceous Interior Seaway of North America. Geological Society of America Bulletin, 102: 1499-1516.

Fanget, A.-S., Berné, S., Jouet, G., Bassetti, M.-A., Dennielou, B., Maillet, G.M. and Tondut, M., 2014. Impact of relative sea level and rapid climate changes on the architecture and lithofacies of the Holocene Rhone subaqueous delta (Western Mediterranean Sea). Sedimentary Geology, 305: 35-53.

Fielding, C.R., Trueman, J. and Alexander, J., 2005. Sedimentology of the modern and Holocene Burdekin River Delta of north Queensland, Australia-controlled by river output, not by waves and tides. In: L. Giosan and J.P. Bhattacharya (Editors), River Deltas-Concepts, Models, and Examples

Special Publication 18, pp. 467-496.

FitzGerald, D.M., 1982. Sediment bypassing at mixed energy tidal inlets, 18th International Conference on Coastal Engineering, pp. 1094-1118. 
FitzGerald, D.M., Rosen, P.S. and van Heteren, S., 1994. New England barriers. In: R.A. Davies Jr. (Editor), Geology of Holocene Barrier Island Systems. Springer, Heidelberg, pp. 305394.

Flemming, B.W. and Barthloma, A., 1995. Tidal Signatures in Modern and Ancient Sediments. IAS Special Publication, 24, 358 pp.

Foreman, M. and Henry, R., 1979. Tidal analysis based on high and low water observations, Institute of Ocean Sciences, Patricia Bay, Sidney, B.C.

Foreman, M.G.G., 1979. Manual for Tidal Heights Analysis and Prediction. Pacific Marine Science Report 77-10. Institute of Ocean Sciences, Patricia Bay, Sidney, B.C., 58 pp.

Franke, D., Barckhausen, U., Heyde, I., Tingay, M. and Ramli, N., 2008. Seismic images of a collision zone offshore NW Sabah/Borneo. Marine and Petroleum Geology, 25: 606-624.

Frey, R.W. and Howard, J.D., 1986. Mesotidal estuarine sequences; a perspective from the Georgia Bight. Journal of Sedimentary Research, 56: 911-924.

Friedrichs, C.T., 1995. Stability Shear Stress and Equilibrium Cross-Sectional Geometry of Sheltered Tidal Channels. Journal of Coastal Research, 11: 1062-1074.

Gaina, C. and Müller, D., 2007. Cenozoic tectonic and depth/age evolution of the Indonesian gateway and associated back-arc basins. Earth-Science Reviews, 83: 177-203.

Galloway, W.E., 1975. Process framework for describing the morphologic and stratigraphic evolution of deltaic depositional systems. In: M.L. Broussard (Editor), Deltas: Models for Exploration. Houston Geological Society, Houston, USA, pp. 87-98.

Gani, M.R. and Bhattacharya, J.P., 2007. Basic building blocks and process variability of a Cretaceous delta: Internal facies architecture reveals a more dynamic interaction of river, wave, and tidal processes than is indicated by external shape. Journal of Sedimentary Research, 77: 284-302.

Gardner, M.H., Cross, T.A., Levorsen, M., Chidsey, T., Adams, R. and Morris, T., 2004. Stacking patterns, sediment volume partitioning, and facies differentiation in shallowmarine and coastal-plain strata of the Cretaceous Ferron Sandstone, Utah. In: T.C. Chidsey, R.D. Adams and T.H. Morris (Editors), Regional to Wellbore Analog for Fluvial-Deltaic Reservoir Modeling: The Ferron Sandstone of Utah. American Association of Petroleum Geologists, Studies in Geology pp. 95-124.

Geleynse, N., Storms, J.E.A., Walstra, D.-J.R., Jagers, H.R.A., Wang, Z.B. and Stive, M.J.F., 2011. Controls on river delta formation: insights from numerical modelling. Earth and Planetary Science Letters, 302: 217-226.

Geuzaine, C. and Remacle, J.F., 2009. Gmsh: A 3-D finite element mesh generator with built-in pre-and post-processing facilities. International Journal for Numerical Methods in Engineering, 79: 1309-1331.

Gil, J., García-Hidalgo, J., Segura, M., García, A. and Carenas, B., 2006. Stratigraphic architecture, palaeogeography and sea-level changes of a third order depositional sequence: the late Turonian-early Coniacian in the northern Iberian Ranges and Central System (Spain). Sedimentary Geology, 191: 191-225.

Gingras, M.K. and MacEachern, J.A., 2012. Tidal ichnology of shallow-water clastic settings. In: R.A. Davis and R.W. Dalrymple (Editors), Principles of Tidal Sedimentology. Springer, New York, pp. 57-77.

Gingras, M.K., MacEachern, J.A. and Dashtgard, S.E., 2012. The potential of trace fossils as tidal indicators in bays and estuaries. Sedimentary Geology, 279: 97-106. 
Ginsburg, R.N., 1975. Tidal Deposits - A Casebook of Recent Examples and Fossil Counterparts. Springer, New York, 428 pp.

Giosan, L. and Bhattacharya, J.P. (Editors), 2005. River deltas: concepts, models, and examples. SEPM Special Publication 83, Tulsa, Oklahoma, 502 pp.

Godin, G., 1993. On tidal resonance. Continental Shelf Research, 13: 89-107.

Godin, G., 1999. The propagation of tides up rivers with special considerations on the upper Saint Lawrence River. Estuarine, Coastal and Shelf Science, 48: 307-324.

Golonka, J., 2004. Plate tectonic evolution of the southern margin of Eurasia in the Mesozoic and Cenozoic. Tectonophysics, 381: 235-273.

Golonka, J., 2007. Late Triassic and Early Jurassic palaeogeography of the world. Palaeogeography, Palaeoclimatology, Palaeoecology, 244: 297-307.

Golonka, J., Gahagan, L., Krobicki, M., Marko, F. and Oszczypko, N., 2006. Plate-tectonic evolution and paleogeography of the circum-Carpathian region. In: J. Golonka and F.J. Picha (Editors), The Carpathians and their Foreland: Geology and Hydrocarbon Resources. AAPG Memoir, pp. 11-46.

Gomis-Cartesio, L.E., Poyatos-Moré, M., Flint, S.S., Hodgson, D.M., Brunt, R.L. and Wickens, H.D., 2016. Anatomy of a mixed-influence shelf edge delta, Karoo Basin, South Africa. In: G.J. Hampson, A.D. Reynolds, B. Kostic and M.R. Wells (Editors), Sedimentology of Paralic Reservoirs: Recent Advances. Special Publication 444. Geological Society of London, pp. SP444.5.

Goodbred, S.L. and Saito, Y., 2012. Tide-dominated deltas. In: R.A. Davis and R.W. Dalrymple (Editors), Principles of Tidal Sedimentology. Springer, New York, pp. 129-149.

Gordon, A.L., Huber, B.A., Metzger, E.J., Susanto, R.D., Hurlburt, H.E. and Adi, T.R., 2012. South China Sea throughflow impact on the Indonesian throughflow. Geophysical Research Letters, 39: 1-7.

Gorman, G.J., Piggott, M. and Pain, C.C., 2007. Shoreline approximation for unstructured mesh generation. Computers \& geosciences, 33: 666-677.

Gorman, G.J., Piggott, M., Wells, M., Pain, C.C. and Allison, P., 2008. A systematic approach to unstructured mesh generation for ocean modelling using GMT and Terreno. Computers \& Geosciences, 34: 1721-1731.

Greb, S.F. and Archer, A.W., 1995. Rhythmic sedimentation in a mixed tide and wave deposit, Hazel Patch sandstone (Pennsylvanian), eastern Kentucky coal field. Journal of Sedimentary Research, 65: 96-106.

Grindrod, J., 1988. The palynology of Holocene mangrove and saltmarsh sediments, particularly in northern Australia. Review of Palaeobotany and Palynology, 55: 229-245.

Gugliotta, M., Flint, S.S., Hodgson, D.M. and Veiga, G.D., 2015. Stratigraphic record of riverdominated crevasse subdeltas with tidal influence (Lajas Formation, Argentina). Journal of Sedimentary Research, 85: 265-284.

Gugliotta, M., Flint, S.S., Hodgson, D.M. and Veiga, G.D., 2016a. Recognition criteria, characteristics and implications of the fluvial to marine transition zone in ancient deltaic deposits (Lajas Formation, Argentina). Sedimentology, 63: 1971-2001.

Gugliotta, M., Kurcinka, C.E., Dalrymple, R.W., Flint, S.S. and Hodgson, D.M., 2016b. Decoupling seasonal fluctuations in fluvial discharge from the tidal signature in ancient deltaic deposits: an example from the Neuquén Basin, Argentina. Journal of the Geological Society of London, 173: 94-107. 
Gugliotta, M., Saito, Y., Nguyen, V.L., Oanh Ta, T.K. and Tamura, T., 2018. Sediment distribution and depositional processes along the fluvial to marine transition zone of the Mekong River delta, Vietnam. Sedimentology, Accepted; In Press.

Guillocheau, F., Robin, C., Allemand, P., Bourquin, S., Brault, N., Dromart, G., Friedenberg, R., Garcia, J.-P., Gaulier, J.-M. and Gaumet, F., 2000. Meso-Cenozoic geodynamic evolution of the Paris Basin: 3D stratigraphic constraints. Geodinamica Acta, 13: 189-245.

Gupta, R. and Johnson, H.D., 2002. High-resolution facies architecture of heterolithic tidal deposits: An integrated outcrop and electrofacies analysis of a complex reservoir. In: M. Lovell and N. Parkinson (Editors), Geological application of well logs. AAPG Methods in Exploration No. 13, pp. 161-184.

Hadley, D.F., Arochukwu, E.C., Nishi, K., Sarginson, M.J., Salleh, H. and Omar, M., 2006. Depositional Modelling of Champion Field, Brunei, Society of Petroleum Engineers Asia Pacific Oil and Gas Conference and Exhibition. Society of Petroleum Engineers, Adelaide, Australia.

Hall, R., 1996. Reconstructing Cenozoic SE Asia. In: R. Hall and D. Blundell (Editors), Tectonic Evolution of Southeast Asia. Geological Society, London, Special Publications, London, UK, pp. 153-184.

Hall, R., 2002. Cenozoic geological and plate tectonic evolution of SE Asia and the SW Pacific: computer-based reconstructions, model and animations. Journal of Asian Earth Sciences, 20: 353-431.

Hall, R., 2009. Southeast Asia's changing palaeogeography. Blumea - Biodiversity, Evolution and Biogeography of Plants, 54: 148-161.

Hall, R., 2011. Australia-SE Asia collision: plate tectonics and crustal flow. Geological Society, London, Special Publications, 355: 75-109.

Hall, R., 2013. The palaeogeography of Sundaland and Wallacea since the Late Jurassic. Journal of Limnology, 72: 1-17.

Hall, R., Ali, J.R., Anderson, C.D. and Baker, S.J., 1995. Origin and motion history of the Philippine Sea Plate. Tectonophysics, 251: 229-250.

Hallam, A., 1981. Facies Interpretation and the Stratigraphic Record. W.H. Freeman, Oxford, $291 \mathrm{pp}$.

Hampson, G.J., Rodriguez, A.B., Storms, J.E.A., Johnson, H.D. and Meyer, C.T., 2008. Geomorphology and High-Resolution Stratigraphy of Progradational Wave-Dominated Shoreline Deposits: Impact on Reservoir-Scale Facies Architecture. 117-142.

Hancock, J. and Rawson, P., 1992. Cretaceous. In: J. Cope, J. Ingham and P.F. Rawson (Editors), Atlas of Palaeogeography and Lithofacies. Geological Society London Memoir

pp. 131-140.

Hancock, J.M. and Kauffman, E., 1979. The great transgressions of the Late Cretaceous. Journal of the Geological Society, 136: 175-186.

Hansen, C.D., MacEachern, J.A., Bann, K., Gingras, M. and Pemberton, S., 2007. Application of the asymmetric delta model to along-strike facies variations in a mixed wave-and riverinfluenced delta lobe, Upper Cretaceous Basal Belly River Formation, central Alberta. In: J.A. MacEachern, K.L. Bann, M.K. Gingras and S.G. Pemberton (Editors), Applied Ichnology. SEPM Short Course Notes 52. SEPM, Tulsa, Oklahoma, pp. 255-271. Haq, B.U., 2014. Cretaceous eustasy revisited. Global and Planetary Change, 113: 44-58. 
Harms, J.C., Southard, J.B. and Walker, R.G., 1982. Structures and Sequences in Clastic Rocks. Short Course 9. SEPM, Tulsa, Oklahoma, 249 pp.

Harris, P.T., Heap, A.D., Bryce, S.M., Porter-Smith, R., Ryan, D.A. and Heggie, D.T., 2002. Classification of Australian Clastic Coastal Depositional Environments Based Upon a Quantitative Analysis of Wave, Tidal, and River Power. Journal of Sedimentary Research, 72: 858-870.

Hawkes, P., Fraser, A. and Einchcomb, C., 1998. The tectono-stratigraphic development and exploration history of the Weald and Wessex basins, Southern England, UK, Development, Evolution and Petroleum Geology of the Wessex Basin. Special Publications 133. Geological Society, London, pp. 39-65.

Hayes, M.O., 1975. Morphology of sand accumulations in estuaries: an introduction to the symposium. In. In: L.E. Cronin (Editor), Estuarine Research. Academic Press, New York, N.Y., pp. 3-22.

Hayes, M.O., 1979. Barrier island morphology as a function of tidal and wave regime. In: S.P. Leatherman (Editor), Barrier Islands. Academic Press, New York, pp. 1-27.

Hayes, M.O., 1980. General morphology and sediment patterns in tidal inlets. Sedimentary geology, 26: 139-156.

Hazebroek, H.P. and Tan, D.N.K., 1993. Tectonic evolution of the NW Sabah continental margin since the Late Eocene. In: G.H. Teh (Editor), Proceedings symposium on the Tectonic framework and energy resources of the western margin of the Pacific Basin. Special Publication. Geological Society of Malaysia, Kuala Lumpur, pp. 195-210.

Heap, A.D., Bryce, S. and Ryan, D.A., 2004. Facies evolution of Holocene estuaries and deltas: a large-sample statistical study from Australia. Sedimentary Geology, 168: 1-17.

Hinz, K., Fritsch, J., Kempter, E., Mohammad, M.A.M., Meyer, J., Mohamed, M.D., Vosberg, D.G.H., Weber, D.I.J. and Benavidez, M.J., 1989. Thrust tectonics along the northwestern continental margin of Sabah/Borneo. Geologische Rundschau, 78: 705-730.

Hinz, K. and Schlüter, H., 1985. Geology of the Dangerous Grounds, South China Sea, and the continental margin off southwest Palawan: Results of SONNE cruises SO-23 and SO-27. Energy, 10: 297-315.

Hjulström, F., 1939. Transportation of Debris by Moving Water. In: P.D. Trask (Editor), Recent Marine Sediments. AAPG, Tulsa, OK, pp. 5-31.

Holgate, N.E., Jackson, C.A.L., Hampson, G.J. and Dreyer, T., 2013. Sedimentology and sequence stratigraphy of the Middle-Upper Jurassic Krossfjord and Fensfjord formations, Troll Field, northern North Sea. Petroleum Geoscience, 19: 237-258.

Holloway, N.H., 1982. North Palawan block, Philippines--Its relation to Asian mainland and role in evolution of South China Sea. AAPG Bulletin, 66: 1355-1383.

Honig, C. and Boyd, R., 1992. Estuarine sedimentation on the eastern shore of Nova Scotia. Journal of Sedimentary Research, 62: 569-583.

Hori, K. and Saito, Y., 2007. Classification, architecture, and evolution of large-river deltas. In: A. Gupta (Editor), Large rivers: geomorphology and management. John Wiley \& Sons, Chichester, UK, pp. 75-96.

Hori, K., Saito, Y., Zhao, Q., Cheng, X., Wang, P., Sato, Y. and Li, C., 2001. Sedimentary facies of the tide-dominated paleo-Changjiang (Yangtze) estuary during the last transgression. Marine Geology, 177: 331-351. 
Hori, K., Saito, Y., Zhao, Q. and Wang, P., 2002. Architecture and evolution of the tidedominated Changjiang (Yangtze) River delta, China. Sedimentary Geology, 146: 249264.

Hovikoski, J., Räsänen, M., Gingras, M., Ranzi, A. and Melo, J., 2008. Tidal and seasonal controls in the formation of Late Miocene inclined heterolithic stratification deposits, western Amazonian foreland basin. Sedimentology, 55: 499-530.

Hovius, N., 1998. Controls on sediment supply by large rivers. In: K.W. Shanley and P.J. McCabe (Editors), Relative Role of Eustasy, Climate and Tectonics in Continental Rocks SEPM Special Publication 59, pp. 3-16.

Howarth, M.J., 1982. Tidal currents of the continental shelf. In: A.H. Stride (Editor), Offshore Tidal Sands: Processes and Deposits. Chapman \& Hall, London, pp. 10-26.

Hu, D., Wu, L., Cai, W., Gupta, A.S., Ganachaud, A., Qiu, B., Gordon, A.L., Lin, X., Chen, Z. and $\mathrm{Hu}, \mathrm{S} ., 2015$. Pacific western boundary currents and their roles in climate. Nature, 522: 299-308.

Hubbard, S.M., Smith, D.G., Nielsen, H., Leckie, D.A., Fustic, M., Spencer, R.J. and Bloom, L., 2011. Seismic geomorphology and sedimentology of a tidally influenced river deposit, Lower Cretaceous Athabasca oil sands, Alberta, Canada. AAPG bulletin, 95: 1123-1145. Huchon, P., Pichon, X.L. and Rangin, C., 1994. Indochina Peninsula and the collision of India and Eurasia. Geology, 22: 27-30.

Hulscher, S.J.M.H., de Swart, H.E. and de Vriend, H.J., 1993. The generation of offshore tidal sand banks and sand waves. Continental Shelf Research, 13: 1183-1204.

Hutchison, C.S., 1996. South-East Asian oil, gas, coal, and mineral deposits. Oxford University Press, Oxford, UK, 368 pp.

Hutchison, C.S., 2010. The North-West Borneo Trough. Marine Geology, 271: 32-43.

Hutchison, C.S., Bergman, S.C., Swauger, D.A. and Graves, J.E., 2000. A Miocene collisional belt in north Borneo: uplift mechanism and isostatic adjustment quantified by thermochronology. Journal of the Geological Society, 157: 783-793.

Ichaso, A.A. and Dalrymple, R.W., 2009. Tide- and wave-generated fluid mud deposits in the Tilje Formation (Jurassic), offshore Norway. Geology, 37: 539-542.

Immenhauser, A., 2009. Estimating palaeo-water depth from the physical rock record. EarthScience Reviews, 96: 107-139.

Ingram, G.M., Chisholm, T.J., Grant, C.J., Hedlund, C.A., Stuart-Smith, P. and Teasdale, J., 2004. Deepwater North West Borneo: hydrocarbon accumulation in an active fold and thrust belt. Marine and Petroleum Geology, 21: 879-887.

Insole, A., Daley, B. and Gale, A., 1998. The Isle of Wight: Geologists' Association Guide No. 60. The Geologists' Association, London, UK, 132 pp.

Jablonski, B.V.J. and Dalrymple, R.W., 2016. Recognition of strong seasonality and climatic cyclicity in an ancient, fluvially dominated, tidally influenced point bar: Middle McMurray Formation, Lower Steepbank River, north-eastern Alberta, Canada. Sedimentology, 63: 552-585.

Jardine, E., 1997. Dual petroleum systems governing the prolific Pattani Basin, offshore Thailand. In: J.V.C. Howes and R.A. Noble (Editors), International Conference on Petroleum Systems of SE Asia and Australasia, Indonesian Petroleum Association, Jakarta, Indonesia, pp. 351-363. 
Jerzykiewicz, T. and Wojewoda, J., 1986. The Radków and Szczeliniec sandstones: an example of giant foresets on a tectonically controlled shelf of the Bohemian Cretaceous Basin (Central Europe). In: J.R. Knight and J.R. McLean (Editors), Shelf Sands and Sandstones. Canadian Society of Petroleum Geologists, Memoir 11, pp. 1-15. Precambrian, Finnmark, North Norway. Sedimentology, 22: 45-74.

Johnson, H.D. and Levell, B.K., 1995. Sedimentology of a transgressive, estuarine sand complex: the Lower Cretaceous Woburn Sands (Lower Greensand), southern England. In: A.G. Plint (Editor), Sedimentary Facies Analysis: a Tribute to the Research and Teaching of Harold G. Reading. IAS Special Publication 22. Blackwell Publishing Ltd., Oxford, UK, pp. 17-46.

Johnson, S.M. and Dashtgard, S.E., 2014. Inclined heterolithic stratification in a mixed tidalfluvial channel: differentiating tidal versus fluvial controls on sedimentation. Sedimentary Geology, 301: 41-53.

Jopling, A.V. and Walker, R.G., 1968. Morphology and origin of ripple-drift cross-lamination, with examples from the Pleistocene of Massachusetts. Journal of Sedimentary Research, 38: 971-984.

Jouanneau, J.-M. and Latouche, C., 1981. The Gironde Estuary. Contributions to Sedimentology, 10. E. Sehweizerbart'sche Verlagsbuchhandlung, Stuttgart.

Julien, P.Y. and Raslan, Y., 1998. Upper-regime plane bed. Journal of Hydraulic Engineering, 124: 1086-1096.

Kantha, L.H. and Clayson, C.A., 2000. Numerical models of oceans and oceanic processes, 66. Elsevier, $750 \mathrm{pp}$.

Klein, G.d., 1970a. Depositional and dispersal dynamics of intertidal sand bars. Journal of Sedimentary Research, 40: 1095-1127.

Klein, G.D., 1970b. Tidal origin of a Precambrian quartzite; the Lower Fine-grained quartzite (middle Dalradian) of Islay, Scotland. Journal of Sedimentary Research, 40: 973-985.

Klein, G.D., 1971. A sedimentary model for determining paleotidal range. Geological Society of America Bulletin, 82: 2585-2592.

Kowalik, Z. and Luick, J., 2013. The Oceanography of Tides. University of Alaska Fairbanks, Fairbanks, Alaska, 157 pp.

Kreisa, R. and Moila, R., 1986. Sigmoidal tidal bundles and other tide-generated sedimentary structures of the Curtis Formation, Utah. Geological Society of America Bulletin, 97: 381-387.

Krystinik, L.F. and DeJarnett, B.B., 1995. Lateral variability of sequence stratigraphic framework in the Campanian and Lower Maastrichtian of the Western Interior Seaway. In: J.C. Van Wagoner and G.T. Bertram (Editors), Sequence Stratigraphy of Foreland Basin Deposits: Outcrop and Subsurface Examples from the Cretaceous of North America. Memoir 64. AAPG, Tulsa, Oklahoma, pp. 11-26.

Kuhnt, W., Holbourn, A., Hall, R., Zuvela, M. and Käse, R., 2004. Neogene history of the Indonesian throughflow. In: P.C.W.K.P.W.D. Hayes (Editor), Continent-Ocean Interactions within East Asian Marginal Seas. Geophysical Monograph. American Geophysical Union, pp. 299-320. 
Kurcinka, C., Dalrymple, R.W. and Gugliotta, M., 2018. Facies and architecture of riverdominated to tide-influenced mouth bars in the lower Lajas Formation (Jurassic), Argentina. AAPG Bulletin, 102: 885-912.

Kvale, E.P., 2012. Tidal constituents of modern and ancient tidal rhythmites: criteria for recognition and analyses. In: R.A. Davis and R.W. Dalrymple (Editors), Principles of Tidal Sedimentology. Springer, New York, pp. 1-17.

Kvale, E.P., Archer, A.W. and Johnson, H.R., 1989. Daily, monthly, and yearly tidal cycles within laminated siltstones of the Mansfield Formation (Pennsylvanian) of Indiana. Geology, 17: 365-368.

Lamb, M.P., Myrow, P.M., Lukens, C., Houck, K. and Strauss, J., 2008. Deposits from WaveInfluenced Turbidity Currents: Pennsylvanian Minturn Formation, Colorado, U.S.A. Journal of Sedimentary Research, 78: 480-498.

Lambiase, J.J., Damit, A.R., Simmons, M.D., Abdoerrias, R. and Hussin, A., 2003. A depositional model and the stratigraphic development of modern and ancient tidedominated deltas in NW Borneo. In: F.H. Sidi, D. Nummedal, P. Imbert, H. Darman and H.W. Posamentier (Editors), Tropical Deltas of Southeast Asia-Sedimentology, Stratigraphy, and Petroleum Geology SEPM Spec. Publ., pp. 109-123.

Leckie, D.A. and Rumpel, T., 2003. Tide-influenced sedimentation in a rift basin-Cretaceous Qishn Formation, Masila Block, Yemen: A billion barrel oil field. AAPG Bulletin, 87: 987-1013.

Lee, T.-Y. and Lawver, L.A., 1995. Cenozoic plate reconstruction of Southeast Asia. Tectonophysics, 251: 85-138.

Leeder, M.R., 2011. Sedimentology and sedimentary basins: from turbulence to tectonics. Wiley-Blackwell, Oxford, UK, 784 pp.

Legler, B., Hampson, G.J., Jackson, C.A.L., Johnson, H.D., Massart, B.Y.G., Sarginson, M. and Ravnås, R., 2014. Facies relationships and stratigraphic architecture of distal, mixed tideand wave-influenced deltaic deposits: Lower Sego Sandstone, Western Colorado, U.S.A. Journal of Sedimentary Research, 84: 605-625.

Legler, B., Johnson, H.D., Hampson, G.J., Massart, B.Y.G., Jackson, C.A.L., Jackson, M.D., ElBarkooky, A. and Ravnås, R., 2013. Facies model of a fine-grained, tide-dominated delta: Lower Dir Abu Lifa Member (Eocene), Western Desert, Egypt. Sedimentology, 60: 1313-1356.

Levell, B.K., 1980. A late Precambrian tidal shelf deposit, the Lower Sandfjord Formation, Finnmark, north Norway. Sedimentology, 27: 539-557.

Levell, B.K., 1987. The nature and significance of regional unconformities in the hydrocarbonbearing Neogene sequences offshore West Sabah. Bulletin of The Geological Society of Malaysia, 21: 55-90.

Levell, B.K., Johnson, H.D., Collins, D.S. and Van Cappelle, M., 2020. Deposition and preservation of fluvio- tidal shallow- marine sandstones: A re- evaluation of the Neoproterozoic Jura Quartzite (western Scotland). Sedimentology, 67: 173-206.

Li, W., Bhattacharya, J.P., Zhu, Y., Garza, D. and Blankenship, E., 2011. Evaluating delta asymmetry using three- dimensional facies architecture and ichnological analysis, Ferron 'Notom Delta', Capital Reef, Utah, USA. Sedimentology, 58: 478-507. 
Li, Z., Bhattacharya, J.P. and Schieber, J., 2015. Evaluating along-strike variation using thinbedded facies analysis, Upper Cretaceous Ferron Notom Delta, Utah. Sedimentology, 62: 2060-2089. deposition in the southern Pattani Trough, Gulf of Thailand. In: P. Dheeradilok, C. Hinthong, P. Chaodumrong, P. Putthaphiban, W. Tansathien, C. Utha-aroon, N. Sattyarak, T. Nuchanong and S. Techawan (Editors), The International Conference on Stratigraphy and Tectonic Evolution of Southeast Asia and the South Pacific, Bangkok, Thailand, pp. 476-489.

Longhitano, S.G., Mellere, D., Steel, R.J. and Ainsworth, R.B., 2012. Tidal depositional systems in the rock record: A review and new insights. Sedimentary Geology, 279: 2-22.

Longhitano, S.G., Sabato, L., Tropeano, M. and Gallicchio, S., 2010. A mixed bioclasticsiliciclastic flood-tidal delta in a micro tidal setting: depositional architectures and hierarchical internal organization (Pliocene, Southern Apennine, Italy). Journal of Sedimentary Research, 80: 36-53.

MacEachern, J.A. and Bann, K.L., 2008. The role of ichnology in refining shallow marine facies models. In: G.J. Hampson, R.J. Steel, P.M. Burgess and R.W. Dalrymple (Editors), Recent Advances in Models of Siliciclastic Shallow-Marine Stratigraphy. SEPM Spec. Publ., pp. 73-116.

MacEachern, J.A., Bann, K.L., Bhattacharya, J.P. and Howell, C.D., 2005. Ichnology of deltas: organism responses to the dynamic interplay of rivers, waves, storms, and tides. In: L. Giosan and J.P. Bhattacharya (Editors), River Deltas-Concepts, Models, and Examples. SEPM Special Publication. SEPM, pp. 45-85.

MacMillan, D.H., 1966. Tides. American Elsevier Publishing Company, New York, 240 pp.

Madec, G. and Imbard, M., 1996. A global ocean mesh to overcome the North Pole singularity. Climate Dynamics, 12: 381-388.

Markwick, P.J. and Valdes, P.J., 2004. Palaeo-digital elevation models for use as boundary conditions in coupled ocean-atmosphere GCM experiments: a Maastrichtian (late Cretaceous) example. Palaeogeography Palaeoclimatology Palaeoecology, 213: 37-63.

Martel, A.T., Allen, P.A. and Slingerland, R., 1994. Use of tidal-circulation modeling in paleogeographical studies: an example from the Tertiary of the Alpine perimeter. Geology, 22: 925-928.

Martinius, A.W. and Gowland, S., 2011. Tide-influenced fluvial bedforms and tidal bore deposits (late Jurassic Lourinhã Formation, Lusitanian Basin, Western Portugal). Sedimentology, 58: 285-324.

Martinius, A.W., Jablonski, B.V.J., Fustic, M., Strobl, R. and van den Berg, J.H., 2015. Fluvial to tidal transition zone facies in the McMurray Formation (Christina River, Alberta, Canada), with emphasis on the reflection of flow intensity in bottomset architecture. In: P.J. Ashworth, J.L. Best and D.R. Parsons (Editors), Fluvial-Tidal Sedimentology. Developments in Sedimentology. Elsevier, pp. 445-480.

Martinius, A.W. and van den Berg, J.H., 2011. Atlas of sedimentary structures in estuarine and tidally-influenced river deposits of the Rhine-Meuse-Scheldt system. EAGE Publications BV, Houten, 298 pp. 
Maselli, V., Normandeau, A., Nones, M., Tesi, T., Langone, L., Trincardi, F. and Bohacs, K.M., 2020. Tidal modulation of river-flood deposits: How low can you go? Geology, 48: 663667.

Mazur, S., Green, C., Stewart, M.G., Whittaker, J.M., Williams, S. and Bouatmani, R., 2012. Displacement along the Red River Fault constrained by extension estimates and plate reconstructions. Tectonics, 31: TC5008.

McBride, R.A., Anderson, J.B., Buynevich, I.V., Cleary, W., Fenster, M.S., Fitzgerald, D.M., Harris, M.S., Hein, C.J., Klein, A.H.F., Liu, B., de Menezes, J.T., Pejrup, M., Riggs, S.R., Short, A.D., Stone, G.W., Wallace, D.J. and Wang, P., 2013. Morphodynamics of barrier systems: a synthesis. In: J.F. Shroder (Editor), Treatise on Geomorphology. Academic Press, San Diego, CA, pp. 166-244.

McCabe, P.J. and Jones, C.M., 1977. Formation of reactivation surfaces within superimposed deltas and bedforms. Journal of Sedimentary Research, 47: 707-715.

McIlroy, D., 2006. Ichnology of a macrotidal tide-dominated deltaic depositional system: Lajas Formation, Neuquén Province, Argentina. In: R. Bromley, L.A. Buatois, J. Genise, M.G. Mángano and R. Melchor (Editors), Sediment-Organism Interactions: A Multifaceted Ichnology. Special Publication 88. SEPM, Tulsa, Oklahoma, pp. 195-211.

McIlroy, D., 2007. Lateral variability in shallow marine ichnofabrics: implications for the ichnofabric analysis method. Journal of the Geological Society, 164: 359-369.

Mellor, G.L., 1996. Introduction to Physical Oceanography. Springer-Verlag, New York, 248 pp.

Miall, A.D., 2015. Updating uniformitarianism: stratigraphy as just a set of 'frozen accidents'. In: D.G. Smith, R.J. Bailey, P.M. Burgess and A.J. Fraser (Editors), Strata and Time: Probing the Gaps in Our Understanding. Special Publication 404. Geological Society of London, pp. 11-36.

Middleton, G.V., 1965. Primary sedimentary structures and their hydrodynamic interpretation, 12. SEPM Special Publication 265 pp.

Miller, K.G., Kominz, M.A., Browning, J.V., Wright, J.D., Mountain, G.S., Katz, M.E., Sugarman, P.J., Cramer, B.S., Christie-Blick, N. and Pekar, S.F., 2005. The Phanerozoic record of global sea-level change. Science, 310: 1293-1298.

Miller, K.G., Mountain, G.S., Wright, J.D. and Browning, J.V., 2011. A 180-Million-Year Record of Sea Level and Ice Volume Variations from Continental Margin and Deep-Sea Isotopic Records. Oceanography, 24: 40-53.

Miller, K.G., Sugarman, P.J., Browning, J.V., Kominz, M.A., Hernández, J.C., Olsson, R.K., Wright, J.D., Feigenson, M.D. and Van Sickel, W., 2003. Late Cretaceous chronology of large, rapid sea-level changes: Glacioeustasy during the greenhouse world. Geology, 31: 585-588.

Miller, M.C., McCave, I.N. and Komar, P.D., 1977. Threshold of sediment motion under unidirectional currents. Sedimentology, 24: 507-527.

Milliman, J.D. and Farnsworth, K.L., 2011. River discharge to the coastal ocean: a global synthesis. Cambridge University Press, Cambridge, UK, 381 pp.

Milliman, J.D. and Syvitski, J.P., 1992. Geomorphic/tectonic control of sediment discharge to the ocean: the importance of small mountainous rivers. The Journal of Geology, 100: $525-544$. 
Mitchell, A.J., Allison, P.A., Gorman, G.J., Piggott, M.D. and Pain, C.C., 2011. Tidal circulation in an ancient epicontinental sea: The Early Jurassic Laurasian Seaway. Geology, 39: 207210.

Mitchell, A.J., Uličný, D., Hampson, G.J., Allison, P.A., Gorman, G.J., Piggott, M.D., Wells, M.R. and Pain, C.C., 2010. Modelling tidal current-induced bed shear stress and palaeocirculation in an epicontinental seaway: the Bohemian Cretaceous Basin, Central Europe. Sedimentology, 57: 359-388.

Morley, C.K., 2016. Major unconformities/termination of extension events and associated surfaces in the South China Seas: Review and implications for tectonic development. Journal of Asian Earth Sciences, 120: 62-86.

Morley, R.J., Swiecicki, T. and Pham, D.T.T., 2011. A sequence stratigraphic framework for the Sunda region, based on integration of biostratigraphic, lithological and seismic data from Nam Con Son basin, Vietnam, Indonesian Petroleum Association 35th Annual Convention, Jakarta, Indonesia, pp. IPA11-G-002.

Mulhern, J.S., Johnson, C.L. and Martin, J.M., 2017. Is barrier island morphology a function of tidal and wave regime? Marine Geology, 387: 74-84.

Müller, R.D., Roest, W.R., Royer, J.Y., Gahagan, L.M. and Sclater, J.G., 1997. Digital isochrons of the world's ocean floor. Journal of Geophysical Research, 102: 3211-3214.

Murtaza, M., Rahman, A.H.A., Sum, C.W. and Konjing, Z., 2018. Facies associations, depositional environments and stratigraphic framework of the Early Miocene-Pleistocene successions of the Mukah-Balingian Area, Sarawak, Malaysia. Journal of Asian Earth Sciences, 152: 23-38.

Muto, T. and Steel, R.J., 1997. Principles of regression and transgression: the nature of the interplay between accommodation and sediment supply. Journal of Sedimentary Research, 67: 994-1000.

Mutti, E., Allen, G. and Rosell, J., 1984. Sigmoidal cross stratification and sigmoidal bars: depositional features diagnostic of tidal sandstones, 5th IAS European Regional Meeting, Marsiglia, pp. 312-313.

Mutti, E., Rosell, J., Allen, G., Fonnesu, F. and Sgavetti, M., 1985. The Eocene Baronia tide dominated delta-shelf system in the Ager Basin. In: M.D. Mila and J. Rosell (Editors), Excursion guidebook: 6th International Association of Sedimentologists European Regional Meeting. International Association of Sedimentologists, Lleida, Spain, pp. 579600.

Myrow, P.M., Fischer, W. and Goodge, J.W., 2002. Wave-modified turbidites: combined-flow shoreline and shelf deposits, Cambrian, Antarctica. Journal of Sedimentary Research, 72: 641-656.

Myrow, P.M. and Southard, J.B., 1996. Tempestite deposition. Journal of Sedimentary Research, 66: 992-1007.

Nanson, R.A., Vakarelov, B.K., Ainsworth, R.B., Williams, F.M. and Price, D.M., 2013. Evolution of a Holocene, mixed-process, forced regressive shoreline: the Mitchell River delta, Queensland, Australia. Marine Geology, 339: 22-43.

Narayan, J., 1971. Sedimentary structures in the lower Greensand of the Weald, England, and Bas-Boulonnais, France. Sedimentary Geology, 6: 73-109. 
Nguyen, V.L., Ta, T.K.O. and Tateishi, M., 2000. Late Holocene depositional environments and coastal evolution of the Mekong River Delta, Southern Vietnam. Journal of Asian Earth Sciences, 18: 427-439.

Nio, S.-D. and Yang, C.-S., 1991. Diagnostic attributes of clastic tidal deposits: a review. In: D. Smith, G.G.E. Reinson, B.A. Zaitlin and R.A. Rahmani (Editors), Clastic Tidal Sedimentology. Canadian Society of Petroleum Geologists, Memoir 16, pp. 3-27.

Nio, S., Siegenthaler, C. and Yang, C., 1983. Megaripple cross-bedding as a tool for the reconstruction of the paleo-hydraulics in a Holocene subtidal environment, SW Netherlands. Geologie en Mijnbouw, 62: 499-510.

Nyberg, B. and Howell, J.A., 2015. Is the present the key to the past? A global characterization of modern sedimentary basins. Geology, 43: 643-646.

Nyberg, B. and Howell, J.A., 2016. Global distribution of modern shallow marine shorelines. Implications for exploration and reservoir analogue studies. Marine and Petroleum Geology, 71: 83-104.

Obradovich, J.D., 1993. A Cretaceous time scale. In: W.G.E. Caldwell and E.G. Kauffman (Editors), Evolution of the Western Interior Basin. Geological Association of Canada, Special Paper 39, St. John's, Newfoundland, pp. 379-396.

Off, T., 1963. Rhythmic linear sand bodies caused by tidal currents. AAPG Bulletin, 47: 324341.

Ogg, J.G., Agterberg, F.P. and Gradstein, F.M., 2004. The Cretaceous period. In: G. F.M., O. J.G. and S. A.G (Editors), A Geologic Time Scale 2004. Cambridge University Press, Cambridge, pp. 344-383.

Olson, W.S., 1972. Sedimentary Model for Determining Paleotidal Range: Discussion. Geological Society of America Bulletin, 83: 537-538.

Open University Course Team, 1999. Waves, Tides and Shallow-water Processes: Second Edition. Butterworth-Heinemann, Oxford, UK, 227 pp.

Orton, G.J. and Reading, H.G., 1993. Variability of deltaic processes in terms of sediment supply, with particular emphasis on grain size. Sedimentology, 40: 475-512.

Pain, C.C., Piggott, M.D., Goddard, A.J.H., Fang, F., Gorman, G.J., Marshall, D.P., Eaton, M.D., Power, P.W. and De Oliveira, C.R.E., 2005. Three-dimensional unstructured mesh ocean modelling. Ocean Modelling, 10: 5-33.

Peltzer, G. and Tapponnier, P., 1988. Formation and evolution of strike- slip faults, rifts, and basins during the India- Asia collision: An experimental approach. Journal of Geophysical Research: Solid Earth, 93: 15085-15117.

Peng, Y., Steel, R.J., Rossi, V.M. and Olariu, C., 2018. Mixed-energy process interactions read from a compound-clinoform delta (paleo-Orinoco Delta, Trinidad): preservation of river and tide signals by mud-induced wave damping. Journal of Sedimentary Research, 88: 75-90.

Perillo, M.M., Best, J.L. and Garcia, M.H., 2014. A new phase diagram for combined-flow bedforms. Journal of Sedimentary Research, 84: 301-313.

Pietrzak, J., Jakobson, J.B., Burchard, H., Vested, H.J. and Petersen, O., 2002. A threedimensional hydrostatic model for coastal and ocean modelling using a generalised topography following co-ordinate system. Ocean Modelling, 4: 173-205.

Piggott, M.D., Gorman, G.J., Pain, C.C., Allison, P.A., Candy, A.S., Martin, B.T. and Wells, M.R., 2008. A new computational framework for multi-scale ocean modelling based on 

1003-1015.

Pingree, R.D. and Griffiths, D.K., 1979. Sand transport paths around the British Isles resulting from M2 and M4 tidal interactions. Journal of the Marine Biological Association of the United Kingdom, 59: 497-513.

Piper, D.J., Kontopoulos, N., Anagnostou, C., Chronis, G. and Panagos, A., 1990. Modern fan deltas in the western Gulf of Corinth, Greece. Geo-Marine Letters, 10: 5-12.

Plink-Björklund, P., 2012. Effects of tides on deltaic deposition: Causes and responses. Sedimentary Geology, 279: 107-133.

Posamentier, H.W. and Walker, R.G. (Editors), 2006. Facies models revisited. SEPM Special Publication 84.

Proudman, J., 1953. Dynamical Oceanography. Methuen-John Wiley, London, 409 pp.

Pugh, D.T., 1987. Tides, surges and mean sea-level: a handbook for engineers and scientists. John Wiley \& Sons, Chichester, UK, 472 pp.

Ramli, N., 1986. Depositional model of a Miocene barred wave-and storm-dominated shoreface and shelf, southeastern Malay Basin, offshore West Malaysia. AAPG Bulletin, 70: 34-47.

Rawson, P.F., 2006. Cretaceous: sea levels peak as the North Atlantic opens, The Geology of England and Wales, 2nd Edition. Geological Society, London, London, UK, pp. 365-393.

Reading, H.G., 1978. Sedimentary Environments and Facies, 60. Blackwell Scientific Publications, Oxford, 557 pp.

Reading, H.G., 1996. Sedimentary environments: processes, facies and stratigraphy. Blackwell Publishing Ltd, Oxford, U.K., 615 pp.

Redfield, A.C., 1958. The influence of the continental shelf on the tides of the Atlantic coast of the United States. Journal of Marine Research, 17: 432-448.

Reineck, H.-E., 1963. Sedimentgefüge im Bereich der südlichen Nordsee. Senckenbergische Naturforschende Gesellschaft, Abhandlungen, 505: 1-138.

Reineck, H.-E. and Singh, I.B., 1980. Depositional Sedimentary Environments: With Reference to Terrigenous Clastics. Springer, Berlin, 549 pp.

Reineck, H.-E. and Wunderlich, F., 1968. Classification and Origin of Flaser and Lenticular Bedding. Sedimentology, 11: 99-104.

Replumaz, A. and Tapponnier, P., 2003. Reconstruction of the deformed collision zone between India and Asia by backward motion of lithospheric blocks. Journal of Geophysical Research, 108: B62285.

Ridd, M.F., Barber, A.J. and Crow, M.J., 2011. The Geology of Thailand. Geological Society of London, London, UK, 626 pp.

Robinson, A., 1966. Residual currents in relation to shoreline evolution of the East Anglian coast. Marine Geology, 4: 57-84.

Rodriguez, A.B., Hamilton, M.D. and Anderson, J.B., 2000. Facies and evolution of the modern Brazos Delta, Texas: wave versus flood influence. Journal of Sedimentary Research, 70: 283-295.

Rossi, V.M., Kim, W., Leva López, J., Edmonds, D., Geleynse, N., Olariu, C., Steel, R.J., Hiatt, M. and Passalacqua, P., 2016. Impact of tidal currents on delta-channel deepening, stratigraphic architecture, and sediment bypass beyond the shoreline. Geology, 44: 927930. 
Rossi, V.M., Perillo, M.M., Steel, R.J. and Olariu, C., 2017. Quantifying mixed-process variability in shallow-marine depositional systems: What are sedimentary structures really telling us? Journal of Sedimentary Research, 87: 1060-1074.

Rossi, V.M. and Steel, R.J., 2016. The role of tidal, wave and river currents in the evolution of mixed-energy deltas: Example from the Lajas Formation (Argentina). Sedimentology, 63: 824-864.

Roy, P., Thom, B. and Wright, L., 1980. Holocene sequences on an embayed high-energy coast: an evolutionary model. Sedimentary Geology, 26: 1-19.

Roy, P., Williams, R., Jones, A., Yassini, I., Gibbs, P., Coates, B., West, R., Scanes, P., Hudson, J. and Nichol, S., 2001. Structure and function of south-east Australian estuaries. Estuarine, Coastal and Shelf Science, 53: 351-384.

Ru, K. and Pigott, J.D., 1986. Episodic rifting and subsidence in the South China Sea. AAPG Bulletin, 70: 1136-1155.

Rubin, D.M. and McCulloch, D.S., 1980. Single and superimposed bedforms: a synthesis of San Francisco Bay and flume observations. Sedimentary Geology, 26: 207-231.

Ruffell, A.H., 1992. Correlation of the Hythe Beds Formation (Lower Greensand Group: earlymid-Aptian), southern England. Proceedings of the Geologists' Association, 103: 273291.

Ruffell, A.H. and Wach, G.D., 1991. Sequence stratigraphic analysis of the Aptian-Albian Lower Greensand in southern England. Marine and Petroleum Geology, 8: 341-353.

Safak, I., 2016. Variability of Bed Drag on Cohesive Beds under Wave Action. Water, 8: 131.

Salahuddin and Lambiase, J.J., 2013. Sediment Dynamics and Depositional Systems of the Mahakam Delta, Indonesia: Ongoing Delta Abandonment On A Tide-Dominated Coast. Journal of Sedimentary Research, 83: 503-521.

Sames, B., Wagreich, M., Wendler, J., Haq, B., Conrad, C., Melinte-Dobrinescu, M., Hu, X., Wendler, I., Wolfgring, E. and Yilmaz, I., 2016. Short-term sea-level changes in a greenhouse world - A view from the Cretaceous. Palaeogeography, Palaeoclimatology, Palaeoecology, 441: 393-411.

Sandal, S.T., 1996. The Geology and Hydrocarbon Resources of Negara Brunei Darussalam. Brunei Shell Petroleum Company, Brunei Museum, Bandar Seri Begawan, Brunei Darussalam, 243 pp.

Schwiderski, E.W., 1980. On charting global ocean tides. Reviews of Geophysics, 18: 243-268. Shanley, K.W., McCabe, P.J. and Hettinger, R.D., 1992. Tidal influence in Cretaceous fluvial strata from Utah, USA: a key to sequence stratigraphic interpretation. Sedimentology, 39: 905-930.

Shanmugam, G., 2013. Modern internal waves and internal tides along oceanic pycnoclines: Challenges and implications for ancient deep-marine baroclinic sands. AAPG Bulletin, 97: 799-843.

Shaw, D.P., 1964. Time in Stratigraphy. McGraw Hill, New York, 365 pp.

Shoup, R.C., Morley, R.J., Swiecicki, T. and Clark, S., 2013. Tectono-stratigraphic Framework and Tertiary Paleogeogeography of Southeast Asia; Gulf of Thailand to South Vietnam Shelf. Houston Geological Society Bulletin, 55: 27-39.

Siddiqui, N.A., Rahman, A.H.A., Sum, C.W., Mathew, M.J. and Menier, D., 2016. Onshore sandstone facies characteristics and reservoir quality of Nyalau Formation, Sarawak, East 
Malaysia: an analogue to subsurface reservoir quality evaluation. Arabian Journal for Science and Engineering, 41: 267-280.

Sisulak, C.F. and Dashtgard, S.E., 2012. Seasonal Controls On the Development And Character of Inclined Heterolithic Stratification In A Tide-Influenced, Fluvially Dominated Channel: Fraser River, Canada. Journal of Sedimentary Research, 82: 244-257.

Sixsmith, P.J., Hampson, G.J., Gupta, S., Johnson, H.D. and Fofana, J.F., 2008. Facies architecture of a net transgressive sandstone reservoir analog: The Cretaceous Hosta Tongue, New Mexico. AAPG Bulletin, 92: 513-547.

Slater, R.D., 1985. A numerical model of tides in the Cretaceous Seaway of North America. The Journal of Geology, 93: 333-345.

Slingerland, R., 1986. Numerical computation of co-oscillating palaeotides in the Catskill epeiric Sea of eastern North America. Sedimentology, 33: 487-497.

Smith, D.G., 1988. Tidal bundles and mud couplets in the McMurray Formation, northeastern Alberta, Canada. Bulletin of Canadian Petroleum Geology, 36: 216-219.

Smith, D.G., Reinson, G.E., Zaitlin, B.A. and Rahmani, R.A., 1991. Clastic Tidal Sedimentology, 16. Memoir of the Canadian Society of Petroleum Geologists, 387 pp.

Sondi, I., Juračić, M. and Pravdić, V., 1995. Sedimentation in a disequilibrium river- dominated estuary: the Raša River Estuary (Adriatic Sea, Croatia). Sedimentology, 42: 769-782.

Soulsby, R., Hamm, L., Klopman, G., Myrhaug, D., Simons, R. and Thomas, G., 1993. Wavecurrent interaction within and outside the bottom boundary layer. Coastal engineering, 21: 41-69.

Southard, J.B. and Boguchwal, L.A., 1990. Bed configurations in steady unidirectional water flows. Part 2. Synthesis of flume data. Journal of Sedimentary Research, 60.

Staub, J.R. and Esterle, J.S., 1994. Peat-accumulating depositional systems of Sarawak, East Malaysia. Sedimentary Geology, 89: 91-106.

Staub, J.R. and Gastaldo, R., 2000. Seasonal sediment transport and deposition in the Rajang River delta, Sarawak, East Malaysia. Sedimentary Geology, 133: 249-264.

Stride, A.H., 1973. Sediment transport by the North Sea. In: E.D. Goldberg (Editor), North Sea Science. MIT Press, Cambridge, MA, pp. 101-130.

Stride, A.H., 1982. Offshore tidal sands: processes and deposits. Chapman \& Hall, London, 222 pp.

Syvitski, J.P. and Milliman, J.D., 2007. Geology, geography, and humans battle for dominance over the delivery of fluvial sediment to the coastal ocean. The Journal of Geology, 115: $1-19$.

Syvitski, J.P., Peckham, S.D., Hilberman, R. and Mulder, T., 2003. Predicting the terrestrial flux of sediment to the global ocean: a planetary perspective. Sedimentary Geology, 162: 524.

Syvitski, J.P. and Saito, Y., 2007. Morphodynamics of deltas under the influence of humans. Global and Planetary Change, 57: 261-282.

Ta, T.K.O., Nguyen, V.L., Tateishi, M., Kobayashi, I., Saito, Y. and Nakamura, T., 2002a. Sediment facies and Late Holocene progradation of the Mekong River Delta in Bentre Province, southern Vietnam: an example of evolution from a tide-dominated to a tideand wave-dominated delta. Sedimentary Geology, 152: 313-325. 
Ta, T.K.O., Nguyen, V.L., Tateishi, M., Kobayashi, I., Tanabe, S. and Saito, Y., 2002b. Holocene delta evolution and sediment discharge of the Mekong River, southern Vietnam. Quaternary Science Reviews, 21: 1807-1819.

Tapponnier, P., Peltzer, G. and Armijo, R., 1986. On the mechanics of the collision between India and Asia. In: M.P. Coward and A.C. Ries (Editors), Collision Tectonics. Special Publications. Geological Society, London, London, UK, pp. 113-157.

Tapponnier, P., Peltzer, G., Le Dain, A., Armijo, R. and Cobbold, P., 1982. Propagating extrusion tectonics in Asia: New insights from simple experiments with plasticine. Geology, 10: 611-616.

Taylor, B., 1992. Rifting and the volcanic-tectonic evolution of the Izu-Bonin-Mariana arc. In: B. Taylor, K. Fujioaka and e. al. (Editors), Proceedings of Ocean Drilling Program Scientific Results, College Station, TX, pp. 625-651.

Taylor, B. and Hayes, D.E., 1983. Origin and History of the South China Sea Basin. In: D.E. Hayes (Editor), The Tectonic and Geologic Evolution of Southeast Asian Seas and Islands: Part 2. Geophysical Monograph. American Geophysical Union, Washington, D.C., pp. 23-56.

Terwindt, J., 1981. Origin and Sequences of Sedimentary Structures in Inshore Mesotidal Deposits of the North Sea. In: S.D. Nio, R.T.E. Shüttenhelm and T.C.E.V. Weering (Editors), Holocene Marine Sedimentation in the North Sea Basin. Special Publication. International Association of Sedimentologists, pp. 4-26.

Terwindt, J. and Breusers, H., 1972. Experiments on the origin of flaser, lenticular and sandclay alternating bedding. Sedimentology, 19: 85-98.

Terwindt, J.H., 1971. Litho-facies of inshore estuarine and tidal-inlet deposits. Geologie en Mijnbouw, 50: 515-526.

Thomas, R.G., Smith, D.G., Wood, J.M., Visser, J., Calverley-Range, E.A. and Koster, E.H., 1987. Inclined heterolithic stratification - terminology, description, interpretation and significance. Sedimentary Geology, 53: 123-179.

Tin, N.T. and Ty, N.D., 1995. Petroleum geology of the Nam Con Son Basin. Bulletin of the Geological Society of Malaysia, 37: 1-11.

Tinterri, R., 2011. Combined flow sedimentary structures and the genetic link between sigmoidal-and hummocky-cross stratification. GeoActa, 10: 1-43.

Todd, S.P., Dunn, M.E. and Barwise, A.J.G., 1997. Characterizing petroleum charge systems in the Tertiary of SE Asia. In: A.J. Fraser, S.J. Matthews and R.W. Murphy (Editors), Petroleum Geology of Southeast Asia. Special Publications 126. Geological Society London, London, UK, pp. 25-47.

Togunwa, O.S., Abdullah, W.H., Hakimi, M.H. and Barbeito, P.J., 2015. Organic geochemical and petrographic characteristics of Neogene organic-rich sediments from the onshore West Baram Delta Province, Sarawak Basin: Implications for source rocks and hydrocarbon generation potential. Marine and Petroleum Geology, 63: 115-126.

Tsimplis, M., Proctor, R. and Flather, R., 1995. A two- dimensional tidal model for the Mediterranean Sea. Journal of Geophysical Research: Oceans, 100: 16223-16239.

Twilley, R.R., Rovai, A.S. and Riul, P., 2018. Coastal morphology explains global blue carbon distributions. Frontiers in Ecology and the Environment, 16: 503-508.

Tyson, R. and Funnell, B., 1987. European Cretaceous shorelines, stage by stage. Palaeogeography, Palaeoclimatology, Palaeoecology, 59: 69-91. 
Uličný, D., 2001. Depositional systems and sequence stratigraphy of coarse- grained deltas in a shallow- marine, strike- slip setting: the Bohemian Cretaceous Basin, Czech Republic. Sedimentology, 48: 599-628. marine, transtensional basin: the Bohemian Cretaceous Basin, Czech Republic. Sedimentology, 56: 1077-1114.

Uličný, D. and Špičáková, L., 1996. Response to high frequency sea-level change in a fluvial to estuarine succession: Cenomanian palaeovalley fill, Bohemian Cretaceous Basin. Geological Society, London, Special Publications, 104: 247-268.

Vakarelov, B.K. and Ainsworth, R.B., 2013. A hierarchical approach to architectural classification in marginal-marine systems: Bridging the gap between sedimentology and sequence stratigraphy. AAPG Bulletin, 97: 1121-1161.

Vakarelov, B.K., Ainsworth, R.B. and MacEachern, J.A., 2012. Recognition of wave-dominated, tide-influenced shoreline systems in the rock record: Variations from a microtidal shoreline model. Sedimentary Geology, 279: 23-41.

van Cappelle, M., Hampson, G.J. and Johnson, H.D., 2018. Spatial and Temporal Evolution of Coastal Depositional Systems and Regional Depositional Process Regimes: Campanian Western Interior Seaway, USA. Journal of Sedimentary Research, 88: 873-897.

van Cappelle, M., Stukins, S., Hampson, G.J. and Johnson, H.D., 2016. Fluvial to tidal transition in proximal, mixed tide-influenced and wave-influenced deltaic deposits: Cretaceous lower Sego Sandstone, Utah, USA. Sedimentology, 63: 1333-1361.

van den Berg, J.H., Boersma, J.R. and Gelder, A.v., 2007. Diagnostic sedimentary structures of the fluvial-tidal transition zone-Evidence from deposits of the Rhine and Meuse. Netherlands Journal of Geosciences/Geologie en Mijnbouw, 86: 287-306.

van Hattum, M.W.A., Hall, R., Pickard, A.L. and Nichols, G.J., 2006. Southeast Asian sediments not from Asia: Provenance and geochronology of north Borneo sandstones. Geology, 34: 589.

Van Straaten, L., 1953. Megaripples in the Dutch Wadden Sea and in the basin of Arcachon (France). Geol. Mijnbouw, 15: 1-11.

Van Wagoner, J.C., Mitchum, R.M., Campion, K.M. and Rahmanian, V.D., 1990. Siliciclastic Sequence Stratigraphy in Well Logs, Cores, and Outcrops: Concepts for High-Resolution Correlation of Time and Facies. Methods in Exploration, 7. AAPG, 55 pp.

Van Yperen, A.E., Poyatos- Moré, M., Holbrook, J.M. and Midtkandal, I., 2020. Internal mouth- bar variability and preservation of subordinate coastal processes in lowaccommodation proximal deltaic settings (Cretaceous Dakota Group, New Mexico, USA). The Depositional Record.

Vaucher, R., Pittet, B., Hormière, H., Martin, E.L. and Lefebvre, B., 2016. A wave-dominated, tide-modulated model for the Lower Ordovician of the Anti-Atlas, Morocco. Sedimentology, 64: 777-807.

Visser, M.J., 1980. Neap-spring cycles reflected in Holocene subtidal large-scale bedform deposits: a preliminary note. Geology, 8: 543-546.

Voigt, T. and Tröger, K., 1996. Sea-level changes during Late Cenomanian and early Turonian in the Saxonian Cretaceous Basin. Mitteilungen aus dem Geologisch-Paläontologischen Institut der Universität Hamburg, 77: 275-290. 
Walker, R.G., 1979. Facies Models. Geoscience Canada Reprint Series, 3. Geological Associalion of Canada, $211 \mathrm{pp}$. Geological Association of Canada, 409 pp.

Walker, R.G. and Plint, A.G., 1992. Wave-and storm-dominated shallow marine systems. In: R.G. Walker and N.P. James (Editors), Facies Models: Response to Sea-Level Change. Geological Association of Canada, St. John's, Newfoundland, pp. 219-238.

Wan Hasiah, A., 2003. Coaly source rocks of NW Borneo: role of suberinite and bituminite in oil generation and expulsion. Geological Society of Malaysia Bulletin, 47: 153-163.

Ward, S.L., Neill, S.P., Van Landeghem, K.J.J. and Scourse, J.D., 2015. Classifying seabed sediment type using simulated tidal-induced bed shear stress. Marine Geology, 367: 94104.

Wei, X., Steel, R.J., Ravnås, R., Jiang, Z., Olariu, C. and Li, Z., 2016. Variability of tidal signals in the Brent Delta Front: New observations on the Rannoch Formation, northern North Sea. Sedimentary Geology, 335: 166-179.

Wells, M.R., 2008. Tidal modelling of modern and ancient seas and oceans, Imperial College London, $527 \mathrm{pp}$.

Wells, M.R., Allison, P.A., Hampson, G.J., Piggott, M.D. and Pain, C.C., 2005a. Modelling ancient tides: the Upper Carboniferous epi-continental seaway of Northwest Europe. Sedimentology, 52: 715-735.

Wells, M.R., Allison, P.A., Piggott, M.D., Gorman, G.J., Hampson, G.J., Pain, C.C. and Fang, F., 2007a. Numerical Modeling of Tides in the Late Pennsylvanian Midcontinent Seaway of North America with Implications for Hydrography and Sedimentation. Journal of Sedimentary Research, 77: 843-865.

Wells, M.R., Allison, P.A., Piggott, M.D., Hampson, G.J., Pain, C.C. and Gorman, G.J., 2010a. Tidal Modeling of an Ancient Tide-Dominated Seaway, Part 1: Model Validation and Application to Global Early Cretaceous (Aptian) Tides. Journal of Sedimentary Research, 80: 393-410.

Wells, M.R., Allison, P.A., Piggott, M.D., Hampson, G.J., Pain, C.C. and Gorman, G.J., 2010b. Tidal Modeling of an Ancient Tide-Dominated Seaway, Part 2: The Aptian Lower Greensand Seaway of Northwest Europe. Journal of Sedimentary Research, 80: 411-439.

Wells, M.R., Allison, P.A., Piggott, M.D., Pain, C.C., Hampson, G.J. and De Oliveira, C.R., 2005b. Large sea, small tides: the Late Carboniferous seaway of NW Europe. Journal of the Geological Society, 162: 417-420.

Wells, M.R., Allison, P.A., Piggott, M.D., Pain, C.C., Hampson, G.J. and Dodman, A., 2007b. Investigating tides in the Early Pennsylvanian Seaway of NW Eurasia using the Imperial College Ocean Model. In: C. Holmden and B.R. Pratt (Editors), Dynamics of Epeiric Seas: Sedimentological, Paleontological and Geochemical Perspectives. Special Paper 48. Geological Association of Canada, pp. 363-387.

Willis, B.J., 2005. Deposits of tide-influenced river deltas. In: L. Giosan and J.P. Bhattacharya (Editors), River Deltas - Concepts, Models, and Examples. SEPM Special Publication, pp. 87-129.

Willis, B.J. and Fitris, F., 2012. Sequence Stratigraphy of Miocene Tide-Influenced Sandstones In the Minas Field, Sumatra, Indonesia. Journal of Sedimentary Research, 82: 400-421. 
Willis, B.J. and Gabel, S., 2001. Sharp-based, tide-dominated deltas of the Sego Sandstone, Book Cliffs, Utah, USA. Sedimentology, 48: 479-506. Robertson and D.M. Alongi (Editors), Tropical Mangrove Ecosystems. Coastal and Estuarine Studies. American Geophysical Union, Washington, DC, pp. 43-62.

Wonham, J.P. and Elliott, T., 1996. High-resolution sequence stratigraphy of a mid-Cretaceous estuarine complex: the Woburn Sands of the Leighton Buzzard area, southern England. In: S.P. Hesselbo and D.N. Parkingson (Editors), Sequence Stratigraphy in the British Isles. Special Publications 103. Geological Society, London, pp. 41-62.

Woodroffe, C.D., Rogers, K., McKee, K.L., Lovelock, C.E., Mendelssohn, I.A. and Saintilan, N., 2016. Mangrove sedimentation and response to relative sea-level rise. Annual Review of Marine Science, 8: 243-66.

Yang, C.S. and Nio, S.D., 1985. The estimation of palaeohydrodynamic processes from subtidal deposits using time series analysis methods. Sedimentology, 32: 41-57.

Yoshida, S., Johnson, H.D., Pye, K. and Dixon, R.J., 2004. Transgressive changes from tidal estuarine to marine embayment depositional systems: The Lower Cretaceous Woburn Sands of southern England and comparison with Holocene analogs. AAPG Bulletin, 88: 1433-1460.

Yoshida, S., Steel, R.J. and Dalrymple, R.W., 2007. Changes in depositional processes-an ingredient in a new generation of sequence-stratigraphic models. Journal of Sedimentary Research, 77: 447-460.

Zheng, W. and Deng, H., 2012. The Tidal Sandstone Characteristic of the Zhuhai Formation, Huizhou Oil Field, Pearl River Mouth Basin, South China Sea. Petroleum Science and Technology, 30: 567-574.

Ziegler, P.A., 1990. Geological Atlas of Western and Central Europe. Maatschappij B.V., Shell Internationale Petroleum, The Hague, $239 \mathrm{pp}$.

Zuchuat, V., Sleveland, A.R., Pettigrew, R.P., Dodd, T.J., Clarke, S.M., Rabbel, O., Braathen, A. and Midtkandal, I., 2019. Overprinted allocyclic processes by tidal resonance in an epicontinental basin: The Upper Jurassic Curtis Formation, east- central Utah, USA. The Depositional Record, 5: 272-305. 


\section{Declaration of interests}

$\bigotimes$ The authors declare that they have no known competing financial interests or personal relationships that could have appeared to influence the work reported in this paper.

$\square$ The authors declare the following financial interests/personal relationships which may be considered as potential competing interests:

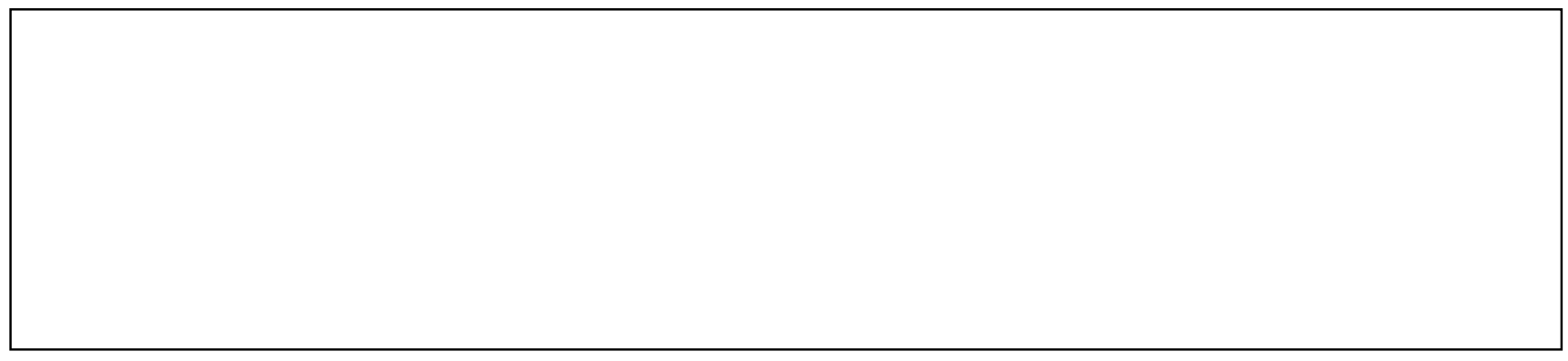

